\title{
Raman Spectroscopy and Ab-Initio Model Calculations on Ionic Liquids Invited Review
}

\section{Berg, Rolf W.}

Published in:

Monatshefte für Chemie

Link to article, DOI:

10.1007/s00706-007-0760-9

Publication date:

2007

Document Version

Publisher's PDF, also known as Version of record

Link back to DTU Orbit

Citation (APA):

Berg, R. W. (2007). Raman Spectroscopy and Ab-Initio Model Calculations on lonic Liquids: Invited Review. Monatshefte für Chemie, 138(11), 1045-1075. https://doi.org/10.1007/s00706-007-0760-9

\section{General rights}

Copyright and moral rights for the publications made accessible in the public portal are retained by the authors and/or other copyright owners and it is a condition of accessing publications that users recognise and abide by the legal requirements associated with these rights.

- Users may download and print one copy of any publication from the public portal for the purpose of private study or research.

- You may not further distribute the material or use it for any profit-making activity or commercial gain

- You may freely distribute the URL identifying the publication in the public portal

If you believe that this document breaches copyright please contact us providing details, and we will remove access to the work immediately and investigate your claim 


\title{
Invited Review \\ Raman Spectroscopy and Ab-Initio Model Calculations on Ionic Liquids
}

\author{
Rolf W. Berg* \\ Department of Chemistry, Technical University of Denmark, Kemitorvet, Lyngby, Denmark
}

Received May 25, 2007; accepted June 28, 2007; published online October 17, 2007

(C) Springer-Verlag 2007

\begin{abstract}
Summary. A review of the recent developments in the study and understanding of room temperature ionic liquids are given. An intimate picture of how and why these liquids are not crystals at ambient conditions is attempted, based on evidence from crystallographical results combined with vibrational spectroscopy and ab-initio molecular orbital calculations. A discussion is given, based mainly on some recent FT-Raman spectroscopic results on the model ionic liquid system of 1-butyl-3-methylimidazolium $\left(\left[\mathrm{C}_{4}\right.\right.$ mim $\left.][X]\right)$ salts. The rotational isomerism of the $\left[\mathrm{C}_{4} \mathrm{mim}\right]^{+}$cation is described: the presence of anti and gauche conformers that has been elucidated in remarkable papers by Hamaguchi et al. Such presence of a conformational equilibrium seems to be a general feature of the room temperature liquids. Then the "localized structure features" that apparently exist in ionic liquids are described. It is hoped that the structural resolving power of Raman spectroscopy will be appreciated by the reader. It is of remarkable use on crystals of known different conformations and on the corresponding liquids, especially in combination with modern quantum mechanics calculations. It is hoped that these interdisciplinary methods will be applied to many more systems in the future. A few examples will be discussed.
\end{abstract}

Keywords. Vibration; Conformational isomerism; Liquid structure; Localized structure; Normal modes.

\section{Introduction to Room Temperature Ionic Liquids}

The term "room temperature ionic liquid" (RTIL) is commonly defined as a liquid that is composed of ions (and perhaps other species) and is a fluid liquid at or close to room (ambient) temperature. It is a

\footnotetext{
* Corresponding author. E-mail: rwb@kemi.dtu.dk
}

synonym of a molten salt (with a low melting point) or a Coulombic liquid. The RTIL material is often colorless, has a low viscosity, and possesses a minimal vapor pressure (not excactly zero [1]), i.e., it is a material with attractive properties for use as a solvent or an alternative reaction medium.

Since their discovery around 1982 [2], the uses of RTILs and their properties and have been described in many generel reviews [3-12] and even the detailed early history of the RTILs has already been told [13].

Generally RTILs are salts of organic cations with organic or inorganic anions. Common examples are salts of the cations such as $\mathrm{N}$-alkylpyridinium [1416] and 1,3-dialkylimidazolium, tetraalkylammonium, tetraalkylphosphonium, or trialkylsulfonium, see Fig. 1. However, also other possibilities exist and have been investigated, like pyrrolidinium [17-20], guanidinium [21, 22], 1,3-diazolium [23], or benzimidazolium [24] salts. In particular, the 1-alkyl-3-methylimidazolium salts are an interesting and useful class of room temperature ionic liquids.

As in all young fields of sciences, there is some confusion with respect to nomenclature. In some papers, abbreviations like $[\mathrm{bmim}]^{+},[B M I M]^{+}$or others have been used for 1-butyl-3-methylimidazolium but we prefer the notation $\left[\mathrm{C}_{4} \mathrm{mim}\right]^{+}$because it avoids the problem with propyl and pentyl, etc. Similar nomenclature problems exist, e.g., for the trifluoromethanesulfonate $\left[\mathrm{CF}_{3} \mathrm{SO}_{3}\right]^{-}$and the bis(trifluoromethanesulfonyl)imide $\left[\left(\mathrm{CF}_{3} \mathrm{SO}_{2}\right)_{2} \mathrm{~N}\right]^{-}$anions 
<smiles>[R7][N+]([R7])([R7])[R7]</smiles><smiles>[R7][Pb]([R7])([R7])[P]</smiles><smiles></smiles>

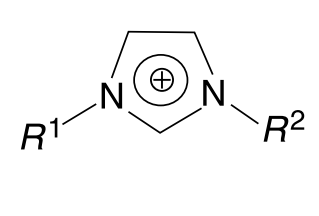

Most commonly used anions:

$\left[\mathrm{PF}_{6}\right]^{-}$

$\left[\mathrm{BF}_{4}\right]^{-}$

$\left[\left(\mathrm{CF}_{3} \mathrm{SO}_{2}\right)_{2} \mathrm{~N}\right]^{-} \quad\left[\mathrm{CF}_{3} \mathrm{SO}_{3}\right]^{-}$

[B $\left.R^{1} R^{2} R^{3} R^{4}\right]^{-}$<smiles>[R7][Sb]([R7])([R7])[R7]</smiles><smiles>[R7][N+]1([R7])CCCC1</smiles>

$R^{1,2,3,4}=$ alkyl

Most commonly used:

ethyl butyl

hexyl octyl cecyl

$\left[\mathrm{CH}_{3} \mathrm{CO}_{2}\right]^{-}$

$\left[\mathrm{CH}_{3} \mathrm{CO}_{2}\right]^{-},\left[\mathrm{NO}_{3}\right]^{-}$

$\mathrm{Br}^{-}, \mathrm{Cl}^{-}, \mathrm{I}^{-}$

$\left[\mathrm{Al}_{2} \mathrm{Cl}_{7}\right]^{-},\left[\mathrm{AlCl}_{4}\right]^{-}$

(decomp.)

\section{Water-insoluble}

Water-soluble

Fig. 1. Structures of ionic liquids, including common organic cations (ammonium, phosphonium, sulfonium, guanidinium, pyridinium, imidazolium, and pyrrolidinium) and anions such as $\mathrm{Cl}^{-}, \mathrm{Br}^{-},\left[\mathrm{BF}_{4}\right]^{-},\left[\mathrm{PF}_{6}\right]^{-},[T f \mathrm{O}]^{-}$(trifluoromethanesulfonate), and $\left[T_{2} \mathrm{~N}\right]^{-}$(bis(trifluoromethylsulfonyl)imide)

that we will call $[T f \mathrm{O}]^{-}$and $\left[T f_{2} \mathrm{~N}\right]^{-}$(Tf is a shorthand notation for triflate); they occur in recent literature also with other acceptable abbreviated names.

Generally, in RTILs the Coulomb interaction plays a major role, in contrast to the situation in ordinary molecular liquids where only dipolar and/or higher order multipolar electrostatic interactions occur. The long-range nature of the Coulomb force tends to make the melting points of ionic crystals much higher than those of molecular crystals. In that sense, the RTILs are extraordinary with their low melting points.

A most interesting and useful property of ionic liquids is that it is possible to tune their physical properties. One such property is the miscibility with other solvents or substrates; tunability is useful, e.g., in process development for product isolation, either by decantation, filtration, or solvent extraction $[25,26]$.

It has been estimated that there are at least a billion $\left(10^{12}\right)$ such ionic liquids [27]. For example, the melting point, water miscibility, density, and viscosity of ionic liquids vary with the anion and the alkyl chain lengths of the cation $[9,28]$. A high yield of an organic reaction can be obtained by the choice of a suitable ionic liquid or a binary mixture of two or more ionic liquids, see e.g., Refs. [29-31]. RTILs have been used as solvent media for organic synthesis and new types of catalysts, lubricants, carbon-nano tubes, etc. [8, 32-39]. The high-temperature stability, nonvolatility, nonflammablility, amphiphilicity, and many other characteristics of RTILs are making them highly useful as the new class of environmentally friendly "green" solvents. A wide potential window (large difference in oxidation and reduction potentials) of certain RTILs may open up for new applications as electrochemical materials in e.g., batteries. Ionic liquids have a potential for being recycled, thus making synthetic processes less expensive, more efficient, and environmentally friendly.

The nature of intermolecular interactions in ionic liquids is of great importance for their general use, and the basic knowledge in the fundamental physical chemistry of these solvent systems is under intensive growth. The number of new publications is increasing steeply and it is difficult to get an overview. Early studies probed the nature of interactions in socalled first-generation chloroaluminate ionic liquids [40], and now also information becomes available for second generation, air-stable systems, such as the imidazolium mixtures. Many RTIL studies have been directed towards possible applications $[8,11$, 


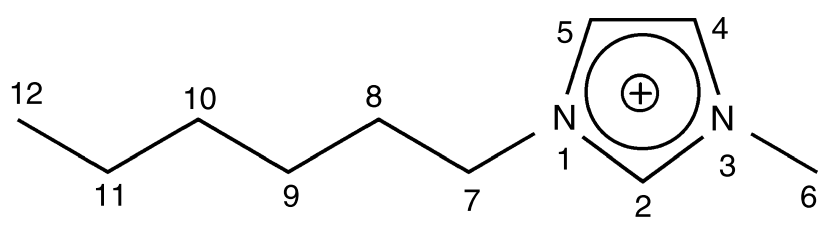

Fig. 2. Numbering scheme in the 1-hexyl-3-methylimidazolium cation, $\left[\mathrm{C}_{6} \mathrm{mim}\right]^{+}$, showing the three ring protons $\mathrm{H} 2$, $\mathrm{H} 4$, and $\mathrm{H} 5$

41]: a number of reports have been published covering theoretical aspects [42-47], X-ray crystallography of the frozen melts [48-52], NMR relaxation, conductivity, viscosity, diffusion [4, 28, 53-59], and gas solubilities in ionic liquids [22, 60].

Hydrogen-bonding is known to occur between the cations and anions in most ionic liquids, as demonstrated by several investigators on $e . g$., systems containing 1-alkyl-3-methylimidazolium. All three ring protons $\mathrm{H} 2, \mathrm{H} 4$, and $\mathrm{H} 5$, see Fig. 2, form strong hydrogen bonds to e.g., halide ions [60-65]. From measurement of the ${ }^{13} \mathrm{C}$ dipole-dipole relaxation rate, Huang et al. [66] found that the hydrogen atom attached to the ring $\mathrm{C} 2$ is hydrogen bonded to the $\left[\mathrm{BF}_{4}\right]^{-}$anion in neat $\left[\mathrm{C}_{2} \mathrm{mim}\right]\left[\mathrm{BF}_{4}\right]$; a finding that was later confirmed by IR and Raman spectroscopy [67]. The degree of hydrogen bonding between the ringbound hydrogen atoms and the anion seems to change significantly when going from e.g., a neat chloride to a hexafluorophosphate. IR spectroscopy has provided detailed information on the hydrogen-bonded interaction between water molecules and ionic liquids in e.g., $\left[\mathrm{C}_{4}\right.$ mim $]\left[\mathrm{PF}_{6}\right]$ and $\left[\mathrm{C}_{4}\right.$ mim $]\left[\mathrm{BF}_{4}\right]$, with the water hydrogen-bonding more strongly to the $\left[\mathrm{BF}_{4}\right]^{-}$anion than to the $\left[\mathrm{PF}_{6}\right]^{-}$, see Refs. [60-63, 68-71].

As expected, in many papers only the anions are varied and the cation is kept or vice versa. Matsumoto et al. e.g., studied syntheses, structures, and properties (e.g., Raman spectra) of 1-ethyl-3-methylimidazolium salts of a series of fluorocomplex anions [72, 73].

Many RTILs are hydroscopic and quickly absorb water when exposed to air; the absorbed water interacts with the anions in the ionic liquids. This was successfully demonstrated by use of near-infrared (NIR) spectrometry for determination of water absorbed in 1-butyl-3-methylimidazolium liquids. Among these $\left[\mathrm{C}_{4} \text { mim }\right]^{+}$RTILs, the borontetrafluoride $\left(\left[\mathrm{BF}_{4}\right]^{-}\right)$, bis(trifluoromethylsulfonyl)imide $\left(\left[T f_{2} \mathrm{~N}\right]^{-}\right)$, and phosphoroushexafluoride $\left(\left[\mathrm{PF}_{6}\right]^{-}\right)$anions interacted with water in decreasing order, and the interaction leads to changes in the structure and behavior of the water [74].

Raman spertroscopy of $\left[\mathrm{C}_{4} \mathrm{mim}\right][\mathrm{Cl}]-\left[E t \mathrm{AlCl}_{2}\right]$ ionic liquids ( $E t=$ ethyl) has shown that the distribution of the ethylchloroaluminate(III) species follows a chlorobasicity pattern similar to that found in alkali chloroaluminate(III) ionic liquids [75, 76]. Hence, in these ionic liquids $\mathrm{Cl}^{-}$and $\left[E_{t} \mathrm{AlCl}_{3}\right]^{-}$ions are found when the liquid is chlorobasic. In moderately acidic ionic liquids, $\left[E t \mathrm{AlCl}_{3}\right]^{-}$and $\left[E t_{2} \mathrm{Al}_{2} \mathrm{Cl}_{5}\right]^{-}$ ions are present, and in highly acidic compositions $\left[E t_{3} \mathrm{~A}_{3} \mathrm{Cl}_{7}\right]^{-}$and $\left[E t_{2} \mathrm{~A}_{2} \mathrm{C} 1\right]_{4}$ are important components. Similar results are found for $\left[\mathrm{C}_{2} \mathrm{mim}\right]$ [C1] - [Et $\left.t_{2} \mathrm{~A} 1 \mathrm{C} 1\right]$ ionic liquid systems [77]. Closer inspection of the Raman spectra of the acidic $\left[\mathrm{C}_{2} \mathrm{mim}\right]$ $[\mathrm{Cl}]-\left[E t \mathrm{AlCl}_{2}\right]$ ionic liquids has revealed that the species $\left[\mathrm{AlCl}_{4}\right]^{-},\left[E t \mathrm{~A}_{2} \mathrm{Cl}_{6}\right]^{-},\left[E t_{2} \mathrm{AlC} 1\right]$, and $\left[E t_{3} \mathrm{Al}_{2} \mathrm{Cl}_{3}\right]$ are present [77]. Hence, exchange of ethyl and chloride ligands must be taking place; a quite likely behavior for such complex mixtures.

The RTILs interact with surfaces and electrodes $[19,78,79]$, and many more studies have been done that what we have room to cite. As one example, in situ Fourier-transform infrared reflection absorption spectroscopy (FT-IRAS) has been utilized to study the molecular structure of the electrified interphase between the 1-ethyl-3-methylimidazolium tetrafluoroborate $\left[\mathrm{C}_{2} \mathrm{mim}\right]\left[\mathrm{BF}_{4}\right]$ liquid and gold substrates [80]. Features in the spectra were interpreted to suggest that $\left[\mathrm{C}_{2} \mathrm{mim}\right]^{+}$ions were adsorbed at the interphase between the gold and the liquid. Each adsorbed $\left[\mathrm{C}_{2} \mathrm{mim}\right]^{+}$ion was oriented with the imidazolium ring molecular plane nearly parallel to the electrode surface at certain potentials [80]. Similar type of results have been obtained by surface enhanced Raman scattering (SERS) for 1-butyl-3-methylimidazolium hexafluorophosphate $\left[\mathrm{C}_{4} \mathrm{mim}\right]\left[\mathrm{PF}_{6}\right]$ adsorbed on silver [78, 81]. When the silver electrode was negatively charged some imidazolium ring vibrational modes and some $\mathrm{N}-\mathrm{CH}_{3}$ vibrations were enhanced, suggesting that the imidazolium rings were parallel to the surface [81]. This seems to be the case also in other systems such as $\left[\mathrm{C}_{4}\right.$ mim $]\left[\mathrm{BF}_{4}\right],\left[\mathrm{C}_{4}\right.$ mim $]\left[\mathrm{PF}_{6}\right]$, 1-methylimidazole, and 1-butylimidazole, studied by Raman spectroscopy, and with depolarization ratios recorded from 2700 to $3300 \mathrm{~cm}^{-1}$ [82]. Mixed systems of organic molecules and ionic liquids that form separate phases (by thermomorphic phase separation) have been also studied by Raman spectroscopy [83]. 


\section{Brief Introduction to Raman Spectroscopy}

\section{Basics}

The effect of Raman scattering was discovered in 1928 by Indian physicists Raman and Krishnan [84] and may be defined as instantaneous inelastic scattering of electromagnetic radiation (light) [85-88]. When a photon collides with a sample, it may be elastically scattered (called Rayleigh scattering) or an amount of energy may be exchanged with the sample (Stokes or anti-Stokes Raman processes) as shown schematically in the quantum energy level diagram in Fig. 3. Accordingly, the outgoing photon has less or more energy than the incoming one. A Raman process corresponds to a (fundamental) transition among certain group vibration energy states. For the Raman spectral band to occur with a significant intensity, the molecular bond stretching or angle deformation vibration must cause a change in the polarizability of the molecule. The ensemble of light scattering bands constitute the Raman spectrum.
Stokes-shift Raman spectra are most often measured; i.e., the scattered photons have lower frequency than the incident radiation.

Dramatic improvements in instrumentation (lasers, detectors, optics, computers, etc.) have during recent years raised the Raman spectroscopy technique to a level where it can be used for "species specific" quantitative chemical analysis. Although not as sensitive as e.g., infrared absorption, the Raman technique has the advantage that it can directly measure samples inside ampoules and other kinds of closed vials because of the transparency of most glasses and window materials. Furthermore, with the use of polarization techniques, one can derive molecular dynamics and other kinds of information that cannot be obtained from infrared spectra. Good starting references dealing with Raman spectroscopy instruments and lasers are perhaps Refs. [89-93].

Raman and Infrared spectroscopies are closely interrelated in that they both depend on characteristic "group" molecular motions in the sample that give

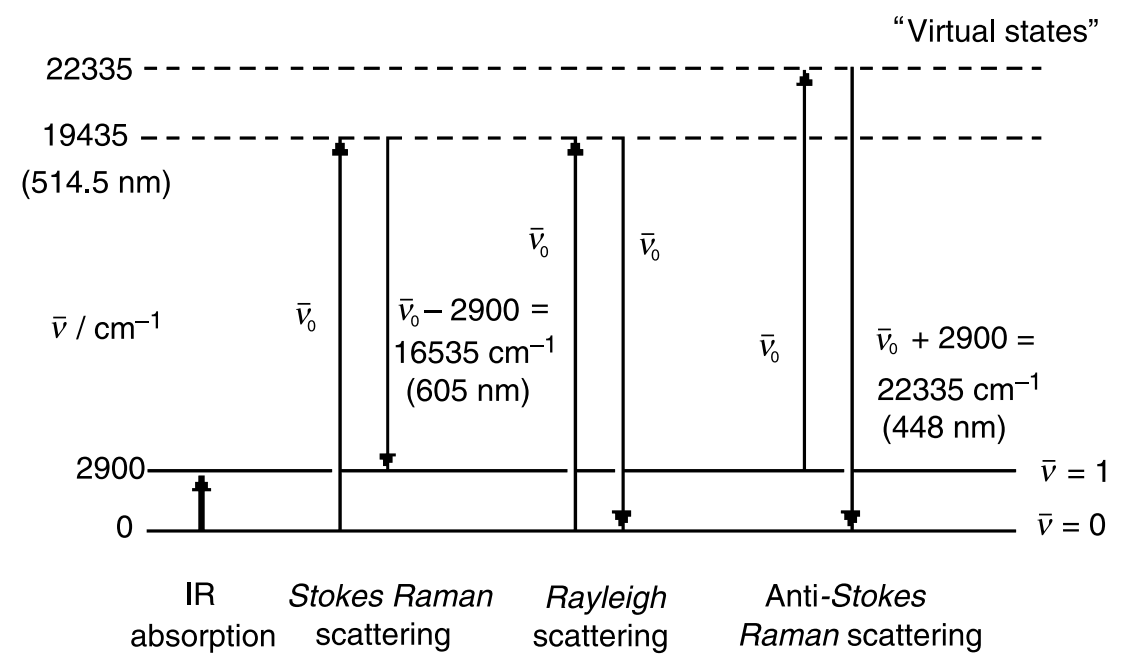

Fig. 3. The relationships between infrared absorption, Rayleigh, and Raman scattering: during the IR absorption process, a quantum of radiation (a photon) of a particular energy $E$ and with a frequency $\nu(E=h \nu)$ is absorbed ( $h$ is Planck's constant). During the absorption the molecular system undergoes a transition from the ground state (quantum number $v=0$ ) to an excited state $(\nu=1)$, in the present case e.g., corresponding to a $\mathrm{CH}_{3}$ group $\mathrm{C}-\mathrm{H}$ bond stretching with a wavenumber shift of $2900 \mathrm{~cm}^{-1}$. In contrast to this, during Rayleigh and Raman scattering, an exiting photon of much higher energy hits the molecular system and raises it to a virtual state, from where it "immediately" falls back. There are two possibilities, here illustrated with green $\mathrm{Ar}^{+}$light of $514.5 \mathrm{~nm}$ wavelength corresponding to $19435 \mathrm{~cm}^{-1}$. In so-called Stokes Raman scattering (not so likely), the system falls back to the $\nu=1$ state (emitting a $16535 \mathrm{~cm}^{-1}$ photon), or in Rayleigh scattering (more likely) to the $\nu=0$ ground state (emitting light at $\sim 19435 \mathrm{~cm}^{-1}$ ), producing the so-called Rayleigh wing). If the system is starting from the $\nu=1$ state (not so likely at room temperature because of the Boltzman distribution), similar transitions can happen. Now also a so-called anti-Stokes Raman process is possible producing photons at $22335 \mathrm{~cm}^{-1}$. Most Raman spectroscopy studies report data corresponding to Stokes Raman transitions. Samples (or impurities therein) having energy states near the "virtual" ones (here at $e . g ., \sim 19435 \mathrm{~cm}^{-1}$ ) may absorb photons from the incident light and later re-emit the light as a broad intensive background called fluorescence 
rise to the vibrational bands in the spectra. As an example, bands occurring near $2950 \mathrm{~cm}^{-1}$ can often be assigned to aliphatic $\mathrm{C}-\mathrm{H}$ stretching transitions (although sometimes in "Fermi-resonance" with overtones and other nonfundamental transitions). So-called empirical group frequency charts are available, specifying "fingerprint" bands, that may be used to identify pure materials or the presence of a particular component in a mixture, see e.g., Refs. [94-99].

Although similar transitional energy ranges occur in IR and Raman spectroscopy, different selection rules govern the intensities in Raman scattering and IR absorption spectra. Hence both types of spectra are often required to fully characterize a substance: a necessary requirement for a molecular motion (such as a vibration, rotation, rotation/vibration, or lattice normal mode) to be measurable in IR spectra it is needed that an oscillating dipole moment is produced during the vibration (in Raman the motion within the molecular system should vary the polarizability). Combinations, differences, or overtones of these transitions can occur, but normally only weakly. Quantum mechanics and group theory, as described in many references, summarize the exact features around the selection rules of the transitions, see e.g., Refs. [85-88, 100, 101].

\section{Experimental, Fluorescence and FT-Raman Spectroscopy Instrumentation}

Applications of Raman spectroscopy in analytical chemistry have been limited by the interferences that arise from the fluorescence of some samples (or from some impurities in the samples), see Fig. 3. In case of strong fluorescence the use of less-energetic near-IR lasers for the excitation is often a requirement. Fourier-transform Raman instruments have been developed, that successfully apply e.g., $\sim 1064 \mathrm{~nm}$ laser excitation (from solid state NdYAG or $\mathrm{Nd}-\mathrm{YVO}_{4}$ lasers) to avoid the fluorescence [102]. The advantage of Raman spectroscopy over IR and other analytical techniques (when the fluorescence problems can be circumvented) stems from the ability of Raman spectroscopy to identify discrete species in situ. Raman spectra can be obtained directly from samples of any phase, in e.g., glass cells. With a minimum effort, temperature and pressure limitations can be overcome. The polarization properties of the Raman scattered light may be employed to select only the isotropic intensity of the symmetric vibrational modes, thereby helping conclusive assignment of the spectra.

The Raman effect is weak, perhaps only $10^{-8}$ of the photons hitting the sample are scattered in Raman. The use of high power laser radiation in the visible region (to circumvent the low scattering efficiency) often results in sample decomposition, and fluorescence interference from impurities must be considered a likely problem for visible light. Recent development of new and relatively cheap charge coupled device detectors (CCD) and notch filters have - in combination with sampling through microscopes - revolutionized the Raman technique for samples that do not emit much fluorescence. The microscope technique - under high magnification - is an effective way to collect Raman light over a large solid angle, and then only minute sample quantities are necessary.

Room temperature ionic liquids have been the object of several Raman spectroscopy studies. Generally, it has been found that RTILs emit an intensive broad fluorescence. In our own experiments, the use of visible laser light (green $514.5 \mathrm{~nm}$ or red $784 \mathrm{~nm}$ ) invariably resulted in strong fluorescence [83, 103]. Similar observations have been reported in many references on RTIL systems. Our experimental spectra, some of which are reported here, needed to be obtained by use of a $1064 \mathrm{~nm}$ near-infrared exciting source (Nd-YAG laser at $\sim 100 \mathrm{~mW}$ of power). The scattered light was filtered and collected over the range $3500 \mathrm{~cm}^{-1}$ (Stokes) to $-1000 \mathrm{~cm}^{-1}$ (antiStokes), in a Bruker IFS66 Fourier-Transform spectrometer with a FRA-106 Raman attachment equipped with a liquid- $\mathrm{N}_{2}$ cooled Ge-diode detector. Our samples were in small glass capillary tubes measured at approximately $23^{\circ} \mathrm{C}$. The spectra were calculated by averaging $\sim 200$ scans followed by apodization and fast-Fourier-transformation to obtain a resolution of $\sim 2 \mathrm{~cm}^{-1}$ and a precision better than $1 \mathrm{~cm}^{-1}$. The spectra were not corrected for (small) intensity changes in detector response versus wavelength.

\section{Brief Introduction to $\boldsymbol{A} \boldsymbol{b}$-Initio Model Calculations}

Ab-initio and semi-empirical Molecular Orbital (MO) model calculations have recently become quite efficient to predict chemical structures and vibrational (i.e., Raman scattering and IR emission) spectra. We and others have used such calculation approaches to better understand certain features of the liquids, 
as explained in the following. The principles underlying the ab-initio model calculations are described in many textbooks and papers, see e.g., Refs. [104106]. Applications in relation to RTILs and similar systems have likewise been reported several times, as discussed later; here we only mention the basic principles.

The MO calculations may nowadays be performed with e.g., the Gaussian $03 \mathrm{~W}$ program package [107]. A guessed molecular geometry (conformation) is used as input to the calculations together with some kind of approximation to the atomic orbitals, normally sums of Gaussian functions (so-called basis sets). Then the total energy is minimized by use of restricted Hartree-Fock (RHF), Møller Plesset (MP2), and Density Functional Theory (DFT) principles and using e.g., third order Becke-Lee-Yang and Parr (B3LYP) procedures [105-107]. Common basis sets used are the split valence basis sets 6$31+\mathrm{G}(\mathrm{d}, \mathrm{p})$ with diffuse orbitals (d) augmented with Pople's polarization functions (p) [107]. The molecular ions are commonly assumed to be in a hypothetical gaseous free state and without any pre-assumed symmetry, but some calculations also involve better approximations to real systems. After the optimization procedures, giving a geometry with a minimum energy - perhaps not a global one - the vibrational frequencies and intensities (spectra) and the eigenvectors for the normal modes are calculated and displayed on a computer screen, to identify the dominating motions. Then the frequencies (wavenumbers) have to be correlated with the results of the Raman and IR experiments.

The calculated and experimental vibrational spectra are in more or less good agreement. The wavenumber (frequency) scale is often calculated as slightly too high, due to the lack of good modeling of the orbitals and interactions with the surroundings. In the gas phase an empirical scale factor of $\sim 0.95$ is therefore sometimes used in order to get fairly accurate vibrational wavenumbers. A scaling factor of 1 was used in our work, but many researchers use scaling to make better fits.

\section{Case Study on Spectra and Structure of Imidazolium-based RTILs}

As mentioned above, vibrational spectroscopy is known to be a very powerful tool in the study of molecular stuctures and intermolecular interactions among ions in RTILs $[70,71,108]$. This is especially so when done in combination with crystal structure studies, as explained in the following.

To illustrate the situation for the theme "Raman spectroscopy applied to the study of RTILs", rather than giving a comprehensive review, we start our discussion with the example of the alkylmethylimidazolium liquids, from $\left[\mathrm{C}_{2} \mathrm{mim}\right]^{+}$to $\left[\mathrm{C}_{18} \mathrm{mim}\right]^{+}$, and a number of different anions. Although other techniques such as infrared spectroscopy, X-ray, and neutron diffraction studies have been used to study these ions in the liquid or solid state or at surfaces $[6,52$, 109-120], a real gain in our understanding came with the combination of crystal structure solution, Raman spectroscopy and ab-initio DFT calculations $[108,121]$. We concentrate the story on the instructive example of the 1-butyl-3-methylimidazolium cation, $\left[\mathrm{C}_{4} \mathrm{mim}\right]^{+}$(see Fig. 2, without carbon atoms 11 and 12), that makes a number of RTILs with varying properties, depending on the different anions [69]. The two prototype RTILs $\left[\mathrm{C}_{4} \mathrm{mim}\right]\left[\mathrm{BF}_{4}\right]$ and $\left[\mathrm{C}_{4}\right.$ mim $]\left[\mathrm{PF}_{6}\right]$ have already been used extensively in fundamental investigations as well as in practical applications. Therefore, the elucidation of their crystal and liquid structures were an important first step for the understanding of RTILs in general [108].

The most fundamental question about RTILs to be discussed is: Why are RTILs liquids at the ambient temperature, despite the fact that they are composed solely of ions? This question can be answered as described in the following.

$\left[\mathrm{C}_{4}\right.$ mim $][\mathrm{Cl}]$ and $\left[\mathrm{C}_{4}\right.$ mim $][\mathrm{Br}]$ are crystals at room temperature, while $\left[\mathrm{C}_{4}\right.$ mim $][\mathrm{I}]$ is a RTIL (melting point $\left.-72^{\circ} \mathrm{C}[10]\right)$. A typical ionic crystal such as $\mathrm{NaI}$ only melts at $\sim 660^{\circ} \mathrm{C}$. By cooling $\left[\mathrm{C}_{4} \mathrm{mim}\right][\mathrm{Cl}]$ and $\left[\mathrm{C}_{4}\right.$ mim $][\mathrm{Br}]$ liquids below their melting points, supercooled liquids are easily obtained. Crystals could be grown of the $\left[\mathrm{C}_{4}\right.$ mim $][\mathrm{Cl}]$ and $\left[\mathrm{C}_{4}\right.$ mim $][\mathrm{Br}]$ salts and X-ray diffraction used to determine the crystal structures. These systems thus comprised unique systems for studying the structure of the $\left[\mathrm{C}_{4} \text { mim }\right]^{+}$ cation in the liquid and crystalline states.

Solid $\left[\mathrm{C}_{4} \mathrm{mim}\right][\mathrm{Cl}]$, was found to be polymorphic: it adopts a monoclinic $\left(\mathrm{mp} \sim 41^{\circ} \mathrm{C}\right)$ and an orthorhombic $\left(\mathrm{mp} \sim 66^{\circ} \mathrm{C}\right.$ ) crystal structure. The polymorphism was discovered almost simultaneously by two groups [116, 117, 122]. Saha et al. [116] and Hayashi et al. [122] by chance found that different types of crystals, called "Crystal (1)" and "Crystal 
(2)", formed when $\left[\mathrm{C}_{4} \operatorname{mim}\right][\mathrm{Cl}]$ liquid was kept at $-18^{\circ} \mathrm{C}$ for $48 \mathrm{~h}$. The orthorhombic "Crystal (2)" dominantly formed but the monoclinic "Crystal (1)" also formed occasionally. Upon leaving "Crystal (2)" for more than $24 \mathrm{~h}$ at dry-ice temperature, "Crystal (2)" converted to "Crystal (1)" [116, 122]. Holbrey et al. [117] independently also obtained two crystal polymorphs, the so-called orthorhombic "Crystal I" and the monoclinic "Crystal II". "Crystal I" was obtained by slowly cooling down the molten liquid to room temperature, while "Crystal II" was obtained by cooling ionic liquid mixtures containing $[\mathrm{Cl}]^{-},\left[\mathrm{PF}_{6}\right]^{-}$and $\left[\mathrm{BF}_{4}\right]^{-}$or by crystallization from a $n$-hexane-benzene mixed solvent. The melting points of "Crystals I and II" were measured to be $\sim 66^{\circ} \mathrm{C}$ and $\sim 41^{\circ} \mathrm{C}$ [117]. Later measurements by Nishikawa et al. [123] showed somewhat different results: "Crystal (1)" melted at temperatures between $47^{\circ} \mathrm{C}$ and $67^{\circ} \mathrm{C}$ depending on individual single crystals, and "Crystal (2)" melted at $64^{\circ} \mathrm{C}$. The DSC curves showed broad melting peaks that were taken to indicate a complex dynamics of the $\left[\mathrm{C}_{4} \mathrm{mim}\right][\mathrm{Cl}]$ "Crystal (1)" structure when the temperature changed. Obviously "Crystal I" corresponds to "Crystal (2)" and "Crystal II" to "Crystal (1)". In the following, we use the Hamaguchi notation "Crystal (1)" and "Crystal (2)".

After the discovery of the $\left[\mathrm{C}_{4}\right.$ mim $][\mathrm{Cl}]$ crystal polymorphism, the crystal structures were determined by X-ray diffraction of $\left[\mathrm{C}_{4}\right.$ mim $][\mathrm{Cl}]$ " Crystal (1)" and $\left[\mathrm{C}_{4}\right.$ mim $][\mathrm{Br}]$ at room temperature [116] and independently, of $\left[\mathrm{C}_{4}\right.$ mim $][\mathrm{Cl}]$ "Crystal (1)"

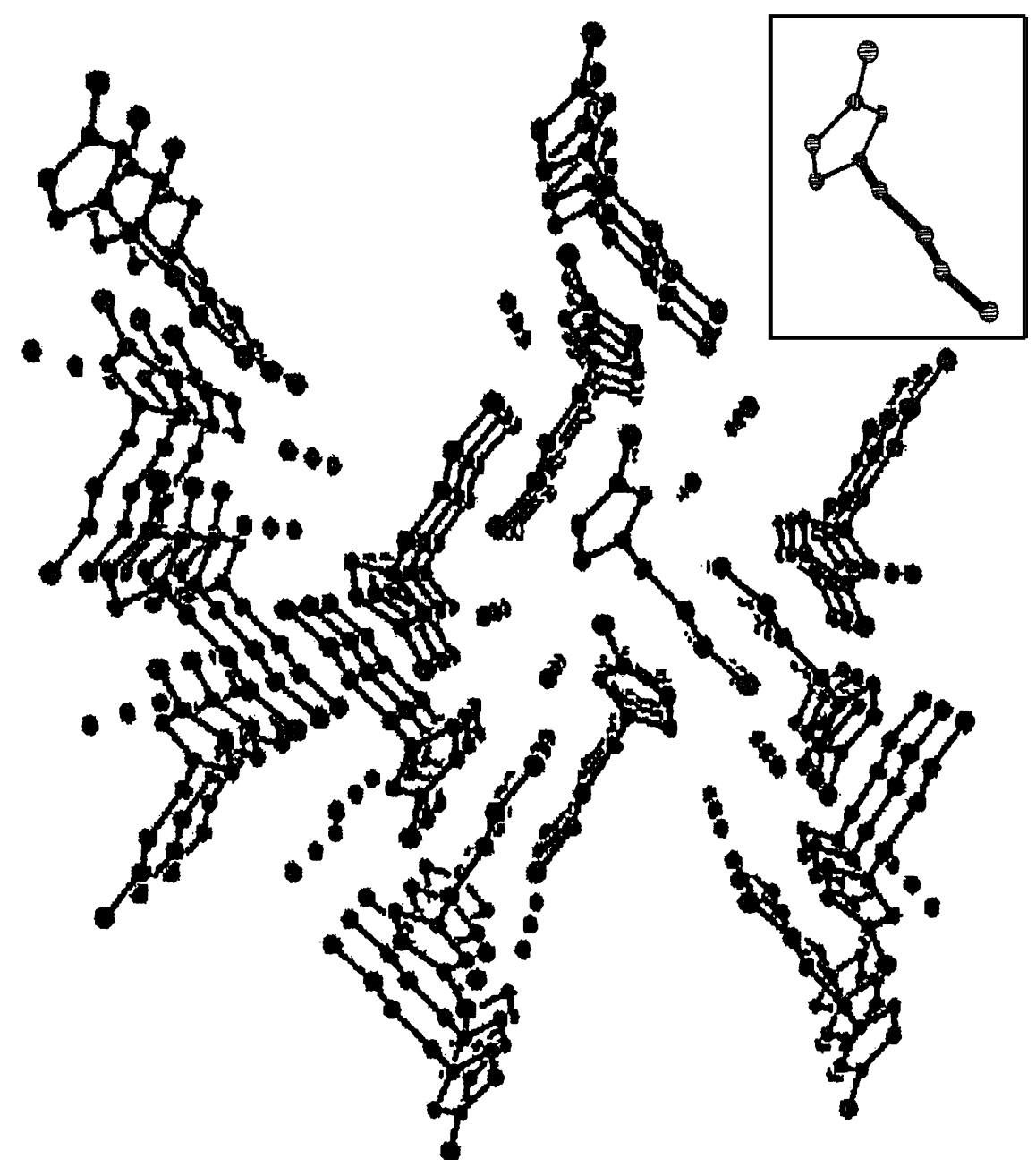

Fig. 4. Crystal structure of $\left[\mathrm{C}_{4}\right.$ mim $][\mathrm{Cl}]$ "Crystal (1)" viewed along the $a$ axis. Only carbon atoms, nitrogen atoms, and chloride anions are shown. The anti-anti $(A A)$ conformation of the $\left[\mathrm{C}_{4} \text { mim }\right]^{+}$cation is shown in the inset. The butyl group $\mathrm{C}-\mathrm{C}$ bonds are shown as thick bars. Note that the cations and chloride anions form characteristic columns along the crystal $a$ axis (figure adapted from Hamaguchi and Ozawa [108]) 
and "Crystal (2)", as well as that of $\left[\mathrm{C}_{4}\right.$ mim $][\mathrm{Br}]$ at $-100^{\circ} \mathrm{C}$ [117]. The two sets of structures determined at different temperatures agreed quite well with each other, taking into account that lattice constants vary with temperature. The molecular structure of the $\left[\mathrm{C}_{4} \text { mim }\right]^{+}$cation in $\left[\mathrm{C}_{4}\right.$ mim $][\mathrm{Cl}]$ "Crystal (2)" is different from that in (1) but it was the same as that in $\left[\mathrm{C}_{4}\right.$ mim $][\mathrm{Br}]$, as also proved later by the Raman spectra.

The $\left[\mathrm{C}_{4} \mathrm{mim}\right]^{+}$cations in the two polymorphs were found predominantly to differ with respect to conformation: the structural results showed that the polymorphism is due to a rotational isomerism of the butyl group of the $\left[\mathrm{C}_{4} \mathrm{mim}\right]^{+}$cation around $\mathrm{C} 7-\mathrm{C} 8$, as defined in Fig. 2. In the monoclinic polymorph, the butyl chain is in anti (or trans) conformation around $\mathrm{C} 7-\mathrm{C} 8$, and in the orthorhombic polymorph it is gauche around $\mathrm{C} 7-\mathrm{C} 8$. The conformational difference reveals itself in the rotation of the butyl chain around the $\mathrm{C} 7-\mathrm{C} 8$ bond, that differed by $106.16^{\circ}$ between the two conformers [117]. The C8-C9 conformation was found to be anti in both polymorphs. In a convenient and obvious notation, these two con- formers of the $\left[\mathrm{C}_{4} \mathrm{mim}\right]^{+}$cation are here referred to as the $A A$ and the $G A$ forms (Hamaguchi et al. denote them $T T$ and $G T$ ). Also the crystal structure of $\left[\mathrm{C}_{4}\right.$ mim $][\mathrm{Br}]$ has been reported [117].

The crystal structure of the monoclinic $\left[\mathrm{C}_{4} \mathrm{mim}\right]$ [Cl] "Crystal (1)" is shown in Fig. 4. Details of structural data are available from the Cambridge Crystallographic Data Centre [124]. The crystal belongs to space group $P 2_{1} / n$ with $a=9.982(10), b=$ $11.590(12), c=10.077(11) \AA$, and $\beta=121.80(2)^{\circ}$. Both the $\left[\mathrm{C}_{4} \mathrm{mim}\right]^{+}$cations and the chloride anions form separate columns extending along the crystal $a$ axis. The imidazolium rings are all planar pentagons. The stretched $n$-butyl group of the $\left[\mathrm{C}_{4} \text { mim }\right]^{+}$cation takes an anti-anti $(A A)$ conformation with respect to the $\mathrm{C} 7-\mathrm{C} 8$ and $\mathrm{C} 8-\mathrm{C} 9$ bonds, as shown in the inset of Fig. 4. The butyl groups stack together (aliphatic interaction) and form columns extending along the $a$ axis, in which all the imidazolium ring planes are parallel with one another. Two types of cation columns with different orientations exist, the planes of the imidazolium rings in the two different columns making an angle of $69.5^{\circ}$. Zig-zag chains of $\mathrm{Cl}^{-}$

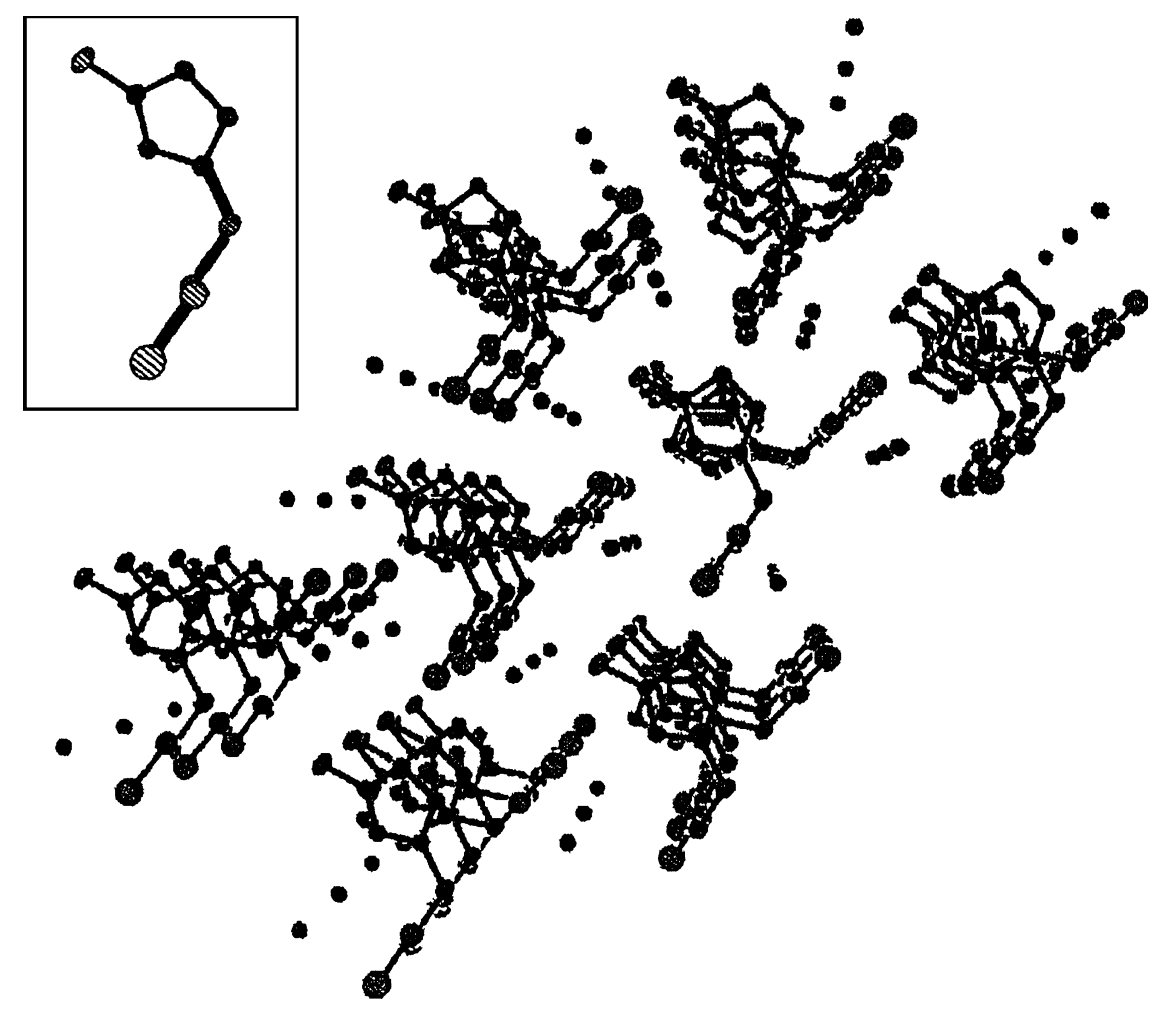

Fig. 5. Crystal structure of $\left[\mathrm{C}_{4} \mathrm{mim}\right][\mathrm{Br}]$ viewed in the direction of the $a$ axis. Only carbon atoms, nitrogen atoms, and bromide anions are shown. The gauche-anti $(G A)$ conformation of the $\left[\mathrm{C}_{4} \text { mim }\right]^{+}$cation is shown in the inset. The butyl group $\mathrm{C}-\mathrm{C}$ bonds are shown as thick bars (figure adapted from Hamaguchi and Ozawa [108]) 
anions directed in the $a$ direction are accommodated in channels formed by four cation columns, of which two opposite columns have the same orientation. The three shortest distances between $\mathrm{Cl}^{-}$anions in the zig-zag chain were $4.84,6.06$, and $6.36 \AA$ and these distances are much larger than the sum of the van der Waals radii of $\mathrm{Cl}^{-}(3.5 \AA)$. There seems to be no specific interaction among the $\mathrm{Cl}^{-}$anions, and they are likely to be aligned under the effect of Coulombic forces. The chloride ion is very close to the hydrogen $\mathrm{H} 2$ in the ring $(2.55 \AA)$, and to the two methylene protons on C7 (2.72 and $2.73 \AA)$ $[116,117]$, meeting the criteria for relatively strong hydrogen bonds $[125,126]$. Similarly strong hydrogen bonds are observed in the orthorhombic form [117]. Also other crystal structures e.g., of the 1ethyl-3-methylimidazolium chloride $\left(\left[\mathrm{C}_{2} \mathrm{mim}\right][\mathrm{Cl}]\right)$ [60], the tetrafluoroborate $\left(\left[\mathrm{C}_{2} \mathrm{mim}\right]\left[\mathrm{BF}_{4}\right]\right)$, and other salts [127] have been reported.

The crystal structure of orthorhombic $\left[\mathrm{C}_{4} \mathrm{mim}\right]-$ $[\mathrm{Br}]\left(\mathrm{mp} 77.6^{\circ} \mathrm{C}[123]\right)$ is shown in Fig. 5. The detailed structural data are available from the Cambridge Crystallographic Data Centre [124]. The $\left[\mathrm{C}_{4}\right.$ mim $][\mathrm{Br}]$ crystal belongs to the space group Pna2 $2_{1}$ with $a=$ $10.0149(14), b=12.0047(15), c=8.5319(11) \AA$. As for the $\left[\mathrm{C}_{4}\right.$ mim $][\mathrm{Cl}]$ "Crystal (1)", the cations and anions form separate columns extending along the $a$ axis. In $\left[\mathrm{C}_{4} \mathrm{mim}\right][\mathrm{Br}]$ the $n$-butyl group takes a gauche-anti $(G A)$ conformation with respect to the C7-C8 and C8-C9 bonds (see inset of Fig. 5). Only one kind of cation column is found. The imidazolium rings are stacked so that the $\mathrm{N}-\mathrm{C}-\mathrm{N}$ moiety of one ring interacts with the $\mathrm{C}=\mathrm{C}$ portion of the adjacent ring. The adjacent ring plane can be obtained by rotation of the ring by about $73^{\circ}$ around an axis involving the two $\mathrm{N}$ atoms. The zig-zag chain of $\mathrm{Br}^{-}$anions resides in the channel produced by four cation columns, extending in the $a$ direction. The shortest three $\mathrm{Br}^{-}-\mathrm{Br}^{-}$distances $(4.77,6.55$, and $8.30 \AA$ ) are all longer than the sum of the van der Waals radii $(3.7 \AA)$. This indicates that there is no specific interaction among the $\mathrm{Br}^{-}$anions and that the zigzag molecular arrangement is a result of Coulombic interactions.

\section{Raman Spectra and Structure of $\left[\mathrm{C}_{4} \mathrm{mim}\right]^{+}$ Liquids}

The information obtained from the study of the $\left[\mathrm{C}_{4} \text { mim }\right]^{+}$crystals can be used as a basis to better

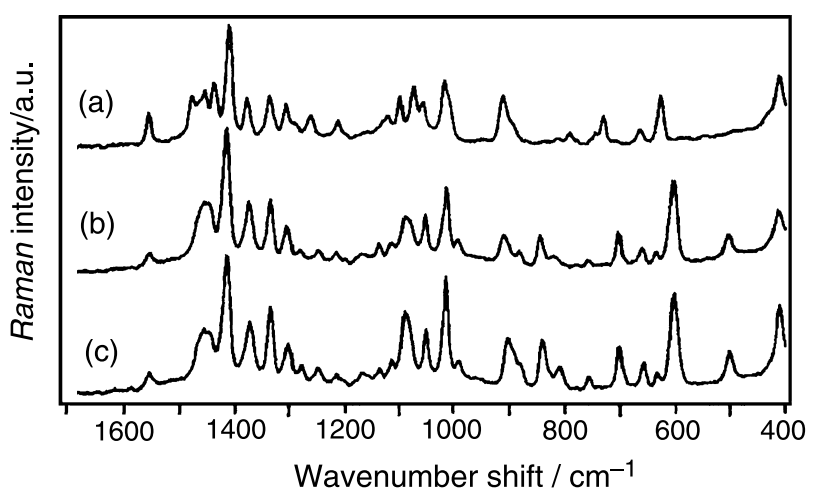

Fig. 6. Raman spectra of (a) $\left[\mathrm{C}_{4}\right.$ mim $][\mathrm{Cl}]$ "Crystal (1)", (b) $\left[\mathrm{C}_{4}\right.$ mim $][\mathrm{Cl}]$ "Crystal (2)", and (c) $\left[\mathrm{C}_{4}\right.$ mim $][\mathrm{Br}]$ crystals. (a) Differs from (b) and (c) (figure has been adapted from Hamaguchi and Ozawa [108])

understand the liquid structure of the $\left[\mathrm{C}_{4} \mathrm{mim}\right][X]$ ionic liquids ( $X$ is an anion). It is well-known that Raman spectroscopy facilitates comparative studies of the structures in crystals and liquids. Raman spectra of $\left[\mathrm{C}_{4}\right.$ mim $][\mathrm{Cl}]$ "Crystals (1) and (2)", and $\left[\mathrm{C}_{4}\right.$ mim $][\mathrm{Br}]$ by Hamaguchi et al. $[108,116,118$, 122, 128] are shown in Fig. 6. As seen, the two polymorphs of $\left[\mathrm{C}_{4} \mathrm{mim}\right][\mathrm{Cl}]$ gave distinct Raman spectra differing considerably, while those of $\left[\mathrm{C}_{4}\right.$ mim $][\mathrm{Cl}]$ "Crystal (2)" and $\left[\mathrm{C}_{4}\right.$ mim $][\mathrm{Br}]$ were almost identical. These findings are consistent with the X-ray diffraction experimental results. The halogen anions are inactive in Raman scattering - except for the lattice vibrations, that are observed in the wavenumber region below $200 \mathrm{~cm}^{-1}$ [129]. Therefore, all the Raman bands seen in Fig. 6 can be ascribed to the $\left[\mathrm{C}_{4} \mathrm{mim}\right]^{+}$cation. Figure 6 was accordingly interpreted to indicate that the $\left[\mathrm{C}_{4} \mathrm{mim}\right]^{+}$cation takes two different conformations in those salts. To be in accordance with the X-rays results, at least the cation must adopt the same molecular conformation in $\left[\mathrm{C}_{4}\right.$ mim $][\mathrm{Cl}]$ "Crystal (2)" and $\left[\mathrm{C}_{4}\right.$ mim $][\mathrm{Br}]$, and a different one in $\left[\mathrm{C}_{4}\right.$ mim $][\mathrm{Cl}]$ "Crystal (1)". In this way it emerged that the Raman spectral differences in Fig. 6 most likely originated from the rotational isomerism around the $\mathrm{C} 7-\mathrm{C} 8$ (the $A A$ and $G A$ isomerism) of the butyl chain of the $\left[\mathrm{C}_{4} \mathrm{mim}\right]^{+}$cation $[122,128]$.

Raman spectra of liquid $\left[\mathrm{C}_{4}\right.$ mim $][X](X=\mathrm{Cl}, \mathrm{Br}, \mathrm{I}$, $\mathrm{BF}_{4}$, and $\left.\mathrm{PF}_{6}\right)$ measured at room temperature are shown in Fig. 7. The spectra of $\left[\mathrm{C}_{4}\right.$ mim $][\mathrm{Cl}]$ "Crystal (1)" and $\left[\mathrm{C}_{4} \mathrm{mim}\right][\mathrm{Br}]$ are also included for reference purposes. Spectra for fluids $\left[\mathrm{C}_{4} \mathrm{mim}\right][\mathrm{Cl}]$ and $\left[\mathrm{C}_{4}\right.$ mim $][\mathrm{Br}]$ were taken from supercooled liquids. 


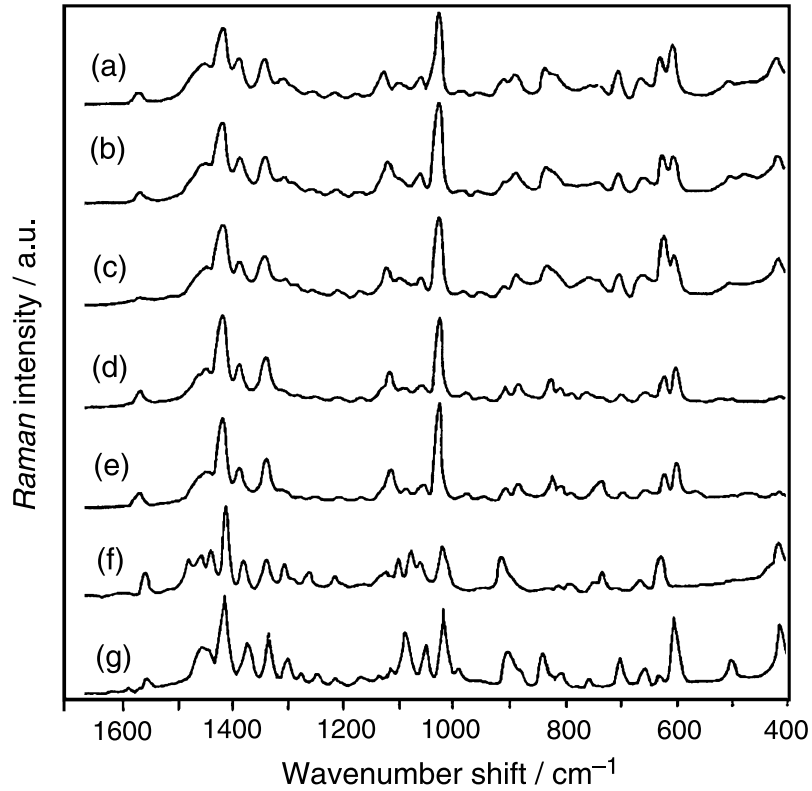

Fig. 7. Raman spectra of liquid $\left[\mathrm{C}_{4}\right.$ mim $][X]$, where $X=\mathrm{C} 1$ (a), $\mathrm{Br}(\mathrm{b}), \mathrm{I}(\mathrm{c}),\left[\mathrm{BF}_{4}\right]$ (d), and $\left[\mathrm{PF}_{6}\right]$ (e). The anion bands in (d) and (e) have been deleted [108]. Spectra of $\left[\mathrm{C}_{4}\right.$ mim $][\mathrm{Cl}]$ "Crystal (1)" and crystalline $\left[\mathrm{C}_{4}\right.$ mim $][\mathrm{Br}]$, respectively, are included as (f) and (g), for reference purposes (figure adapted from Hamaguchi and Ozawa [108])

The Raman spectra of the $\left[\mathrm{C}_{4}\right.$ mim $][X]$ liquids were surprisingly alike. One should note that the Raman spectral bands of the separate $\left[\mathrm{BF}_{4}\right]^{-}$and $\left[\mathrm{PF}_{6}\right]^{-}$ anions - that are already well known [97] - have been deleted in Fig. 7. However, from the similarity of the spectra it seems that the structural properties of the $\left[\mathrm{C}_{4} \mathrm{mim}\right]^{+}$cation in these liquids are very similar. But what else can be deduced from the spectra?

\section{Normal Mode Analysis and Rotational Isomerism of the $\left[\mathrm{C}_{4} \text { mim }\right]^{+}$Cation}

To pursue this question further, Ozawa et al. [128] have performed density functional calculations (DFT) with Gaussian98 at the $B 3 L Y P / 6-31+\mathrm{G}^{* *}$ level. In the calculation, the structures of the $A A$ and $G A$ forms of $\left[\mathrm{C}_{4} \mathrm{mim}\right]^{+}$were optimized in the vicinity of the determined X-ray crystal structures for $\left[\mathrm{C}_{4}\right.$ mim $][\mathrm{Cl}]$ "Crystal (1)" and $\left[\mathrm{C}_{4}\right.$ mim $][\mathrm{Br}]$, respectively. The structures of the optimized $\left[\mathrm{C}_{4} \mathrm{mim}\right]^{+}$ cations in the two crystals are depicted in Fig. 8, together with the experimental spectra (in a limited wavenumber region of $1000-400 \mathrm{~cm}^{-1}$ ). The calculated fundamental frequencies and intensities were included in Fig. 8 as thick vertical bars. As seen, the
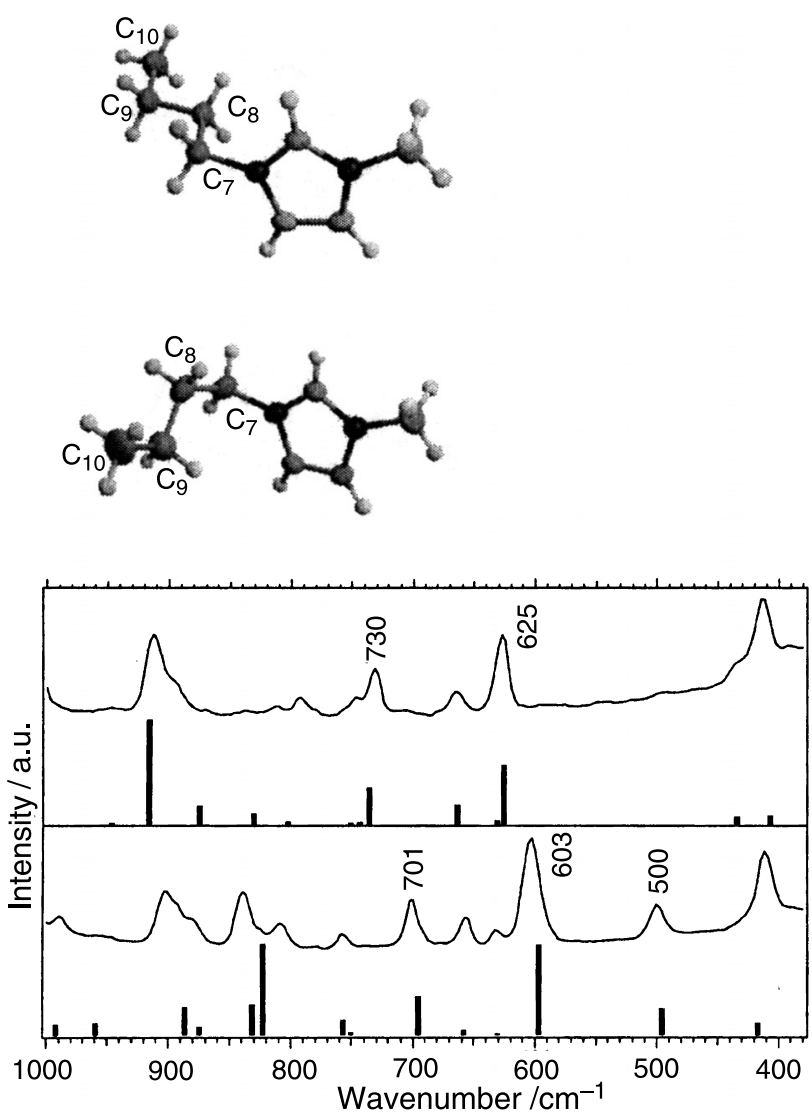

Fig. 8. Optimized structures of the $\left[\mathrm{C}_{4} \mathrm{mim}\right]^{+}$cation in the two crystals. Experimental (continuous lines) and calculated Raman spectra (solid vertical bars) of $\left[\mathrm{C}_{4}\right.$ mim $][\mathrm{Cl}]$ "Crystal (1)" (above) and $\left[\mathrm{C}_{4} \mathrm{mim}\right][\mathrm{Br}]$ (below) are shown (figure has been adapted from Hamaguchi and Ozawa [108] and Ozawa et al. [128])

calculated "bar"-spectra reproduced the observed spectra quite well.

The normal mode calculation was used to elucidate the rotational isomerization equilibrium of the $\left[\mathrm{C}_{4} \operatorname{mim}\right][X]$ liquids. In the wavenumber region near $800-500 \mathrm{~cm}^{-1}$, where ring deformation bands are expected, two Raman bands appeared at $\sim 730 \mathrm{~cm}^{-1}$ and $\sim 625 \mathrm{~cm}^{-1}$ in the $\left[\mathrm{C}_{4}\right.$ mim $][\mathrm{Cl}]$ "Crystal (1)". In the $\left[\mathrm{C}_{4} \mathrm{mim}\right][\mathrm{Br}]$ these bands were not found. Here instead, another couple of bands appeared at $\sim 701 \mathrm{~cm}^{-1}$ and $\sim 603 \mathrm{~cm}^{-1}$. To assist the interpretatation of the spectra, the normal modes of vibrations calculated by Hamaguchi and Ozawa [108] are shown in Fig. 9. It shows modes for the $\left[\mathrm{C}_{4} \text { mim }\right]^{+}$ion of the geometry of $\left[\mathrm{C}_{4} \mathrm{mim}\right][\mathrm{Cl}]$ "Crystal (1)" at 735 and $626 \mathrm{~cm}^{-1}$; and similarly the modes for $\left[\mathrm{C}_{4} \mathrm{mim}\right][\mathrm{Br}]$ occurring at 696 and $596 \mathrm{~cm}^{-1}$. Obviously the $626 \mathrm{~cm}^{-1}$ band of $\left[\mathrm{C}_{4} \mathrm{mim}\right]-$ 


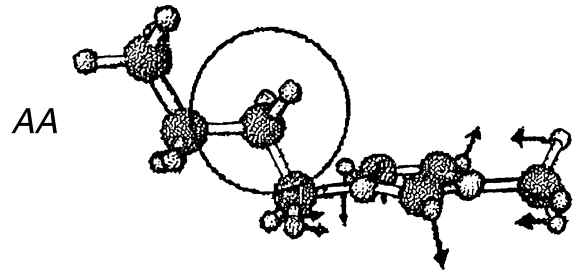

$626 \mathrm{~cm}^{-1}$

$G A$

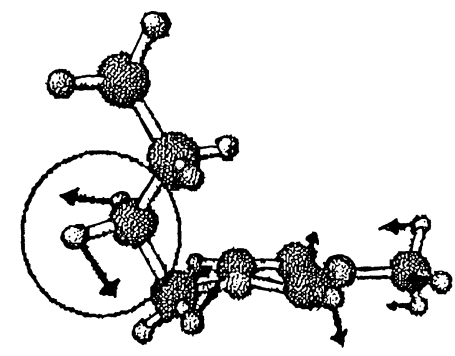

$596 \mathrm{~cm}^{-1}$

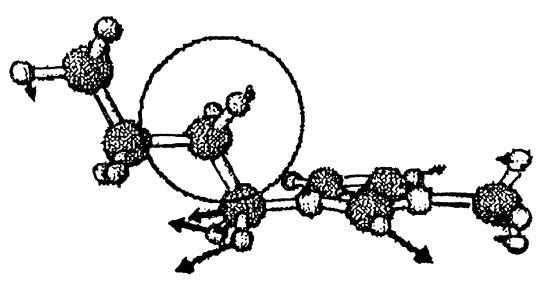

$735 \mathrm{~cm}^{-1}$

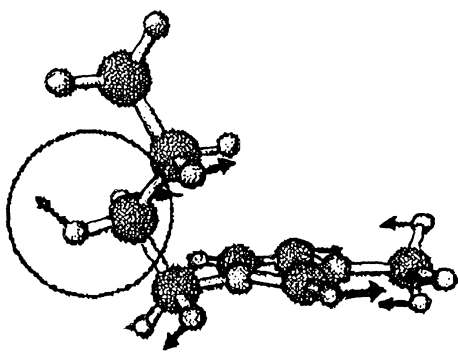

$696 \mathrm{~cm}^{-1}$

Fig. 9. Calculated normal modes of key bands of the $A A$ and $G A$ forms of the $\left[\mathrm{C}_{4} \mathrm{mim}\right]^{+}$cation. The arrows indicate vibrational amplitudes of atoms. The $\mathrm{C} 8$ methylene group is surrounded by a circle. Obviously it appears that the $\mathrm{CH}_{2}$ rocking vibration is coupled to the ring modes only for the GA conformer, thereby lowering the frequencies. Graphics adapted from Hamaguchi and Ozawa [108]

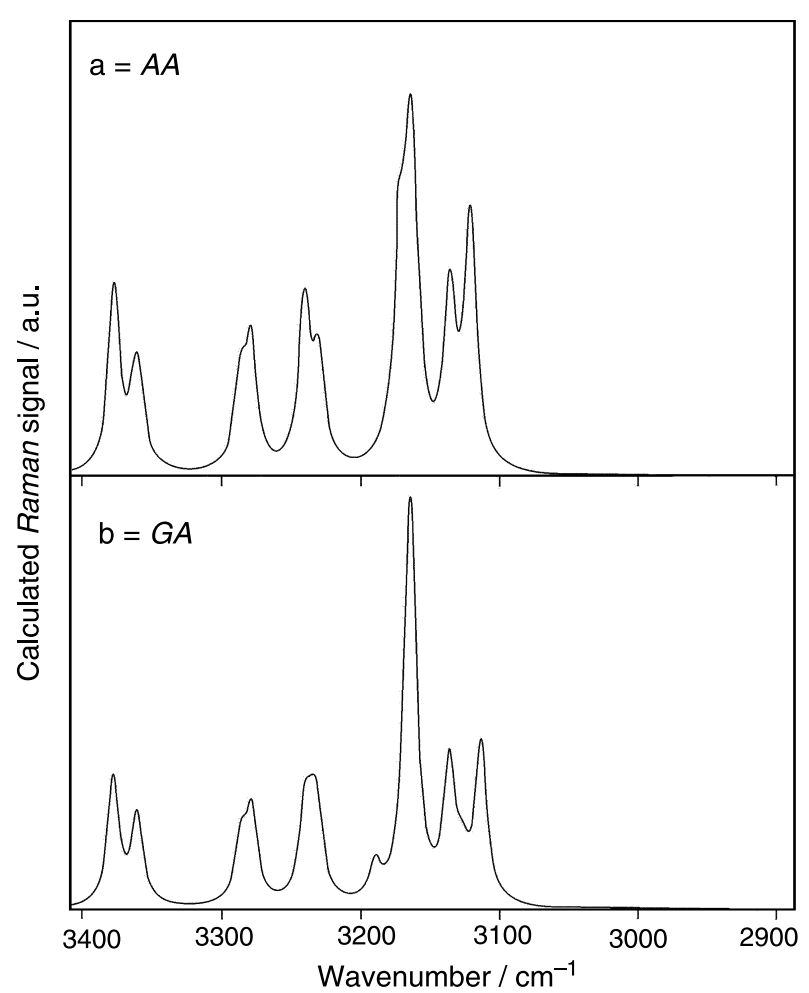

Fig. 10. Calculated Raman spectra of two conformers of the $\left[\mathrm{C}_{4} \mathrm{mim}\right]^{+}$cation in the range between 3400 and $2900 \mathrm{~cm}^{-1}$. (a) The anti-anti conformer; (b) the gauche-anti conformer. Data from Ref. [130]

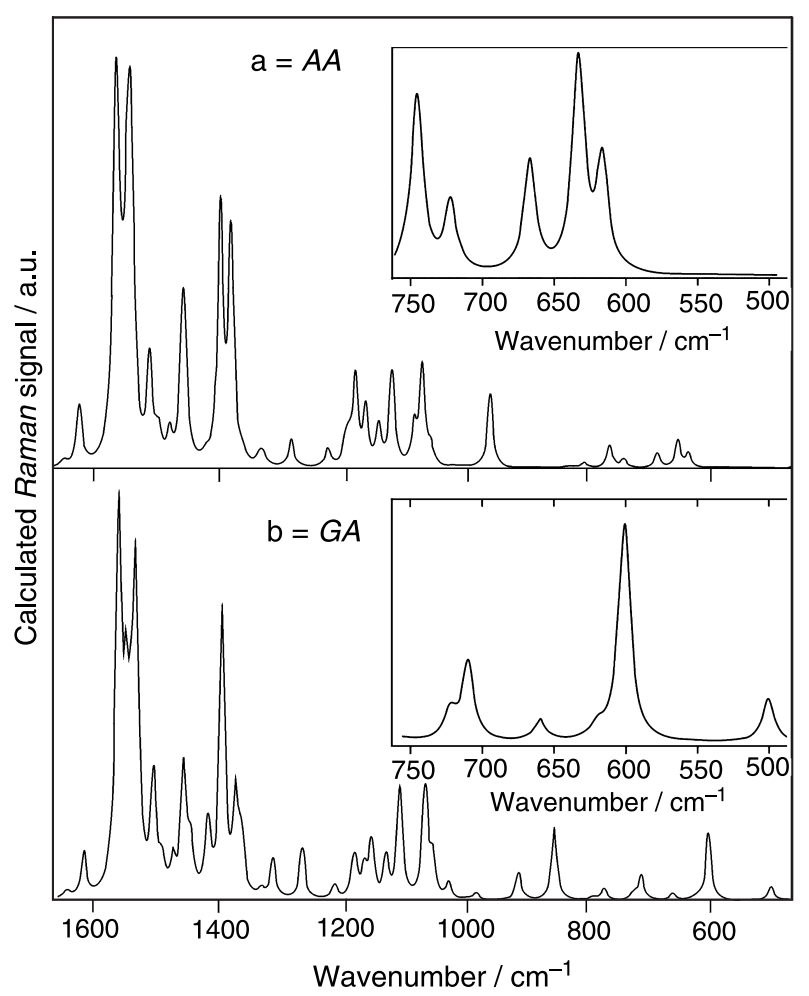

Fig. 11. Calculated Raman spectra of two conformers of the $\left[\mathrm{C}_{4} \text { mim }\right]^{+}$cation in the range between 1650 and $400 \mathrm{~cm}^{-1}$. (a) The anti-anti conformer; (b) the gauche-anti conformer. Data from Refs. [103] and [130] 
Table 1. Approximate descriptions* of vibrational frequencies (IR and Raman bands) as determined in $M P 2$ calculations for the $\left[\mathrm{C}_{4} \mathrm{mim}\right]^{+}$cation with the butyl group either in the $A A$ (anti-anti) conformation or in the $G A$ (gauche-anti) conformation, derived from movements as depicted on a PC-screen

\begin{tabular}{|c|c|c|c|c|}
\hline \multirow[b]{2}{*}{ Mode } & \multicolumn{2}{|r|}{ Butyl group in the $A A$ (anti-anti) conformation } & \multicolumn{2}{|c|}{ Butyl group in the $G A$ (gauche-anti) conformation } \\
\hline & $\bar{\nu} / \mathrm{cm}^{-1}$ & Approximate description & $\bar{\nu} / \mathrm{cm}^{-1}$ & Approximate description \\
\hline 1 & 30.4 & $\mathrm{~N}-\mathrm{C} 7$ tor & 27.5 & $\mathrm{~N}-\mathrm{C} 7$ tor \\
\hline 2 & 58.3 & $\mathrm{~N}-\mathrm{C} 6$ tor & 58.3 & $\mathrm{~N}-\mathrm{C} 6$ tor \\
\hline 3 & 74.3 & $\mathrm{C} 7-\mathrm{C} 8$ tor & 76.6 & $\mathrm{~N}-\mathrm{C} 6$ tor $+\mathrm{C} 7-\mathrm{C} 8$ tor \\
\hline 4 & 81.8 & $\mathrm{~N}-\mathrm{C} 6$ tor $+\mathrm{N}-\mathrm{C} 7-\mathrm{C} 8$ bend & 82.5 & $\mathrm{C} 7-\mathrm{C} 8$ tor \\
\hline 5 & 116.5 & $\mathrm{~N}-\mathrm{C} 7$ tor & 156.7 & $\mathrm{~N}-\mathrm{C} 6$ oopl bend $+\mathrm{C} 8 \mathrm{H}_{2}$ rock \\
\hline 6 & 203.6 & chain def $+\mathrm{N}-\mathrm{C} 6$ oopl bend & 205.1 & chain def $+\mathrm{N}-\mathrm{C} 6$ oopl bend \\
\hline 7 & 250.9 & $\mathrm{~N}-\mathrm{C} 6+\mathrm{N}-\mathrm{C} 7 \mathrm{H}_{2}$ oopl ooph bend & 251.1 & $\mathrm{~N}-\mathrm{C} 6+\mathrm{N}-\mathrm{C} 7 \mathrm{H}_{2}$ oopl ooph bend \\
\hline 8 & 252.8 & C9-C10 tor & 258.4 & C9-C10 tor \\
\hline 9 & 278.8 & $\mathrm{C} 7 \mathrm{H}_{2}$ rock $+\mathrm{C}_{6} \mathrm{H}_{3}$ ipl iph bend & 296.1 & $\mathrm{C} 7 \mathrm{H}_{2}$ rock $+\mathrm{C} \mathrm{H}_{3}$ ipl iph bend \\
\hline 10 & 327.1 & ring wag + chain def & 333.3 & ring wag + chain def \\
\hline 11 & 407.0 & ring rot $+\mathrm{C} 7 \mathrm{H}_{2}$ rock $+\mathrm{C} 6 \mathrm{H}_{3}$ rock & 418.0 & ring rot $+\mathrm{C}_{7} \mathrm{H}_{2}$ rock $+\mathrm{N}-\mathrm{C}_{6} \mathrm{H}_{3}$ ipl rock \\
\hline 12 & 441.0 & $\begin{array}{l}\mathrm{N}-\mathrm{C} 7 \text { oopl bend }+\mathrm{N}-\mathrm{C} 6 \text { oopl ooph bend }+ \\
\text { chain bend }+\mathrm{CH}_{2} \text { wag }+ \text { ring rot }\end{array}$ & 503.7 & $\begin{array}{l}\mathrm{N}-\mathrm{C} 7 \text { oopl bend }+\mathrm{N}-\mathrm{C} 7-\mathrm{C} 8-\mathrm{C} 9 \\
\text { angles bend }\end{array}$ \\
\hline 13 & 619.6 & $\begin{array}{l}\text { ring oopl def }+\mathrm{C} 7 \mathrm{H}_{2} \text { rock }+\mathrm{C} 7- \\
\text { C8-C9 bend }\end{array}$ & 603.9 & $\begin{array}{l}\mathrm{N}-\mathrm{C} 6 \mathrm{~N}-\mathrm{C} 7 \text { iph str }+ \text { ring oopl def }+ \\
\mathrm{C} 8 \mathrm{H}_{2} \text { rock }+\mathrm{N}-\mathrm{C} 7-\mathrm{C} 8 \text { bend }\end{array}$ \\
\hline 14 & 636.2 & $\begin{array}{l}\text { ring def }(\mathrm{C} 2-\mathrm{H} \text { oopl bend })+\mathrm{N}-\mathrm{C} 6 \mathrm{~N}-\mathrm{C} 7 \mathrm{iph} \\
\text { str }+\mathrm{C} 7 \mathrm{H}_{2} \text { rock }+\mathrm{C} 7-\mathrm{C} 8-\mathrm{C} 9 \text { bend }\end{array}$ & 622.8 & $\begin{array}{l}\text { ring def }(\mathrm{C} 2-\mathrm{H} \mathrm{C} 4-\mathrm{H} \text { iph oopl bend })+ \\
\mathrm{C} 8 \mathrm{H}_{2} \text { rock }+\mathrm{N}-\mathrm{C} 7-\mathrm{C} 8 \text { bend }\end{array}$ \\
\hline 15 & 670.2 & $\begin{array}{l}\mathrm{N}-\mathrm{C} 6 \mathrm{str}+\text { ring def }(\mathrm{N} 1 \text { and } \mathrm{H} \text { on } \mathrm{C} 2 \text { oopl } \\
\text { ooph departure })+\mathrm{C} 8 \mathrm{H}_{2} \text { wag }+\mathrm{N}-\mathrm{C} 7-\mathrm{C} 8 \text { bend }\end{array}$ & 662.8 & $\begin{array}{l}\text { ring def (bend around line } \mathrm{NN})+\mathrm{C} 8 \mathrm{H}_{2} \\
\text { rock }+\mathrm{N}-\mathrm{C} 7-\mathrm{C} 8 \text { bend }\end{array}$ \\
\hline 16 & 725.5 & ring $\mathrm{C}-\mathrm{H}$ oopl bend (bend around $\mathrm{NN}$ line) & 712.8 & $\begin{array}{l}\mathrm{N}-\mathrm{C} 6 \mathrm{~N}-\mathrm{C} 7 \text { ooph str }+ \text { ring ipl def }+\mathrm{C}^{8} \mathrm{H}_{2} \\
\text { rock }+\mathrm{C} 7-\mathrm{C} 8 \text { tor }\end{array}$ \\
\hline 17 & 748.8 & $\begin{array}{l}\mathrm{N}-\mathrm{C} 6 \mathrm{~N}-\mathrm{C} 7 \text { ooph str }+ \text { ring ipl def }+ \\
\mathrm{N}-\mathrm{C} 7-\mathrm{C} 8 \text { and } \mathrm{C} 7-\mathrm{C} 8-\mathrm{C} 9 \text { bend }\end{array}$ & 725.1 & $\begin{array}{l}\text { ring } \mathrm{C}-\mathrm{H} \text { oopl bend (bend around } \\
\text { NN line) }\end{array}$ \\
\hline 18 & 754.6 & chain $\mathrm{CH}_{2}$ sci + rock & 773.5 & $\begin{array}{l}\text { chain } \mathrm{CH}_{2} \text { rock }+ \text { ring } \mathrm{C}-\mathrm{H} \text { oopl iph bend } \\
\text { (umbrella) }\end{array}$ \\
\hline 19 & 791.7 & ring $\mathrm{C}-\mathrm{H}$ oopl iph bend (umbrella) & 790.4 & ring $\mathrm{C}-\mathrm{H}$ oopl iph bend (umbrella) \\
\hline 20 & 813.7 & C4-H C5-H oopl ooph bend (twi) & 811.5 & C4-H C5-H oopl ooph bend (twi) \\
\hline 21 & 819.3 & chain $\mathrm{CH}_{2}$ sci & 853.9 & chain $\mathrm{CH}_{2}$ sci \\
\hline 22 & 945.3 & chain def $+{\mathrm{C} 10 \mathrm{H}_{2} \text { rock }}$ & 912.4 & chain def $+{\mathrm{C} 10 \mathrm{H}_{3} \text { rock }}$ \\
\hline 23 & 969.8 & chain def $\left(\mathrm{CH}_{2}\right.$ twi + rock $)$ & 981.5 & chain def $\left(\mathrm{CH}_{2} \mathrm{sci}+\right.$ rock $)$ \\
\hline 24 & 1043.6 & ring def + chain def & 1025.7 & ring def + chain def \\
\hline 25 & 1057.3 & ring def $+\mathrm{N}-\mathrm{C} 6 \mathrm{str}+\mathrm{C} 4-\mathrm{H} \mathrm{C} 5-\mathrm{H}$ ipl iph bend & 1051.9 & ring def $+\mathrm{N}-\mathrm{C} 6 \mathrm{str}+\mathrm{N}-\mathrm{C} 7 \mathrm{str}+\mathrm{C} 7-\mathrm{C} 8 \mathrm{str}$ \\
\hline 26 & 1070.3 & $\mathrm{C} 4-\mathrm{H}$ ipl bend $+\mathrm{C} 7-\mathrm{C} 8$ str & 1064.0 & $\begin{array}{l}\text { C4-H C5-H ipl bend (sci) + N-C6 str }+ \\
\text { N-C7 str }+ \text { C7-C8 str }\end{array}$ \\
\hline 27 & 1106.6 & chain def & 1104.9 & chain def \\
\hline 28 & 1128.4 & $\mathrm{C}_{6} \mathrm{H}_{3}$ ipl rock + ring def & 1127.4 & $\mathrm{C}_{6} \mathrm{H}_{3}$ ipl rock + ring def \\
\hline 29 & 1149.9 & C4-H C5-H ipl bend (sci) & 1151.0 & C4-H C5-H ipl bend (sci) \\
\hline 30 & 1167.0 & chain def (C-C str) & 1162.6 & chain def (C-C str) \\
\hline 31 & 1176.9 & $\mathrm{C}_{6} \mathrm{H}_{3}$ def (oopl rock) & 1176.4 & $\mathrm{C}_{6} \mathrm{H}_{3}$ def (oopl rock) \\
\hline 32 & 1182.7 & $\mathrm{C} 2-\mathrm{H}$ ipl bend, $\mathrm{C} \mathrm{H}_{3}$ def, chain $\mathrm{CH}_{2}$ def & 1180.5 & $\mathrm{C} 2-\mathrm{H}$ ipl bend, $\mathrm{C}_{6} \mathrm{H}_{3}$ def, chain $\mathrm{CH}_{2}$ def \\
\hline 33 & 1212.3 & $\mathrm{C} 6-\mathrm{N}$ C7-N ooph str + ring $\mathrm{C}-\mathrm{H}$ ipl bend & 1211.1 & C6-N C7-N ooph str + ring $\mathrm{C}-\mathrm{H}$ ipl bend \\
\hline 34 & 1272.5 & ring $\mathrm{CH}$ iph ipl bend + chain $\mathrm{CH}_{2}$ def & 1263.6 & ring $\mathrm{CH}$ iph ipl bend + chain $\mathrm{CH}_{2}$ def \\
\hline 35 & 1318.4 & ring $\mathrm{CH}$ iph ipl bend + chain $\mathrm{CH}_{2}$ wag & 1311.0 & ring $\mathrm{CH}$ iph ipl bend + chain $\mathrm{CH}_{2}$ def \\
\hline 36 & 1324.3 & ring $\mathrm{CH}$ iph ipl bend + chain $\mathrm{CH}_{2}$ def & 1329.2 & ring $\mathrm{CH}$ iph ipl bend + chain $\mathrm{CH}_{2}$ def \\
\hline 37 & 1353.0 & chain $\mathrm{CH}_{2}$ def + ring $\mathrm{CH}$ iph ipl bend & 1362.5 & chain $\mathrm{CH}_{2}$ def \\
\hline 38 & 1371.8 & $\mathrm{C} 8 \mathrm{H}_{2} \mathrm{C}_{9} \mathrm{H}_{2}$ twi & 1371.7 & chain $\mathrm{CH}_{2}$ def \\
\hline 39 & 1388.9 & ring breathing $+\mathrm{C} 7 \mathrm{H}_{2}$ twi & 1393.3 & ring breathing $+\mathrm{C} 7 \mathrm{H}_{2}$ twi \\
\hline 40 & 1413.6 & $\mathrm{C} 7 \mathrm{H}_{2} \mathrm{C} 9 \mathrm{H}_{2}$ wag & 1416.7 & $\mathrm{C} \mathrm{H}_{2}$ wag \\
\hline 41 & 1443.7 & chain $\mathrm{CH}_{2}$ wag & 1445.1 & chain $\mathrm{CH}_{2}$ wag \\
\hline 42 & 1450.6 & ring asym $\mathrm{str}+\mathrm{C} \mathrm{H}_{2} \mathrm{twi}+\mathrm{C}_{6} \mathrm{H}_{3}$ def & 1456.1 & ring asym $\mathrm{str}+\mathrm{C} 7 \mathrm{H}_{2} \mathrm{twi}+\mathrm{C}_{6} \mathrm{H}_{3}$ def \\
\hline
\end{tabular}


Table 1 (continued)

\begin{tabular}{|c|c|c|c|c|}
\hline \multirow[b]{2}{*}{ Mode } & \multicolumn{2}{|r|}{ Butyl group in the $A A$ (anti-anti) conformation } & \multicolumn{2}{|c|}{ Butyl group in the $G A$ (gauche-anti) conformation } \\
\hline & $\bar{\nu} / \mathrm{cm}^{-1}$ & Approximate description & $\bar{\nu} / \mathrm{cm}^{-1}$ & Approximate description \\
\hline 43 & 1472.7 & $\mathrm{C}_{10 H_{3}}$ def (umbrella) & 1473.0 & $\mathrm{C}_{10 H_{3}}$ def (umbrella) \\
\hline 44 & 1490.9 & ring asym str $+\mathrm{C} 6 \mathrm{H}_{3}$ def (umbrella) & 1491.1 & ring asym str $+\mathrm{C} 6 \mathrm{H}_{3}$ def (umbrella) \\
\hline 45 & 1505.4 & $\mathrm{C}_{6} \mathrm{H}_{3}$ def (umbrella) & 1504.8 & $\mathrm{C}_{6} \mathrm{H}_{3}$ def (umbrella) \\
\hline 46 & 1534.6 & $\mathrm{C}_{6} \mathrm{H}_{3}$ def & 1531.8 & $\mathrm{C} 8 \mathrm{H}_{2}$ def (sci) \\
\hline 47 & 1539.1 & $\mathrm{C} \mathrm{H}_{2}+\mathrm{C} 8 \mathrm{H}_{2}$ bend (sci) & 1534.5 & $\mathrm{C}_{6} \mathrm{H}_{3}$ def \\
\hline 48 & 1545.1 & chain $\mathrm{CH}_{2}$ bend (sci) & 1541.3 & $\mathrm{C} 7 \mathrm{H}_{2}$ bend (sci) \\
\hline 49 & 1554.8 & 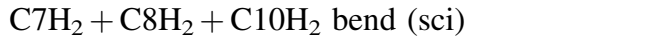 & 1549.0 & $\mathrm{C} 8 \mathrm{H}_{2}+\mathrm{C} \mathrm{H}_{2}+\mathrm{C} 10 \mathrm{H}_{2}$ bend (sci) \\
\hline 50 & 1559.8 & $\mathrm{C} 10 \mathrm{H}_{3}$ def & 1559.5 & $\mathrm{C}_{10 \mathrm{H}_{3}}$ def \\
\hline 51 & 1562.7 & $\mathrm{C}_{6} \mathrm{H}_{3}$ def & 1562.2 & $\mathrm{C}_{6} \mathrm{H}_{3}$ def \\
\hline 52 & 1566.6 & chain $\mathrm{CH}_{2}$ bend (sci) & 1565.4 & $\mathrm{C} 8 \mathrm{H}_{2}+\mathrm{C} 9 \mathrm{H}_{2}+\mathrm{C} 10 \mathrm{H}_{2}$ bend (sci) \\
\hline 53 & 1620.5 & $\mathrm{C} 4-\mathrm{C} 5$ ring str $+\mathrm{C} 4-\mathrm{H}+\mathrm{C} 5-\mathrm{H}$ ipl sym bend & 1618.2 & $\mathrm{C} 4-\mathrm{C} 5$ ring str $+\mathrm{C} 4-\mathrm{H}+\mathrm{C} 5-\mathrm{H}$ ipl sym bend \\
\hline 54 & 1645.7 & $\mathrm{C} 2-\mathrm{N}$ ring asym $\mathrm{str}+\mathrm{C} 2-\mathrm{H}$ ipl bend & 1644.3 & $\mathrm{C} 2-\mathrm{N}$ ring asym $\mathrm{str}+\mathrm{C} 2-\mathrm{H}$ ipl bend \\
\hline 55 & 3120.7 & $\mathrm{C} 8 \mathrm{H}_{2}+\mathrm{C} 9 \mathrm{H}_{2}$ iph str (sym) & 3113.1 & $\mathrm{C} 8 \mathrm{H}_{2}+\mathrm{C} 9 \mathrm{H}_{2}$ iph str (sym) \\
\hline 56 & 3128.6 & $\mathrm{C} 8 \mathrm{H}_{2}+\mathrm{C} 9 \mathrm{H}_{2}$ ooph str (sym) & 3126.5 & $\mathrm{C} 8 \mathrm{H}_{2}+\mathrm{C} 9 \mathrm{H}_{2}$ ooph str (sym) \\
\hline 57 & 3135.6 & $\mathrm{C}_{10 \mathrm{H}_{3}}$ iph str (sym) & 3136.1 & $\mathrm{C}_{10 \mathrm{H}_{3}}$ iph str (sym) \\
\hline 58 & 3160.9 & $\mathrm{C} \mathrm{H}_{2}$ iph str (sym) & 3162.8 & $\mathrm{C} \mathrm{H}_{2}$ iph str $(\mathrm{sym})+\mathrm{C} 8 \mathrm{H}_{2}+\mathrm{C} \mathrm{H}_{2}$ ooph str \\
\hline 59 & 3164.3 & $\mathrm{C} 6 \mathrm{H}_{3}$ iph str (sym) & 3164.3 & $\mathrm{C}_{6} \mathrm{H}_{3}$ iph str (sym) \\
\hline 60 & 3171.6 & $\mathrm{C} 8 \mathrm{H}_{2}+\mathrm{C} 9 \mathrm{H}_{2}$ ooph str (asym) & 3165.5 & $\mathrm{C} \mathrm{H}_{2}$ sym str $+\mathrm{C} 8 \mathrm{H}_{2}+\mathrm{C} 9 \mathrm{H}_{2}$ str (asym) \\
\hline 61 & 3190.6 & $\mathrm{C} 8 \mathrm{H}_{2}+\mathrm{C} 9 \mathrm{H}_{2}$ ooph str (asym) & 3189.4 & $\mathrm{C} 8 \mathrm{H}_{2}+\mathrm{C} 9 \mathrm{H}_{2}$ ooph str (asym) \\
\hline 62 & 3229.5 & $\mathrm{C}_{10 \mathrm{H}_{3}}$ ooph $\operatorname{str}($ asym) & 3230.7 & ${\mathrm{C} 10 \mathrm{H}_{3}}_{3}$ ooph $\operatorname{str}($ asym $)$ \\
\hline 63 & 3232.0 & $\mathrm{C} 7 \mathrm{H}_{2}$ ooph str (asym) & 3234.2 & 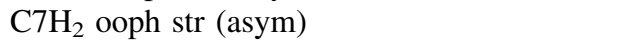 \\
\hline 64 & 3240.4 & $\mathrm{C}_{10 \mathrm{H}_{3}}$ ooph str $(\mathrm{sym})$ & 3240.1 & ${\mathrm{C} 10 \mathrm{H}_{3}}_{3}$ ooph str $(\mathrm{sym})$ \\
\hline 65 & 3278.6 & $\mathrm{C} 6 \mathrm{H}_{3}$ ooph str (asym) & 3278.6 & $\mathrm{C} 6 \mathrm{H}_{3}$ ooph str (asym) \\
\hline 66 & 3286.3 & $\mathrm{C} 6 \mathrm{H}_{3}$ ooph str (sym) & 3286.4 & ${\mathrm{C} 6 \mathrm{H}_{3}}_{3}$ ooph str (sym) \\
\hline 67 & 3359.7 & C3-H C4-H ooph str (asym) & 3360.7 & C3-H C4-H ooph str (asym) \\
\hline 68 & 3363.0 & $\mathrm{C} 2-\mathrm{H}$ str & 3361.9 & $\mathrm{C} 2-\mathrm{H}$ str \\
\hline 69 & 3377.4 & C3-H C4-H iph str (sym) & 3378.5 & C3-H C4-H iph str (sym) \\
\hline
\end{tabular}

* Key of approximate group vibrations: asym asymmetric, bend angle bending (scissoring), breathing all ring bonds iph, def more complicated deformation of skeleton, ipl in plane, iph in phase (symmetric), oopl out of ring plane, ooph opposite motion, out of phase (asymmetric), ring imidazole core, rot ring rotation, as a wheel, with carbon $\mathrm{H}$ atoms, rock rocking (like $\mathrm{V}$ to $V$ by rotation around an axis out of the paper), sci non-connected scissoring, str bond stretching, sym symmetric, tor torsion around specified bond, twi twisting of $\mathrm{CH}_{2}$ group or chain, wag wagging (like $\mathrm{V}$ to $\mathrm{v}$ by rotation around an axis in the paper, $\rightarrow$ )

[Cl] "Crystal (1)" and the $596 \mathrm{~cm}^{-1}$ band of $\left[\mathrm{C}_{4} \mathrm{mim}\right][\mathrm{Br}]$ originate from similar kind of ring deformation vibrations, but they have different magnitudes of the coupling with the $\mathrm{CH}_{2}$ rocking motion of the $\mathrm{C} 8$ carbon (encircled in Fig. 9). It thus seems that more intensive coupling occurs between (i) the $\mathrm{CH}_{2}$ rocking motion and (ii) the ring deformation vibrations in the $G A$ form $\left(596 \mathrm{~cm}^{-1}\right)$ than in the $A A$ form $\left(626 \mathrm{~cm}^{-1}\right)$, resulting in an overall lower frequency of the mode and a lower wavenumber position of the Raman band [108].

By comparing their normal coordinate analysis results and their liquid experimental Raman spectra in Fig. 7, Hamaguchi et al. [108, 116, 118, 122, 128] concluded that the two rotational isomers $A A$ and $G A$ must coexist in the ionic liquid state $(A A$ and
$G A$ were called $T T$ and $G T$ by Hamaguchi et al.). According to the Raman spectra of all the liquids in Fig. 7, both of the key bands for the $A A$ conformer (625 and $730 \mathrm{~cm}^{-1}$ bands), and for the $G A$ conformer (the 603 and $701 \mathrm{~cm}^{-1}$ bands), respectively, appeared in the spectra. Therefore, the two isomers of rotational freedom around the C7-C8 and C8-C9 bonds - anti-anti and gauche-anti - must coexist in these $\left[\mathrm{C}_{4} \mathrm{mim}\right][X]$ liquids.

Furthermore, the observed relative intensity of the $625 \mathrm{~cm}^{-1}$ band to that of the $603 \mathrm{~cm}^{-1}$ band should be correlatable with the $A A / G A$ population ratio of the conformation equilibruim. The observed ratios depended slightly on the anion: for the halides, it seems to increase in the order $\left[\mathrm{BF}_{4}\right]^{-} \approx$ $\left[\mathrm{PF}_{6}\right]^{-} \approx \mathrm{Cl}^{-}<\mathrm{Br}^{-}<\mathrm{I}^{-}[108]$. 
During our work on $\left[\mathrm{C}_{4} \mathrm{mim}\right]^{+}$and $\left[\mathrm{C}_{6} \mathrm{mim}\right]^{+}$, we have repeated the experiments and calculations for the $\left[\mathrm{C}_{4} \mathrm{mim}\right]^{+}$cation and found the results of
Hamaguchi et al. to be essentially reproducible (details explained in Ref. [103]). Our calculated Raman spectra in the whole range for the $A A$ (anti-

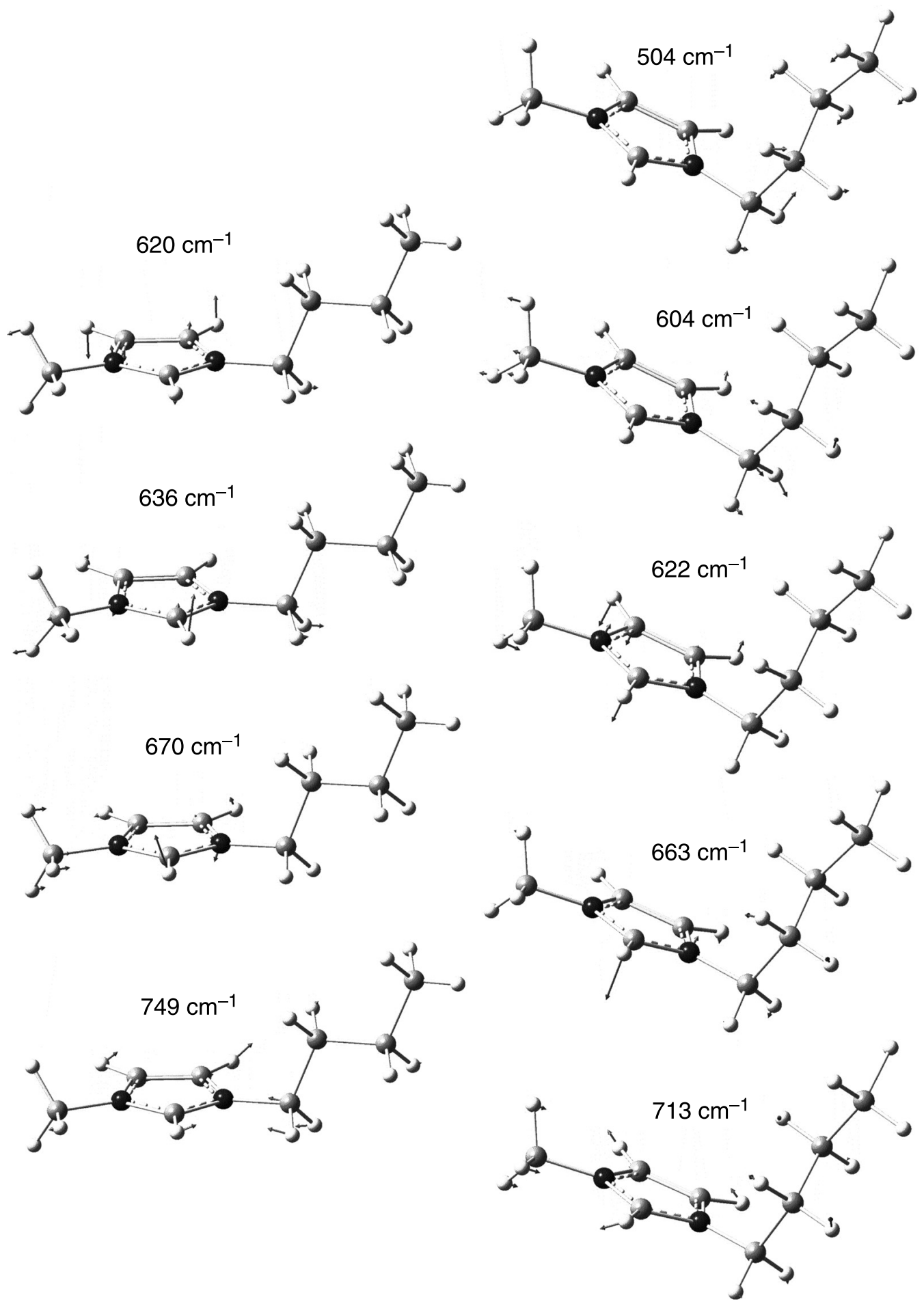

Fig. 12. Some of our calculated normal modes of certain bands of the $A A$ and $G A$ forms of the $\left[\mathrm{C}_{4} \text { mim }\right]^{+}$cation. The arrows

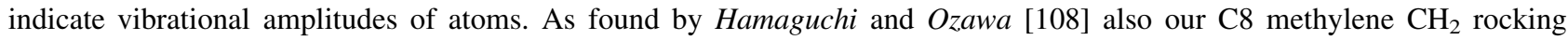
vibration was coupled to the ring modes only for the gauche-anti conformer Refs. [103] and [130] 
anti) and $G A$ (gauche-anti) conformers of $\left[\mathrm{C}_{4} \mathrm{mim}\right]^{+}$ are shown in Figs. 10 and 11. Our assignments (approximate descriptions of the modes giving origin to the Raman bands) are listed in Table 1, based on the calculated vibrational frequencies and we communicate the intensities of the infrared and Raman bands. The movements were depicted on a PC-screen and assignments were derived using the Gaussian03W software. Our recalculated modes of the $\left[\mathrm{C}_{4} \mathrm{mim}\right]^{+}$cation were obtained with somewhat higher frequencies: the modes at 626 , 735,596 and $696 \mathrm{~cm}^{-1}$ by Hamaguchi et al. in Fig. 9 became 636 and $749 \mathrm{~cm}^{-1}$ for our $A A$, and 622 and $713 \mathrm{~cm}^{-1}$ for our $G A$ modes, see Fig. 12. According to the calculated minimum energy $E_{\mathrm{e}}$ of the conformers, the $G A$ was more stable than the $A A$ conformer, but at $298.15 \mathrm{~K}$ the Gibbs energy of the $A A$ conformer was $0.168 \mathrm{~kJ} \mathrm{~mol}^{-1}$ less than that of the $G A$ conformer, indicating $52 \%$ of anti-anti vs. $48 \%$ of gauche-anti or almost equal amounts of the two conformers at equilibrium at room temperature [103]. A higher difference between the $A A$ and $G A$ energy was found in other calculations [131]. These results are consistent with the observation of both conformers being simultaneously present in the spectra of the $\left[\mathrm{C}_{4} \mathrm{mim}\right]^{+}$ liquids as observed by Ozawa et al. [128], see Fig 7.

Our obtained experimental Raman signals for the $\left[\mathrm{C}_{4} \text { mim }\right]^{+}$cation liquids are given in Fig. 13 and the assignments are specified in Table 2, based on the calculations, some of which are summarized in

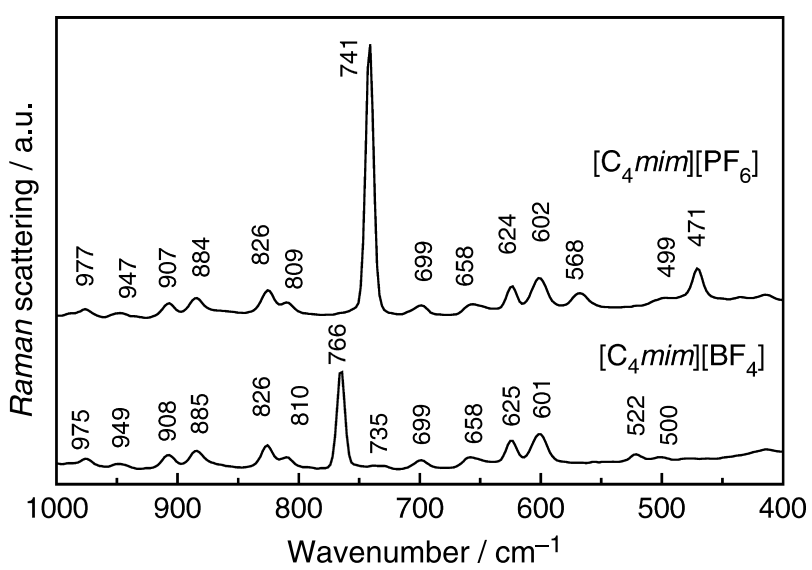

Fig. 13. Details of FT-Raman spectra of the $\left[\mathrm{C}_{4}\right.$ mim $]\left[\mathrm{PF}_{6}\right]$ and $\left[\mathrm{C}_{4}\right.$ mim $]\left[\mathrm{BF}_{4}\right]$ ionic liquids at $\sim 25^{\circ} \mathrm{C}$ [130]. Note that the characteristic bands of the $A A$ and $G A$ forms of the $\left[\mathrm{C}_{4} \text { mim }\right]^{+}$cation are present in both melts, as also found e.g., by Hamaguchi and Ozawa [108]

Table 3. Note that bands from the $\left[\mathrm{PF}_{6}\right]^{-}$and $\left[\mathrm{BF}_{4}\right]^{-}$ anions are visible, $\nu_{1}\left(\left[\mathrm{PF}_{6}\right]^{-}\right)$symmetric stretching at $741 \mathrm{~cm}^{-1}, \nu_{2}\left(\left[\mathrm{PF}_{6}\right]^{-}\right)$stretching at $568 \mathrm{~cm}^{-1}$, $\nu_{5}\left(\left[\mathrm{PF}_{6}\right]^{-}\right)$symmetric bending at $471 \mathrm{~cm}^{-1}$, $\nu_{1}\left(\left[\mathrm{BF}_{4}\right]^{-}\right)$symmetric stretching at $766 \mathrm{~cm}^{-1}$, and $\nu_{4}\left(\left[\mathrm{BF}_{4}\right]^{-}\right)$bending at $522 \mathrm{~cm}^{-1}[130]$. Similar kind of experimental and calculational results for $\left[\mathrm{C}_{n} \mathrm{mim}\right]$ $[X]$ liquids were obtained by Carper and others [132-136].

To conclude the situation for $\left[\mathrm{C}_{4} \mathrm{mim}\right]^{+}$, Hamaguchi and Ozawa [108] and Ozawa et al. [128] have discovered by the combined use of X-ray crystal-

Table 2. Experimentally observed Raman spectral bands for two common $\left[\mathrm{C}_{4} m i m\right]^{+}$ionic liquids, given in $\mathrm{cm}^{-1}$, and approximate assignments

\begin{tabular}{|c|c|c|}
\hline \multicolumn{2}{|c|}{$\bar{\nu} / \mathrm{cm}^{-1}$} & \multirow[t]{2}{*}{ Assignments* } \\
\hline$\left[\mathrm{C}_{4} \mathrm{mim}^{+}\left[\mathrm{PF}_{6}\right]^{-}\right.$ & {$\left[\mathrm{C}_{4} \mathrm{mim}^{+}\left[\mathrm{BF}_{4}\right]^{-}\right.$} & \\
\hline 498 & 500 & $\mathrm{~N}-\mathrm{C} 7$ opl bend $+\mathrm{N}-\mathrm{C} 7-\mathrm{C} 8-\mathrm{C} 9$ angles bend $(G A 12)$ \\
\hline 568 & & $\nu_{2}\left(\mathrm{PF}_{6}^{-}\right)$stretching \\
\hline 601 & 601 & $\mathrm{~N}-\mathrm{C} 6 \mathrm{~N}-\mathrm{C} 7 \mathrm{iph}$ str + ring oopl def $+\mathrm{C} 8 \mathrm{H}_{2}$ rock $+\mathrm{N}-\mathrm{C} 7-\mathrm{C} 8$ bend $(G A 13)$ \\
\hline 624 & 625 & $\begin{array}{l}\text { ring def }(\mathrm{C} 2-\mathrm{H} \text { oopl bend })+\mathrm{N}-\mathrm{C} 6 \mathrm{~N}-\mathrm{C} 7 \text { iph str }+\mathrm{C}^{-} \mathrm{H}_{2} \text { rock }+ \\
\mathrm{C} 7-\mathrm{C} 8-\mathrm{C} 9 \text { bend }(A A 14)\end{array}$ \\
\hline 656 & 658 & $\begin{array}{l}\mathrm{N}-\mathrm{C} 6 \mathrm{str}+\text { ring def }(\mathrm{N} 1 \text { and } \mathrm{H} \text { on } \mathrm{C} 2 \text { oopl ooph departure })+\mathrm{C}^{2} \mathrm{H}_{2} \text { wag }+ \\
\mathrm{N}-\mathrm{C} 7-\mathrm{C} 8 \text { bend }(A A 15)+\text { ring def (bend around line } \mathrm{NN})+\mathrm{C} 8 \mathrm{H}_{2} \text { rock }+ \\
\mathrm{N}-\mathrm{C} 7-\mathrm{C} 8 \text { bend }(G A 15)\end{array}$ \\
\hline 698 & 699 & $\mathrm{~N}-\mathrm{C} 6 \mathrm{~N}-\mathrm{C} 7$ ooph str + ring ipl def $+\mathrm{C} 8 \mathrm{H}_{2}$ rock $+\mathrm{C} 7-\mathrm{C} 8$ tor $(G A 16)$ \\
\hline $\begin{array}{l}\text { 730? hidden } \\
741\end{array}$ & $\sim 735$ & $\begin{array}{l}\mathrm{N}-\mathrm{C} 6 \mathrm{~N}-\mathrm{C} 7 \text { ooph str }+ \text { ring ipl def }+\mathrm{N}-\mathrm{C} 7-\mathrm{C} 8 \text { and } \mathrm{C} 7-\mathrm{C} 8-\mathrm{C} 9 \text { bend }(A A 17) \\
\nu_{1}\left(\mathrm{PF}_{6}^{-}\right) \text {stretching }\end{array}$ \\
\hline
\end{tabular}

* Key for descriptions of approximate group vibrations, see Table 1; $A A$ and $G A$ mode numbers given in parentheses 
Table 3. Selected vibrational modes as determined in $M P 2$ calculations for the $\left[\mathrm{C}_{4} m i m\right]^{+}$cation in $A A$ and $G A$ conformation. Given are the predicted wavenumber, relative IR and Raman intensities as well as descriptions of the selected modes [103]

\begin{tabular}{|c|c|c|c|c|}
\hline Mode & $\bar{\nu} / \mathrm{cm}^{-1}$ & $\begin{array}{l}\text { IR intensity/ } \\
\mathrm{km} \mathrm{mol}^{-1}\end{array}$ & $\begin{array}{l}\text { Raman activity/ } \\
\AA^{4} \mathrm{amu}^{-1}\end{array}$ & Approximate description* \\
\hline \multicolumn{5}{|c|}{$\left[\mathrm{C}_{4} \mathrm{mim}\right]^{+}$cation in $A A$ conformation } \\
\hline 13 & 620 & 0.52 & 1.34 & ring oopl def $+\mathrm{C} \mathrm{H}_{2}$ rock $+\mathrm{C} 7-\mathrm{C} 8-\mathrm{C} 9$ bend \\
\hline 14 & 636 & 9.40 & 2.59 & $\begin{array}{l}\text { ring def }(\mathrm{C} 2-\mathrm{H} \text { oopl bend })+\mathrm{N}-\mathrm{C} 6 \mathrm{~N}-\mathrm{C} 7 \text { iph str }+\mathrm{C}^{-} \mathrm{H}_{2} \\
\text { rock }+\mathrm{C} 7-\mathrm{C} 8-\mathrm{C} 9 \text { bend }\end{array}$ \\
\hline 15 & 670 & 12.23 & 1.36 & $\begin{array}{l}\mathrm{N}-\mathrm{C} 6 \mathrm{str}+\operatorname{ring} \text { def }(\mathrm{N} 1 \text { and } \mathrm{H} \text { on } \mathrm{C} 2 \text { oopl ooph departure })+\mathrm{C}^{2} \mathrm{H}_{2} \\
\text { wag }+\mathrm{N}-\mathrm{C} 7-\mathrm{C} 8 \text { bend }\end{array}$ \\
\hline 17 & 749 & 13.06 & 2.13 & $\mathrm{~N}-\mathrm{C} 6 \mathrm{~N}-\mathrm{C} 7$ ooph str + ring ipl def $+\mathrm{N}-\mathrm{C} 7-\mathrm{C} 8$ and $\mathrm{C} 7-\mathrm{C} 8-\mathrm{C} 9$ bend \\
\hline \multicolumn{5}{|c|}{$\left[\mathrm{C}_{4} m i m\right]^{+}$cation in $G A$ conformation } \\
\hline 12 & 504 & 0.65 & 1.1920 & $\mathrm{~N}-\mathrm{C} 7$ opl bend $+\mathrm{N}-\mathrm{C} 7-\mathrm{C} 8-\mathrm{C} 9$ angles bend \\
\hline 13 & 604 & 1.46 & 5.9919 & ring ipl def $+\mathrm{C} 8 \mathrm{H}_{2}$ rock $+\mathrm{N}-\mathrm{C} 7-\mathrm{C} 8$ bend \\
\hline 14 & 623 & 2.82 & 0.3563 & $\begin{array}{l}\text { ring def }(\mathrm{C} 2-\mathrm{H} \mathrm{C} 4-\mathrm{H} \text { iph oopl bend })+\mathrm{C}^{2} \mathrm{H}_{2} \text { rock }+ \\
\mathrm{N}-\mathrm{C} 7-\mathrm{C} 8 \text { bend }\end{array}$ \\
\hline 15 & 663 & 15.62 & 0.5566 & ring def (bend around line $\mathrm{NN}$ ) $+\mathrm{C} 8 \mathrm{H}_{2}$ rock $+\mathrm{N}-\mathrm{C} 7-\mathrm{C} 8$ bend \\
\hline 16 & 713 & 6.65 & 2.1455 & $\mathrm{~N}-\mathrm{C} 6 \mathrm{~N}-\mathrm{C} 7$ ooph str + ring ipl def $+\mathrm{C}^{-} \mathrm{H}_{2}$ rock $+\mathrm{C} 7-\mathrm{C} 8$ tor \\
\hline
\end{tabular}

* For key of approximate group vibrations, see Table 1

lography, Raman spectroscopy, and DFT calculations that

- One can use certain Raman bands as key bands to probe the conformation around the $\mathrm{C} 7-\mathrm{C} 8$ bond of the $\left[\mathrm{C}_{4} \mathrm{mim}\right]^{+}$cation.

- The calculated bands at $\sim 626-636 \mathrm{~cm}^{-1}$ and $\sim 735-749 \mathrm{~cm}^{-1}$ are characteristic of the $A A$ conformer (anti-anti conformation around the $\mathrm{C} 7-\mathrm{C} 8$ bond), as compared to the experimental values of $\sim 624$ and $\sim 730 \mathrm{~cm}^{-1}$ (Table 2), whereas the $\sim 596-604 \mathrm{~cm}^{-1}$ and $\sim 696-713 \mathrm{~cm}^{-1}$ calculated bands are characteristic of the $G A$ conformer (gauche-anti conformation). Furthermore a characteristic frequency was calculated as $\sim 504$ (Table 1), as compared to experimental values of $\sim 500$, $\sim 602$, and $\sim 699 \mathrm{~cm}^{-1}$ (Table 2).

- Experimentally, the Raman spectral bands are occurring at easily recognizable peak positions and with intensities obtainable from ab-initio DFT calculations. Bands measured by Ozawa and Hamaguchi at 701, 625, 603, and $500 \mathrm{~cm}^{-1}$ correspond within experimental error to our $\left[\mathrm{C}_{4} \mathrm{mim}\right]-$ $\left[\mathrm{PF}_{6}\right]$ liquid bands at $698,624,601$, and $498 \mathrm{~cm}^{-1}$ (Table 2).

In a more refined gas phase ion pair model aimed at understanding the interaction in the $\left[\mathrm{C}_{4} \mathrm{mim}\right]\left[\mathrm{PF}_{6}\right]$ liquid, Meng et al. [44] in a combined spectroscopic, semi-empirical and ab-initio study, observed hydrogen bonding between the $\left[\mathrm{PF}_{6}\right]^{-}$ion and the hydro- gen atom at $\mathrm{C} 2$ in the aromatic ring of the $\left[\mathrm{C}_{4} \mathrm{mim}\right]^{+}$ cation. Virtually identical theoretical results were obtained using both $H F$ and DFT. The DFT minimized structure is shown in Fig. 14. Obviously Meng et al. [44] have reached an anti-gauche $(A G)$ conformation that probably just is local but not a global minimum. The hydrogen bonding has previously been detected by ${ }^{13} \mathrm{C}$ NMR relaxation studies on

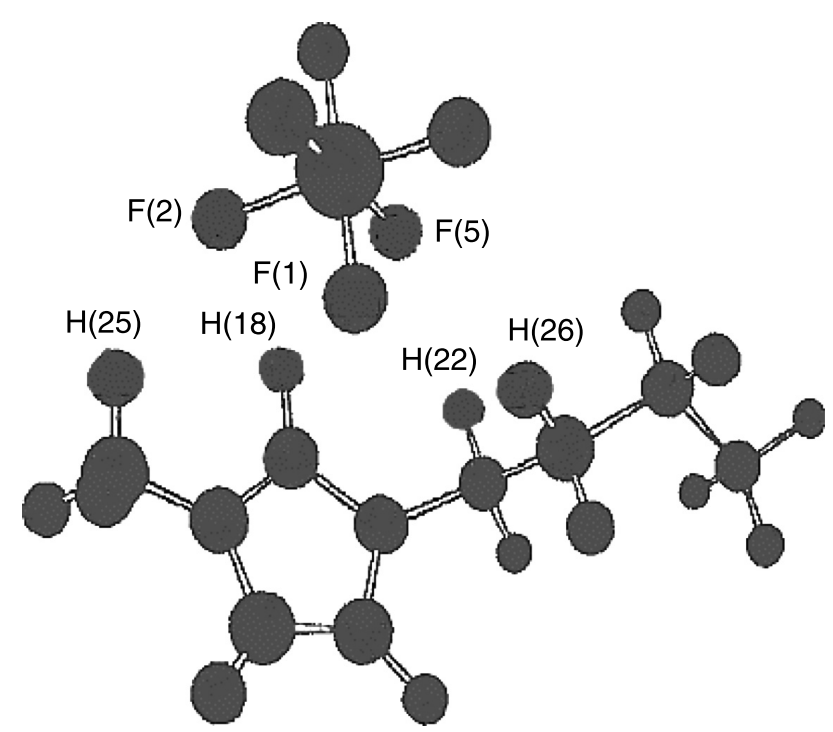

Fig. 14. Minimized molecular structure of $\left[\mathrm{C}_{4} \mathrm{mim}\right]\left[\mathrm{PF}_{6}\right]$ $\left(B 3 L Y P / 6-31 \mathrm{G}^{*}\right)$ [44]. Found hydrogen bonds included:

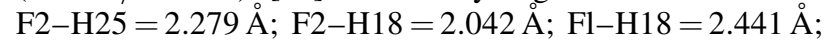
$\mathrm{F} 5-\mathrm{H} 18=2.070 \AA, \quad \mathrm{F} 5-\mathrm{H} 22=2.419 \AA$, and $\mathrm{Fl}-\mathrm{H} 26=$ $2.377 \AA$. Figure adapted from Meng et al. [44] 
$\left[\mathrm{C}_{4}\right.$ mim $]\left[\mathrm{PF}_{6}\right]$ and related systems in the liquid state [44-46, 59, 133, 134].

It is well known that hydrogen bonding significantly supports the formation of ion pairs (and even higher aggregates) in electrolyte solutions when compared to systems without specific interactions. Hanke et al. [43] in another simulation study found that the largest probability for finding an anion is near $\mathrm{C} 2$ below and above the ring. Most likely dimeric and tetrameric ion pairs and higher aggregates are formed with a type of layer structure, in which the anions are located mainly above and below the aromatic ring near C2 [44, 45]. The occurrence of hydrogen bonding in addition to the Coulombic interactions was put forward to explain the quite high viscosity and other specific macroscopic properties of the $\left[\mathrm{C}_{4} \mathrm{mim}\right]\left[\mathrm{PF}_{6}\right]$ ionic liquid.

\section{Other Studies on $\left[\mathrm{C}_{n} \text { mim }\right]^{+}$Liquids}

Ionic liquids based on 1-alkyl-3-methylimidazolium halides have also been studied, e.g., by Turner et al. [131] who performed more systematic ab-initio calculations utilizing Gaussian98 and $6-31 \mathrm{G}^{*}$ and 6$31+\mathrm{G}^{*}$ basis sets but reported no spectral data. The calculated interaction energy was found to increase in magnitude with decreasing alkyl chain length at the Hartree-Fock level, but no trend was found with increasing halide anionic radius. Linear trends between melting point and interaction energy were found to exist for the 1-butyl-3-methylimidazolium halide series as well as for the 1-alkyl-3-methylimidazolium iodide series [131].

Talaty et al. [132] measured IR and Raman spectra of a series of 1-alkyl-3-methyl-imidazolium hexafluorophosphate ionic liquids $\left(\left[\mathrm{C}_{2} \mathrm{mim}\right]\left[\mathrm{PF}_{6}\right]\right.$ to $\left[\mathrm{C}_{4}\right.$ mim $\left.]\left[\mathrm{PF}_{6}\right]\right)$ and correlated the results with their own ab-initio DFT calculations at the 6-311+ $\mathrm{G}(2 \mathrm{~d}, \mathrm{p})$ level. They suggested that common Raman $\mathrm{C}-\mathrm{H}$ stretching frequencies in these liquids may serve as possible probes in studies of ionic interactions. Hydrogen bonding interactions were observed between the fluorine atoms of the $\left[\mathrm{PF}_{6}\right]^{-}$anion and the $\mathrm{C} 2$ hydrogen on the imidazolium ring, and between $\left[\mathrm{PF}_{6}\right]^{-}$anion and the $\mathrm{H}$ atoms on the adjacent alkyl side chains. There are at least four discernible strong vibrations in the $2878-2970 \mathrm{~cm}^{-1}$ region of the $\left[\mathrm{C}_{2}\right.$ mim $]\left[\mathrm{PF}_{6}\right]$ Raman spectrum [132]. These Raman vibrations are represented by the calculated vibrations in the $3153-3220 \mathrm{~cm}^{-1}$ region and represent a complex combination of multiple stretching and bending vibrations. The weak Raman bands observed at 3116 and $3179 \mathrm{~cm}^{-1}$ were assigned to vibrations associated with the imidazolium ring $(\mathrm{H}-\mathrm{C}-\mathrm{C}-\mathrm{H}$ and $\mathrm{N}-(\mathrm{C}-$ $\mathrm{H})-\mathrm{N}) \mathrm{C}-\mathrm{H}$ stretches. Unfortunately, the observed Raman spectrum is weak in this region, making peak identification difficult [132], and is further complicated by the likely presence of "Fermi resonance".

Similarly, studies were done on $\left[\mathrm{C}_{2} \mathrm{mim}\right]\left[\mathrm{BF}_{4}\right]$ and other 1-ethyl-3-methylimidazolium liquid salts [67, 127, 137]. In the Raman spectral range 200$500 \mathrm{~cm}^{-1}$, Umebayashi et al. [137] for liquids contain-
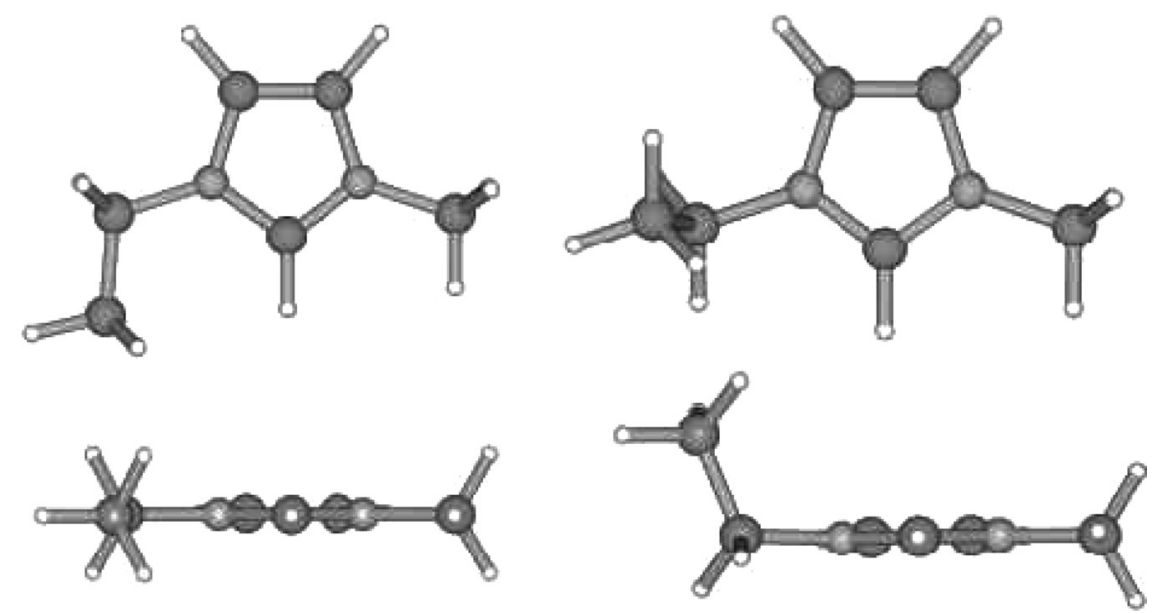

Fig. 15. Calculated structures of the $\left[\mathrm{C}_{2} \mathrm{mim}\right]^{+}$cation, showing the two different torsion conformers obtainable by rotation of the ethyl group around the $\mathrm{C}-\mathrm{N}$ bond relative to the imidazolium ring. Planar (left) and nonplanar (right) rotamers are viewed perpendicular to and along the ring plane. The nonplanar form is known from X-ray structures [127]. Figure adopted from Umebayashi et al. [137] 
ing $\left[\mathrm{BF}_{4}\right]^{-},\left[\mathrm{PF}_{6}\right]^{-},\left[\mathrm{CF}_{3} \mathrm{SO}_{3}\right]^{-}$, and $\left[\left(\mathrm{CF}_{3} \mathrm{SO}_{2}\right)_{2} \mathrm{~N}\right]^{-}$ found bands at 241, 297, 387, 430, and $448 \mathrm{~cm}^{-1}$ that must originate from the $\left[\mathrm{C}_{2} \mathrm{mim}\right]^{+}$ion. However, the $448 \mathrm{~cm}^{-1}$ band could not be reproduced by theoretical calculations in terms of a single given $\left[\mathrm{C}_{2} \mathrm{mim}\right]^{+}$conformer. The ethyl group bound to one $\mathrm{N}$ atom of the imidazolium ring is able to rotate around the $\mathrm{C}-\mathrm{N}$ bond to yield two different torsional conformers, see Fig. 15. The energy barrier of this rotation was calculated with an energy amplitude of $\sim 2 \mathrm{KJ} \mathrm{mol}^{-1}$ [137]. Two local minima were found, suggesting that the two conformers can be present in equilibrium. Full geometry optimizations followed by normal frequency analyses indicated that the two conformers of minimum energy were those with planar and nonplanar ethyl groups against the imidazolium ring plane, and that the nonplanar conformer was the most favorable. The Raman bands at 241, 297,387 , and $430 \mathrm{~cm}^{-1}$ were found to mainly originate from the nonplanar conformer, whereas the $448 \mathrm{~cm}^{-1}$ band originated from the planar conformer. Indeed, the enthalpy for conformational change from nonplanar to planar $\left[\mathrm{C}_{2} \mathrm{mim}\right]^{+}$, obtained experimentally by analyzing band intensities of the conformers at various temperatures, was practically the same as the enthalpy evaluated by the theoretical calculations. We thus conclude that the $\left[\mathrm{C}_{2} \mathrm{mim}\right]^{+}$ ion exists as planar or nonplanar conformers in equilibrium in its liquid salts [137], and this was confirmed by X-ray diffraction [127]. For the longer chain $\left[\mathrm{C}_{n} \text { mim }\right]^{+}$systems also non-planar forms are most stable, e.g., compare with the $A A$ and $G A$ conformers of $\left[\mathrm{C}_{4} \mathrm{mim}\right]^{+}$in Fig. 9.

We have shown [103] that the same situation as for $\left[\mathrm{C}_{4} \mathrm{mim}\right]^{+}$exists for longer alkyl chain systems, at least for the 1-hexyl-3-methylimidazolium cation. This hexyl cation was chosen because the $\left[\mathrm{C}_{6} \text { mim }\right]^{+}$ liquids have perhaps the lowest melting points of the 1-alkyl-3-methyl-imidazolium series of system. Our objective was to determine in a similar manner if any conformers - such as $A A$ and $G A$ for the butyl case - would also be present in the hexyl chain. Raman spectra for $\left[\mathrm{C}_{6} \mathrm{mim}\right]^{+}$cation systems have bands at 698, 623, and $601 \mathrm{~cm}^{-1}$ (but no distinct band at $\sim 498 \mathrm{~cm}^{-1}$ ). A comparison between typical experimental spectra is shown in Fig. 16. Also the calculations came out in much the same way, as can be seen by comparing the results in Fig. 17 with those from Fig. 11 (insets).

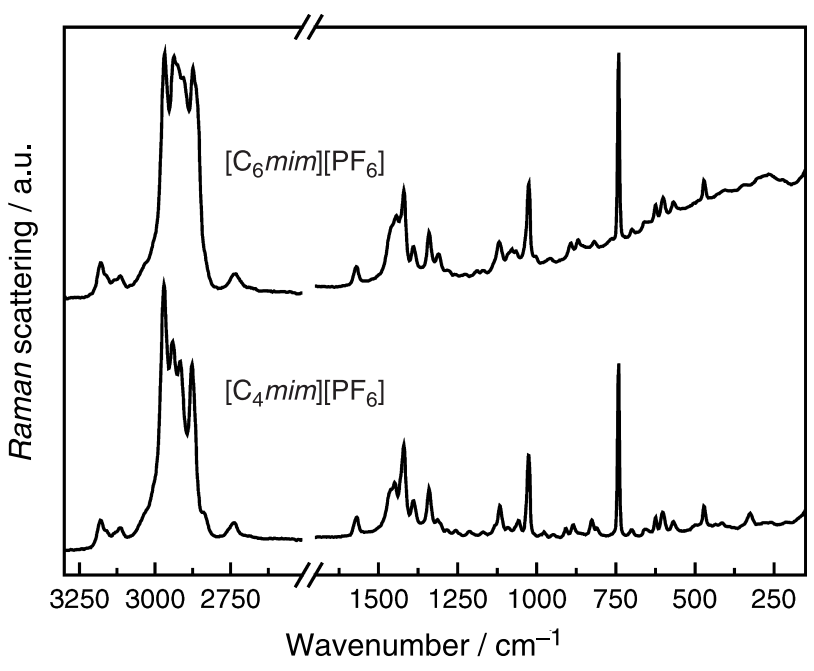

Fig. 16. FT-Raman spectra of the $\left[\mathrm{C}_{6}\right.$ mim $]\left[\mathrm{PF}_{6}\right]$ and $\left[\mathrm{C}_{4}\right.$ mim $]\left[\mathrm{PF}_{6}\right]$ ionic liquids at $\sim 25^{\circ} \mathrm{C}$. Note that the characteristic bands of the $A A$ and $G A$ forms of the $\left[\mathrm{C}_{4} \mathrm{mim}^{+}\right.$ cation are very much like the $A A A A$ and $G A A A$ bands from the $\left[\mathrm{C}_{6} \mathrm{mim}\right]^{+}$cation $[103,130]$

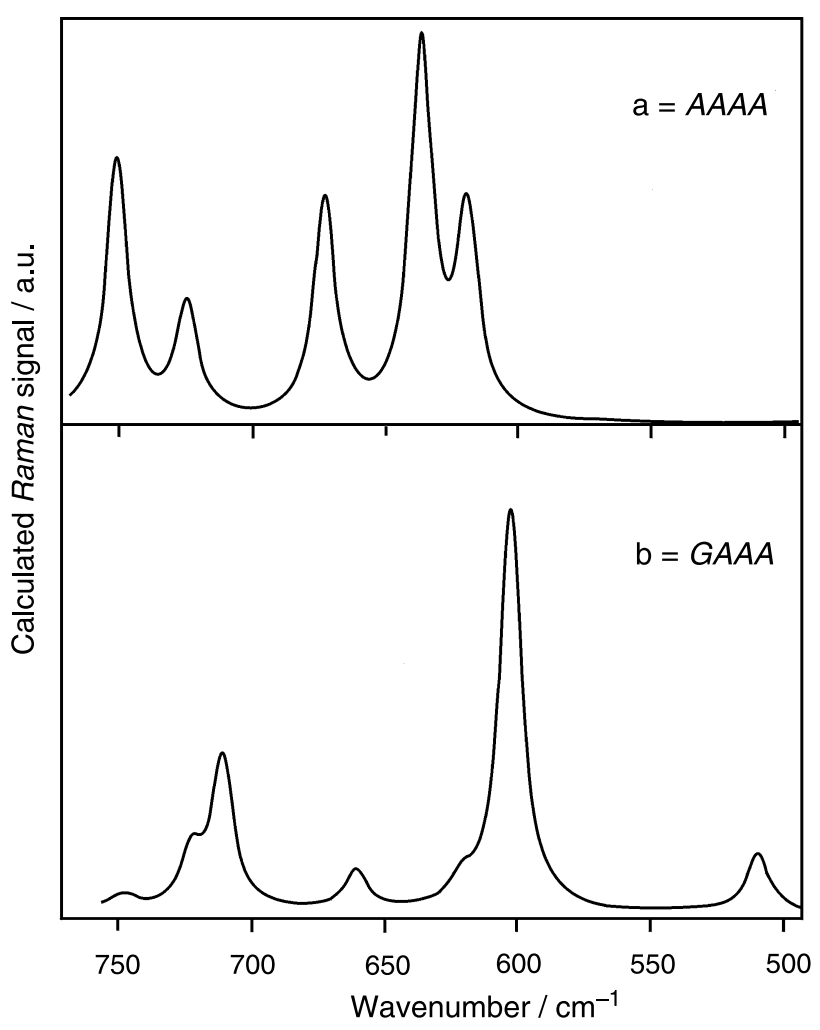

Fig. 17. Our calculated Raman spectra of two conformers of the hexyl $\left[\mathrm{C}_{6} \text { mim }\right]^{+}$cation between 750 and $500 \mathrm{~cm}^{-1}$. (a) All-anti conformer AAAA; (b) gauche-anti-anti-anti GAAA conformer [103] 
All in all, it was recognized, both from spectra and calculations that the characteristic frequencies do not change significantly when the butyl group was exchanged for a hexyl group, and we conclude that the $A A-G A$ isomerism phenomenon probably is general, and not specific to the $\left[\mathrm{C}_{4} \mathrm{mim}\right][X]$ ionic liquids. For a discussion of the hexyl systems we refer to our comprehensive report [103].

\section{Conformational Equilibria in Liquids versus Temperature}

The rotation around C7-C8 can most likely interconvert the $A A$ and $G A$ conformers. As mentioned previously in the discussion connected to Figs. 7 and 8, the $A A / G A$ ratio changes with the cation. The series of 1-alkyl-3-methylimidazolium cations, $\left[\mathrm{C}_{\mathrm{n}} \mathrm{mim}\right]^{+}$, where $\mathrm{n}$ is the number of carbon atoms in the alkyl chain, generate RTILs with the $\left[\mathrm{BF}_{4}\right]^{-}$anion [109]. Figure 18 shows the Raman spectra of $\left[\mathrm{C}_{\mathrm{n}} \mathrm{mim}\right]\left[\mathrm{BF}_{4}\right]$ from $n=10$ to 2 in the liquid state at room temperature. For $\left[\mathrm{C}_{2} \mathrm{mim}\right]\left[\mathrm{BF}_{4}\right]$ there can be no rotational isomerism around $\mathrm{C} 7-\mathrm{C} 8$ because $\mathrm{C} 8$ is the end methyl group [67]. Consequently, only one Raman band is observed at $596 \mathrm{~cm}^{-1}$, which corresponds to the band from the $G A$ conformation of $\left[\mathrm{C}_{4} \mathrm{mim}\right]\left[\mathrm{BF}_{4}\right]$. This observation was rationalized by Hamaguchi and

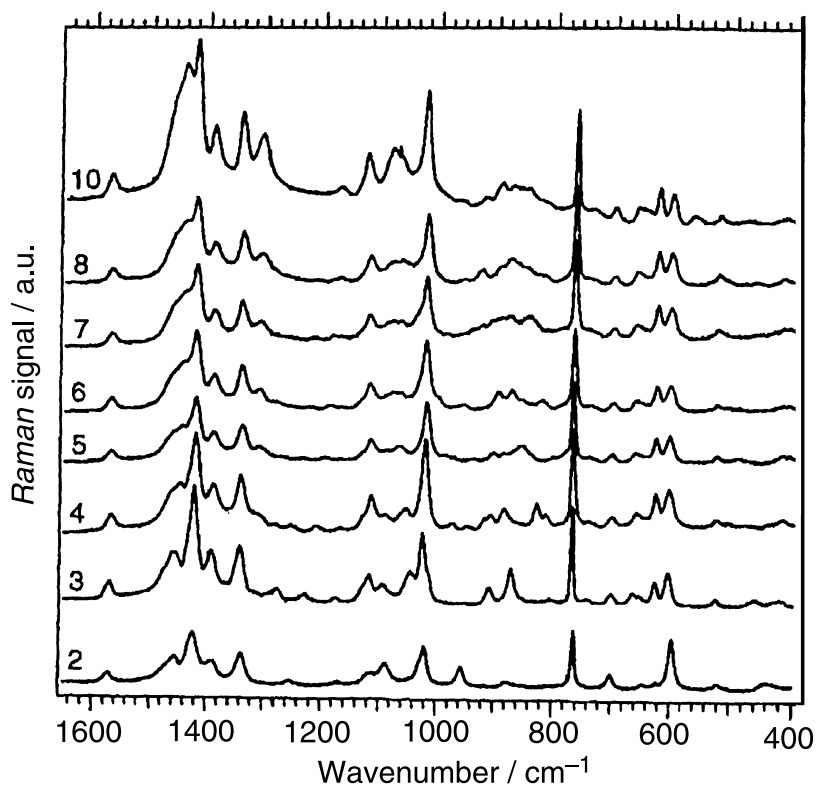

Fig. 18. Raman spectra of 1-alkyl-3-methylimidazolium tetrafluoroborate liquids, $\left[\mathrm{C}_{n}\right.$ mim $]\left[\mathrm{BF}_{4}\right]$ for $n=10,8,7,6,5,4$, 3 , 2. The figure has been adapted from Hamaguchi and Ozawa [108]
Ozawa [108] who noted that the methyl rocking motion of the $\mathrm{C} 8$ carbon is strongly coupled to the ring deformation vibration and pushes down the frequency in $\left[\mathrm{C}_{2} \text { mim }\right]^{+}$exactly as in the case of the $G A$ conformation of the $\left[\mathrm{C}_{4} \text { mim }\right]^{+}$cation.

For a side-chain carbon number larger than two $(n>2)$, the $625 / 603 \mathrm{~cm}^{-1}$ Raman intensity ratio increases with increasing $n$. The $A A$ kind of band at $625 \mathrm{~cm}^{-1}$ (all-anti) is weaker in intensity than the gauche band (at $603 \mathrm{~cm}^{-1}$ for $n=3$ ), but the intensity ratio is reversed for $n=10$. Since the vibrational modes giving rise to those bands are very similar to each other - being localized within the imidazolium ring and around the C7 and C8 carbons (see Fig. 12) - their Raman cross sections are thought to be quite independent of the chain length [103]. Therefore, the $625 / 603 \mathrm{~cm}^{-1}$ Raman intensity ratio can be regarded as a direct measure of the $A A A \ldots / G A A \ldots$ isomer ratio. The observed increase of the $625 / 603 \mathrm{~cm}^{-1}$ Raman intensity ratio with $\mathrm{n}$ then means that the $A A A \ldots / G A A \ldots$ isomer ratio increases as the chain becomes longer. In other words, the Raman spectra show that the $A A A \ldots$ structure is stabilized relatively to the $G A A \ldots$. conformation for longer alkyl chains. Such stabilization of the all-A conformation is understandable only if we assume interactions among the cations. Otherwise, the relative stability would be determined alone by the energy difference between the anti and gauche conformations around the C7-C8 bond and would be likely to be independent of the chain length. From the crystal structure of the $\left[\mathrm{C}_{4}\right.$ mim $][\mathrm{Cl}]$ "Crystal (1)" it is known that two $\left[\mathrm{C}_{4} \mathrm{mim}\right]^{+}$cations make a pair through an aliphatic interaction between the two alkyl groups. The chain-length dependence of the $A A / G A$ ratio therefore most probably is due to an aliphatic interaction between the two butyl chains of the $\left[\mathrm{C}_{4} \text { mim }\right]^{+}$cations. In Fig. 18, broad Raman features are observed for longer-chain $\left[\mathrm{C}_{n} \operatorname{mim}\right]\left[\mathrm{BF}_{4}\right]$ liquids $(n=7-10)$ in the wavenumber region of $800-950 \mathrm{~cm}^{-1}$, where hydrogen rocking and bending vibrations of the methylene groups are located. These broad features are indicative of aliphatic interactions between the alkyl chains [108], similar to the interactions found for certain $\left[\mathrm{C}_{n} \operatorname{mim}\right][\mathrm{Cl}]$ and $\left[\mathrm{C}_{n}\right.$ mim $]\left[\mathrm{PF}_{6}\right]$ salts and meso-phase liquid crystals when $n>12$, see $[52,114,138]$. This interaction through the alkyl chains is likely to operate also in the $\left[\mathrm{C}_{4} \operatorname{mim}\right][X]$ RTILs. 
Wide-angle X-ray scattering results on the $\left[\mathrm{C}_{4}\right.$ mim $][\mathrm{I}]$ room temperature ionic liquids show prominent peaks in the residual radial distribution curve [118], indicating certain periodical arrangements of the iodide anions. The existence of different rotamers and local structures has also been found by interpretation of results from optical heterodynedetected Raman-induced Kerr-effect spectroscopy (OHD-RIKES) [139], from neutron scattering and diffraction experiments versus temperature [111113, 140], from Coherent anti-Stokes Raman Scattering (CARS) [141] and by theoretical molecular dynamics calculations [43, 47, 142-144]. The local structures may also lead to other unique properties of ionic liquids; for example, if magnetic anions are aligned in RTILs, novel magnetic liquids will be created $[145,146]$.

An unusually long equilibration time has been observed upon melting of a small piece of single crystal of the $A A$ polymorph of $\left[\mathrm{C}_{4}\right.$ mim $][\mathrm{Cl}]$ "Crystal (1)" [108]. The crystal was heated rapidly from room temperature to form a droplet of liquid in a non-equilibrium state. The sample was kept at $72^{\circ} \mathrm{C}$ to let it equilibrate thermally while Raman spectra were recorded. The time-resolved Raman spectra are reproduced in Fig. 19. As seen, in the beginning (before melting) only the band at $625 \mathrm{~cm}^{-1}$ of the $A A\left[\mathrm{C}_{4} \mathrm{mim}\right]^{+}$cation was observed in the 600 to $630 \mathrm{~cm}^{-1}$ region. After melting, the $625 \mathrm{~cm}^{-1}$ band remained strong for some time and the band at $603 \mathrm{~cm}^{-1}$ due to the $G A$ conformer became stronger. After about $10 \mathrm{~min}$ the $A A / G A$ intensity ratio be-

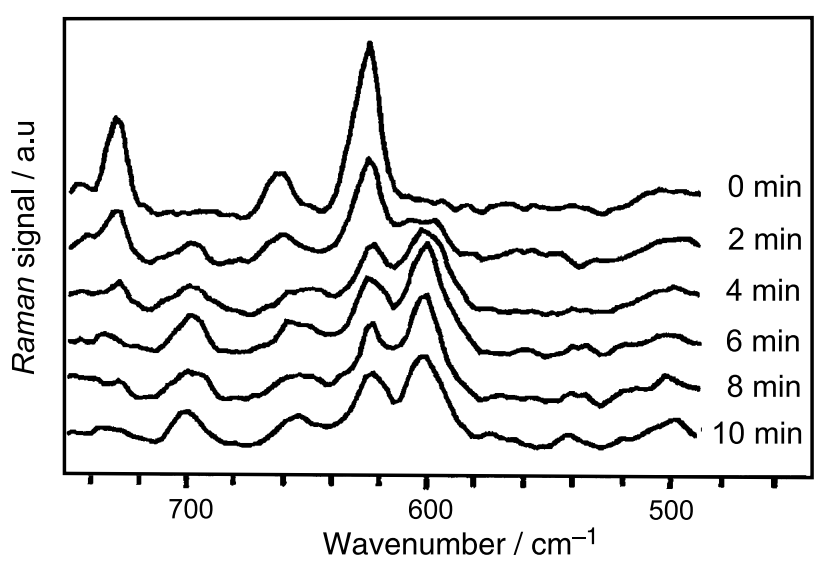

Fig. 19. Time-resolved Raman spectra of the melting and thermal equilibration process at $72^{\circ} \mathrm{C}$ for a $\left[\mathrm{C}_{4}\right.$ mim $][\mathrm{Cl}]$ "Crystal (1)" sample. The figure has been adapted from Hamaguchi and Ozawa [108] and Hamaguchi et al. [147] came constant. Hamaguchi and Ozawa [108] have reasonably interpreted this to mean that the rotational isomers do not interconvert momentarily at the molecular level, and that the conversion most probably takes place through a conversion of a larger local structure as a whole.

The enthalpy difference between the $A A$ and $G A$ conformers in the 1-butyl-3-methylimidazolium tetrafluoroborate RTILs is much smaller than the corresponding enthalpy difference between the conformers of a free butane chain. This indicates that the 1-butyl-3-methylimidazolium cations most likely form local liquid structures specific to each rotational isomers [108]. Coexistence of these local structures - incorporating different rotational isomers - seems to hinder the crystallization. This is probably the reason for the low melting points of such RTILs. These local structures most probably distinguish RTILs from conventional molecular liquids and may explain why RTILs phases are between a liquid and a crystal.

\section{Local Structures in Ionic Liquids}

From NMR spectroscopy it is known that conformational isomers of alkane chains give coalesced peaks indicating transformation between the conformers taking place much faster than a second. Accordingly, one should expect single $\left[\mathrm{C}_{4} \mathrm{mim}\right]^{+}$cations undergoing $A A$ to $G A$ transformation almost instantaneously [147]. The observed $\sim 10 \mathrm{~min}$. long equilibration time in liquid $\left[\mathrm{C}_{4}\right.$ mim $][\mathrm{Cl}]$ (Fig. 19) therefore has been taken to indicate that the conformers do not transform at the single molecular level but only interconvert through slow collective transformations of ensembles of $\left[\mathrm{C}_{4} \mathrm{mim}\right]^{+}$cations (analogous to a phase transition) $[108,147]$. Most probably the two rotational isomers are incorporated in specific local structures tending to interconvert only through conversion of the local structures as a whole and giving rize to wide pre-melting ranges and other features [123].

The ordering of the anions in ionic liquids has for the case of $\left[\mathrm{C}_{4}\right.$ mim $][\mathrm{I}]$ - been confirmed by large-angle X-ray scattering experiments [118], that gave peaks in the differential radial distribution function at $4.5,5.5,8.5$, and $9.2 \AA$. The shortest distance, $4.5 \AA$, corresponds very well to the shortest halogen-halogen distance of the crystal structures of $\left[\mathrm{C}_{4}\right.$ mim $][\mathrm{Cl}]$ "Crystal (1)" (4.84 $\left.\mathrm{A}\right)$ and $\left[\mathrm{C}_{4}\right.$ mim $]$ - 

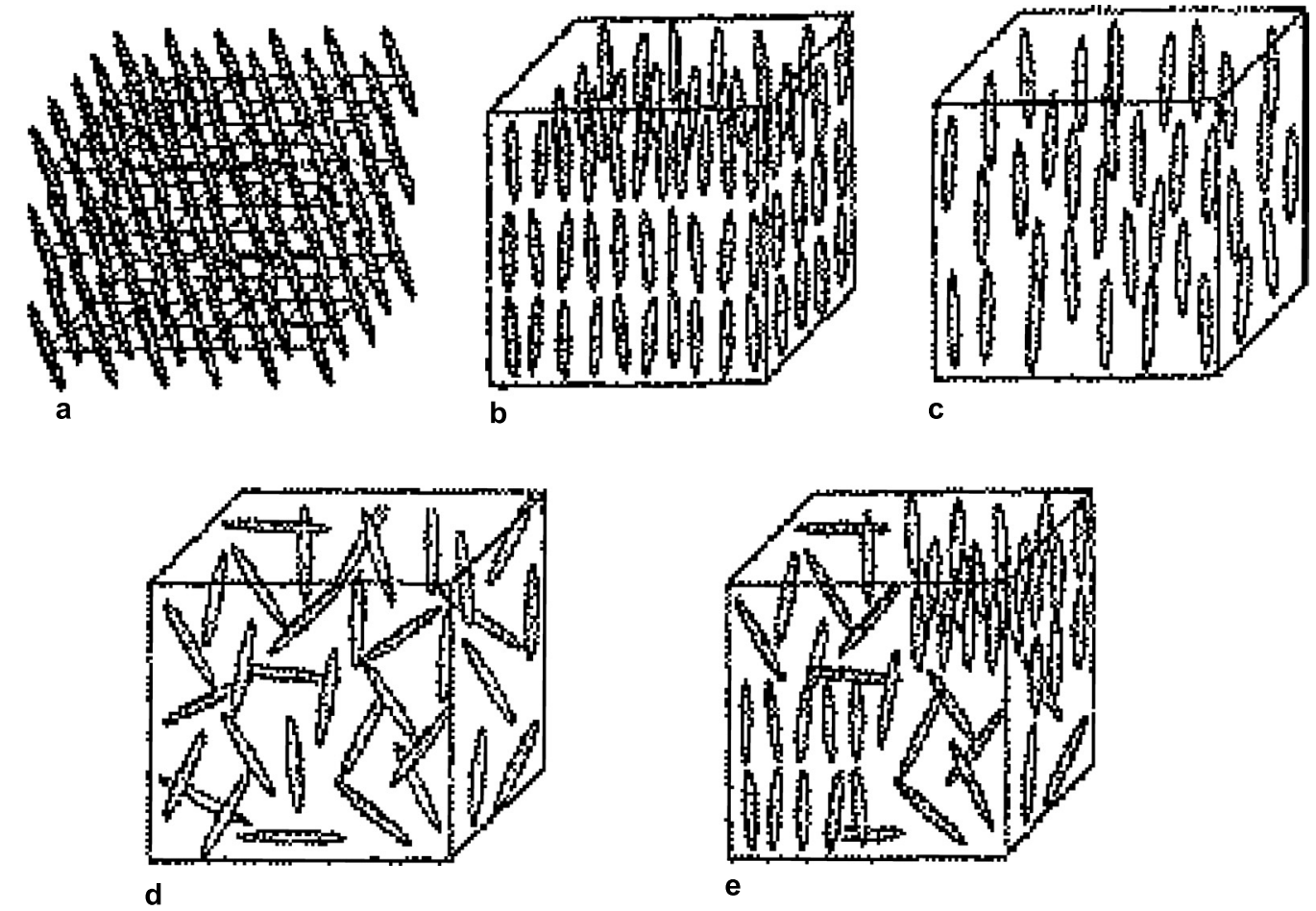

Fig. 20. Conceptual structure of ionic salt crystals and liquids: (a) crystal, (b, c) liquid crystals, (d) liquid, and (e) ionic liquid, according to the model of Hamaguchi and Ozawa [108]. Figure adapted from Hamaguchi and Ozawa [108]

[Br] (4.65 $\AA$ ). The other distances were correlated to the other halogen-halogen distances in the zig-zag chains shown in Figs. 4 and 5.

In this way it seems that the zig-zag chains found in the $\left[\mathrm{C}_{4}\right.$ mim $][X]$ crystals do exist in the ionic liquid state as well, at least partially. Thus, by combining Raman spectroscopy with several other experimental and theoretical techniques, Hamaguchi et al. have come to mean that both the cations and anions in $\left[\mathrm{C}_{4}\right.$ mim $][X]$ RTILs might have local ordering of their structures. Their conceptual structure of ionic liquids is reproduced in Fig. 20.

According to the model, the supposed local structures are positioned and oriented randomly, and there seems to be no translational and orientational order at the macroscopic level. The local structure modeling of Ozawa and Hamaguchi for the $\left[\mathrm{C}_{4} \mathrm{mim}\right][X]$ RTILs is shown in Fig. 20e in comparison with the structures of a crystal (a), liquid crystals (b and c), and a conventional liquid (d). In the crystal (a), component molecules or ions are arranged to form a periodic lattice with long-range order. In a standard liquid state (d), the molecules or ions take random positions and random orientations and there is no order. In liquid crystals (b and c), different kinds of long-range order exist, with e.g., only partial orientational order (b) or random position (c).

In $\left[\mathrm{C}_{4}\right.$ mim $][X]$ RTILs, the supposed "local structures" are positioned and oriented randomly, and there seems to be no translational and orientational order at the macroscopic level. Taking into account that the $\left[\mathrm{C}_{4}\right.$ mim $][X]$ RTILs are all transparent (not opaque), the dimension of those "local structures" must be much smaller than the wavelength of visible light $(<100 \AA)$ [108, 147].

Microphase segregation in imidazolium-based ionic liquids has also been discussed, and the existence of polar and nonpolar microsegregated domains in ionic liquids has been predicted in molecular simulation dynamics [148]. The structural analysis helps the understanding of solvation of nonpolar, polar, and associating solutes in these media $[140,148]$. The existence of an extended hydrogen-bonded network structure was suggested by Abdul-Sada et al. [65] for 1-alkyl-3-methylimidazolium halides based on results from fast-atom bombardment mass spectroscopy. Charge ordering in RTILs was discussed by Hardacre et al. [111, 112]. They obtained the radial distribution curves of dimethylimidazolium chloride and hexafluoro- 
phosphate liquids using neutron diffraction and argued for charge ordering of ions in RTILs resembling what is found in the solid state. Charge ordering has also been discussed in a number of molecular dynamics computer simulation studies on 1-alkyl-3-methylimidazolium-based RTILs in recent few years [47, 142-144, 149-159]. The radial distribution functions calculated in these papers all have suggested long-range charge ordering, giving support to the idea that RTILs are unique in having more structure ordering than do conventional molecular liquids.

Many unique properties may be expected to arise from these local structures in RTILs. One example is the unusually high viscosity of certain RTILs arising from the hindering of the translational motion of the ions. Magnetic behavior is another most unusual and interesting property that arise when magnetic ions (strongly interacting with one another) are locally aligned in a liquid. Recently it was demonstrated $[145,146]$ that magnetic RTILs can be made by mixing imidazolium chlorides $\left(\left[\mathrm{C}_{4} \mathrm{mim}\right][\mathrm{Cl}]\right.$ or $\left[n \mathrm{C}_{4}\right.$ mim $][\mathrm{Cl}]$ ) and $\mathrm{FeCl}_{3}$, forming 1-butyl-3-methylimidazolium tetrachloroferrate $\left[\mathrm{C}_{4} \mathrm{mim}\right]\left[\mathrm{FeCl}_{4}\right]$ and 1-butyronitrile-3-methylimidazolium tetrachloroferrate $\left[n \mathrm{C}_{4}\right.$ mim $]\left[\mathrm{FeCl}_{4}\right]$ (IUPAC name of $\left[n \mathrm{C}_{4} \mathrm{mim}\right]^{+}$ cation: 1-(3-cyanopropyl)-3-methyl-1H-imidazol-3ium). These nearly paramagnetic liquids show strong responses to magnetic fields, probably because of local ordering of the magnetic high-spin $\left[\mathrm{FeCl}_{4}\right]^{-}$ anions. The surfaces of the liquids bend (deviate from being horizontal) when they are approached by a magnet, an interesting property that might find applications. FT-Raman spectroscopy indicated that the magnetic liquids contained $\left[\mathrm{C}_{4} \mathrm{mim}\right]^{+}$and $\left[n \mathrm{C}_{4} \text { mim }\right]^{+}$cations. The constitution of the liquids thus were confirmed by their Raman spectra. By combining many different cations and magnetic anions it might be possible to prepare superparamagnetic or even ferromagnetic ionic liquids [145, 146].

Another interesting behavior of an ionic liquid has been observed: the molecular arrangements of 1-butyronitrile-3-methylimidazolium halides, in the presence and absence of intruded water molecules, form a new kind of ice that has been studied by Raman spectroscopy [160, 161]. Single crystals of the ice were isolated and the structure elucidated by single-crystal X-ray crystallography. Apparently the water changes the physical properties of the ionic liquid at the molecular level and this was found to change the conformation of the $n$-butyronitrile chain of the cation. The hydrogen bonding interaction between the anion and the water molecule seems to lead to loose molecular packing arrangements of the RTIL. As the unique properties are related to the structures and molecular arrangements of the RTILs, the presence of water, wanted or unwanted, must be carefully examined in any kind of IL research and applications [161].

\section{Other Systems}

The molecular reorientational dynamics in the ionic liquid 1-ethyl-3-methylimidazolium butanesulfonate $\left[\mathrm{C}_{2}\right.$ mim $]\left[\mathrm{C}_{4} \mathrm{H}_{9} \mathrm{SO}_{3}\right]$ have been studied by DFT gasphase calculations with $B 3 L Y P /(6-311+\mathrm{G}(2 \mathrm{~d}, \mathrm{p}))$ basis sets and ${ }^{13} \mathrm{C}$ NMR relaxation rates [162]. The ${ }^{13} \mathrm{C}$ pseudo-rotational correlation times were used to calculate corrected maximum nuclear Overhauser effect (NOE) factors. Rotational correlation times are compared with viscosity data and indicate several $\left[\mathrm{C}_{2}\right.$ mim $]\left[\mathrm{C}_{4} \mathrm{H}_{9} \mathrm{SO}_{3}\right]$ phase changes over the temperature range from 5 to $55^{\circ} \mathrm{C}$.

Raman spectra of 1-butylpyridinium chloride aluminum trichloride liquid systems (e.g. [bupy]$\left[\mathrm{AlCl}_{4}\right]$, Fig. 1) were obtained at ambient temperatures already in 1978 in a pioneering work [14]. The [bupy] $\left[\mathrm{FeCl}_{4}\right]$ also is a RTIL, and in the phase diagram of the binary system $[$ bupy $][\mathrm{Cl}]-\mathrm{FeCl}_{3}$ liquids are formed in a wide mol fraction composition range from 0.26 to 0.58 [16]. Unrestricted $H F$ calculations were performed with $6-31 \mathrm{G}^{*}$ basis sets in order to predict the structures, energies, bond lengths, and vibrational (Raman) frequencies. Both the Raman scattering experiments and the ab-initio calculations indicate that $\left[\mathrm{FeCl}_{4}\right]^{-}$is the predominant anion in the ionic liquid at a mole fraction of $0.50[16]$.

High level ab-initio quantum chemical computer simulations have been made to develop a molecular force field suitable for ionic liquids containing cations of the imidazolium, pyrrolidinium, and tri- and tetra-alkylammonium, and the trifluoromethylsufate and bis(trifluoromethylsulfonyl)imide anions (also known as triflate and bistriflylimide) [149, 150]. One of the torsions in the bistriflylimide anion, corresponding to the dihedral angle $\mathrm{S}-\mathrm{N}-\mathrm{S}-\mathrm{C}$, has a complex energy profile which was precisely reproduced. The calculations were tested by confrontation against liquid-phase Raman spectroscopic data 
[151]. The force field was specifically developed to describe the conformational aspects of dialkylimidazolium cations.

In addition to these studies, the structure of the bis(trifluoromethylsulfonyl)imide $\left(\left[T f_{2} \mathrm{~N}\right]^{-}\right)$anion in the liquid state has been investigated by means of IR and Raman spectroscopy and ab-initio self-consistent Hartree-Fock and DFT calculations on the free ion, aiming at a determination of the equilibrium geometry and understanding of the vibrational spectrum [137, 163-165]. A pronounced delocalization of the negative charge on the nitrogen and oxygen atoms was found, and a marked double-bond character of the $\mathrm{S}-\mathrm{N}-\mathrm{S}$ moiety for the anion [163, 164]. A tentative assignment of some characteristic vibrations of the $\left[T f_{2} \mathrm{~N}\right]^{-}$anion was performed using the spectra of aqueous solutions for comparison in order to analyze the conformational isomerism and ion-pairing effects [163, 164].

The Raman spectra of the 1-ethyl-3-methylimidazolium liquid $\left[\mathrm{C}_{2}\right.$ mim $]\left[T f_{2} \mathrm{~N}\right]$ show relatively strong bands arising from the $\left[T f_{2} \mathrm{~N}\right]^{-}$ion at $\sim 398$ and $\sim 407 \mathrm{~cm}^{-1}$, see Fig. 21 [165]. Interestingly, the $\sim 407 \mathrm{~cm}^{-1}$ band, relative to the $\sim 398 \mathrm{~cm}^{-1}$ one, is appreciably intensified with raising temperature. This feature is suggesting that an equilibrium is established between $\left[\mathrm{Tf}_{2} \mathrm{~N}\right]^{-}$conformers in the liquid state, see Fig. 22. According to the DFT calculations (followed by normal frequency analyses), two conformers of $C_{2}$ and $C_{1}$ point group symmetry (a two-fold rotational axis and no symmetry), respectively, constitute global and local minima, and have an energy difference of $2.2-3.3 \mathrm{~kJ} \mathrm{~mol}^{-1}$ [165]. The wagging omega- $\mathrm{SO}_{2}$ vibration appeared at 396 and $430 \mathrm{~cm}^{-1}$ for the $C_{1}$ conformer and at 387 and

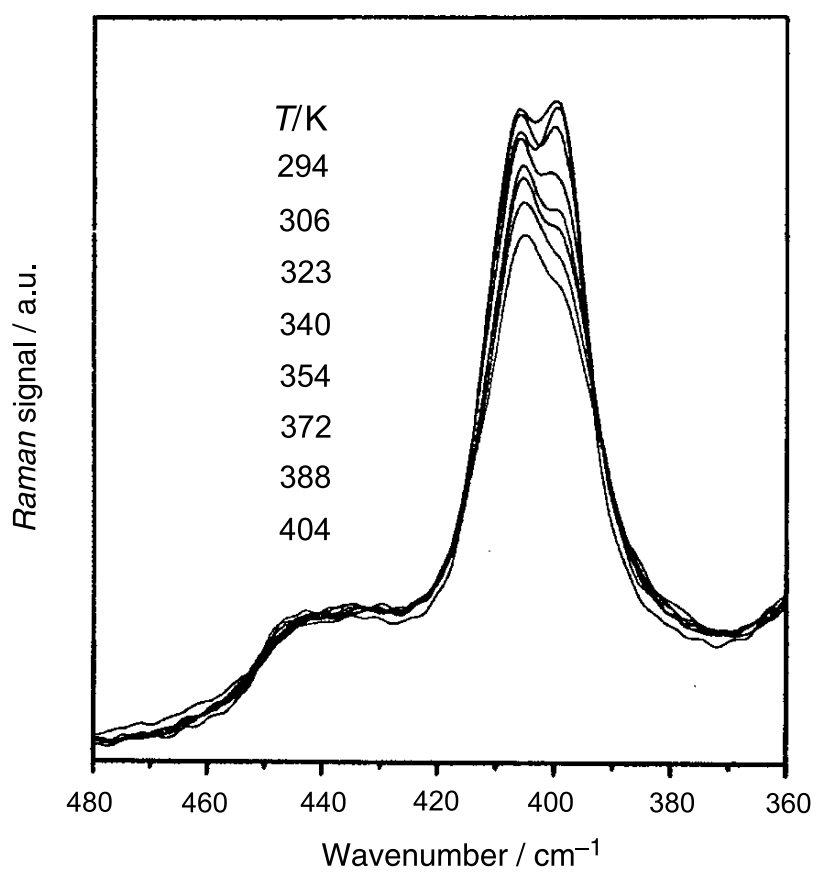

Fig. 21. Raman spectra of the 1-ethyl-3-methylimidazolium liquid $\left[\mathrm{C}_{2}\right.$ mim $]\left[T f_{2} \mathrm{~N}\right]$ showing the temperature dependent $\mathrm{SO}_{2}$ wagging bands at $\sim 398$ and $\sim 407 \mathrm{~cm}^{-1}$. According to Fujii et al. [165] the bands arise from different conformers of the $\left[T f_{2} \mathrm{~N}\right]^{-}$ion, known also from crystal structures [166]. Figure adapted from Fujii et al. [165]

$402 \mathrm{~cm}^{-1}$ for the $C_{2}$ one. Observed Raman spectra over the range $380-440 \mathrm{~cm}^{-1}$ were deconvoluted to extract the intrinsic bands of $\left[T f_{2} \mathrm{~N}\right]^{-}$conformers. The enthalpy of the conformational change from $C_{2}$ to $C_{1}$ was evaluated. This enthalpy value came out in good agreement with that obtained by theoretical calculations. It was concluded that a conformational equilibrium indeed must exist between the $C_{I}$ and $C_{2}$ conformers of the $\left[T f_{2} \mathrm{~N}\right]^{-}$ion in the liquid
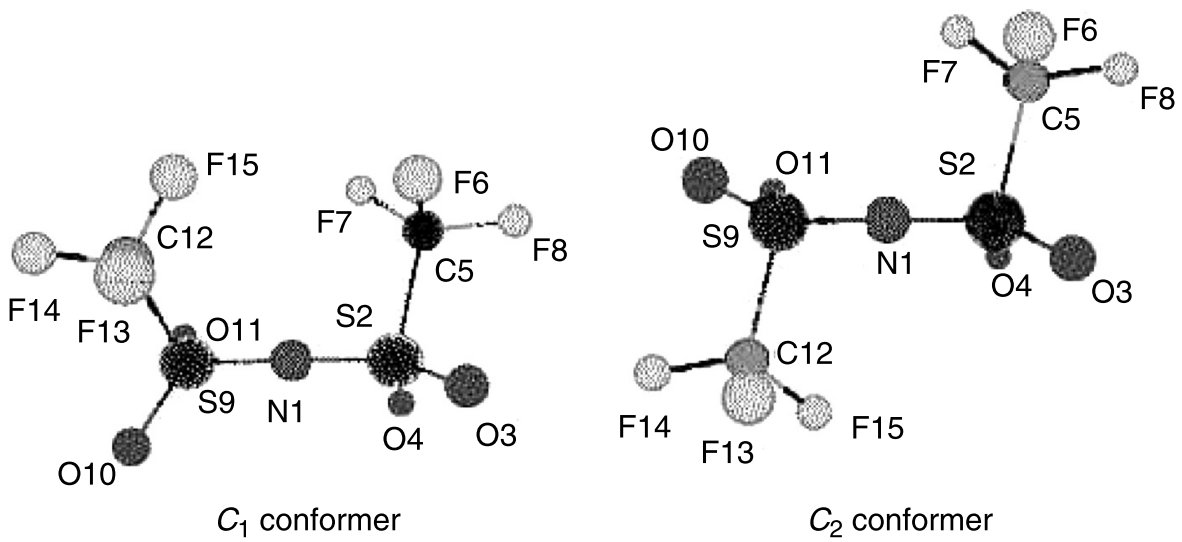

Fig. 22. Different conformers of symmetry $C_{1}$ and $C_{2}$ of the $\left[T f_{2} \mathrm{~N}\right]^{-}$ion, as determined by Fujii et al. [165] by means of DFT calculations for the 1-ethyl-3-methylimidazolium liquid $\left[\mathrm{C}_{2} m i m\right]\left[T f_{2} \mathrm{~N}\right]$. Figure adapted from Fujii et al. [165] 


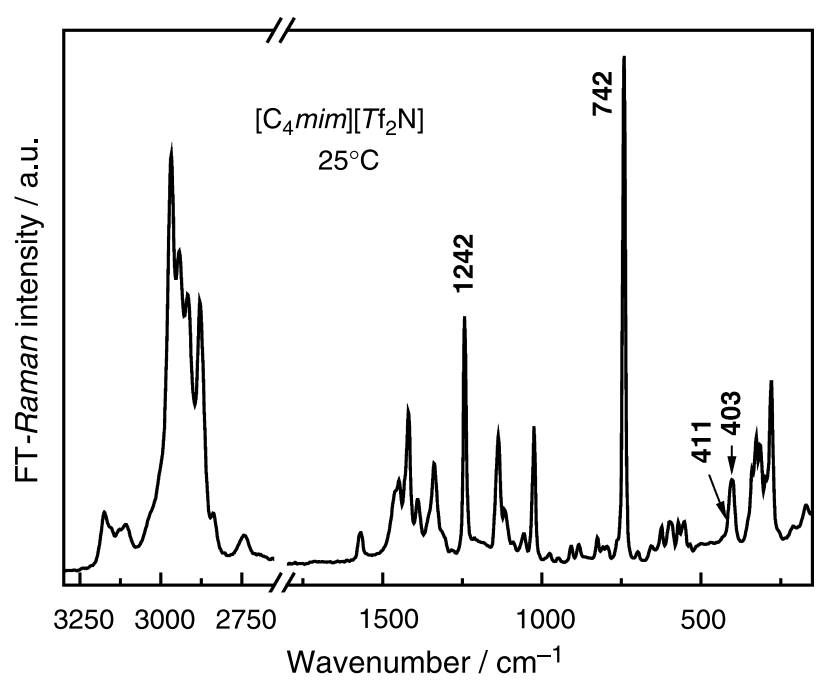

Fig. 23. Our Raman spectrum of liquid $\left[\mathrm{C}_{4} \operatorname{mim}\right]\left[T f_{2} \mathrm{~N}\right]$. Apparently the splitting between the two conformation sensitive bands for the $\left[T f_{2} \mathrm{~N}\right]^{-}$ion, near $\sim 400 \mathrm{~cm}^{-1}$, is not so large in this liquid as for the 1-ethyl $\left[\mathrm{C}_{2}\right.$ mim $]\left[T f_{2} \mathrm{~N}\right]$ case [165]. The $\mathrm{CF}_{3}$ symmetric stretching and deformation bands are seen at 1242 and $742 \mathrm{~cm}^{-1}$. The $A A / G A$ conformational equilibrium bands at $500-700 \mathrm{~cm}^{-1}$ discussed in relation with Fig. 7 can also be weakly seen [130]

$\left[\mathrm{C}_{2} \operatorname{mim}\right]\left[T f_{2} \mathrm{~N}\right]$. The $C_{2}$ conformer is more favorable than the $C_{l}$ one [165]. Three different geometries (named cis and trans by the authors) have recently been determined in the $\mathrm{X}$-ray crystal structure of the salt $\mathrm{Li}_{2}\left[\mathrm{C}_{2}\right.$ mim $]\left[T f_{2} \mathrm{~N}\right]_{3}[166]$.

We were able to obtain the same wagging $\omega-\mathrm{SO}_{2}$ vibrational bands in our Raman spectrum of liqiud $\left[\mathrm{C}_{4}\right.$ mim $]\left[T f_{2} \mathrm{~N}\right]$, see Fig. 23. Apparently the splitting between the two bands (at $\sim 411$ and $\sim 403 \mathrm{~cm}^{-1}$ ) is not so large for the case of the 1-butyl-3-methylimidazolium bis(trifluoromethylsulfonyl)imide liquid. The symmetric $\mathrm{CF}_{3}$ stretching and deformation bands are seen very strongly at $\sim 1242$ and $\sim 742 \mathrm{~cm}^{-1}$ in our spectra, as found also by Rey et al. [163, 164]. The bands at $500-750 \mathrm{~cm}^{-1}$ discussed in relation with Fig. 7 can be faintly seen, showing that the $A A / G A$ conformational equilibrium of the butyl group in $\left[\mathrm{C}_{4} \mathrm{mim}\right]^{+}$is established, as discovered by Hamaguchi and Ozawa [108].

The $\left[T f_{2} \mathrm{~N}\right]^{-}$anion was further studied and discussed in Raman investigations on the ionic liquid $\mathrm{N}$-propyl- $\mathrm{N}$-methylpyrrolidinium bis(trifluoromethylsulfonyl)imide ([P13][Tf $\left.\left.f_{2} \mathrm{~N}\right]\right)$ and its $2 / 1$ mixture with $\mathrm{Li}\left[T f_{2} \mathrm{~N}\right]$ [17], as well as on the $N$-butyl- $N$-methylpyrrolidinium bis(trifluoromethanesulfonyl)imide $\left([P 14]\left[T f_{2} \mathrm{~N}\right]\right)$. Here $P$ denotes pyrrolidinium and the digits the number of carbon atoms on radicals $R^{1}$ and $R^{2}$, see Fig. 1 . Also the $[P 14]^{+}$ion is commonly called [bmpy] ${ }^{+}$for 1-butyl-1-methylpyrrolidinium or $N$-butyl- $N$-methylpyrrolidinium ( $\mathrm{N}$ is atom number 1$)$. This $[b m p y]^{+}$cation has been used for making suitable RTILs such as $[b m p y]\left[T f_{2} \mathrm{~N}\right]$ and [bmpy][TfO] that has been found useful as reaction media $[167,168]$.

The results by Fujimori et al. [20] have shown that the $\left[T f_{2} \mathrm{~N}\right]^{-}$anions have only a very weak interaction with the $[P 13]^{+}$cations, that were sterically shielded, but were strongly coordinated to the $\mathrm{Li}^{+}$ cations. The studies were performed over a temperature range extending from -100 to $+60^{\circ} \mathrm{C}$, i.e., in the crystalline and melt states. For comparison purposes, the study [17] was extended to the [P13]I, a precursor used in the synthesis of $[P 13]\left[T f_{2} \mathrm{~N}\right]$. Extensive NMR characterization of the $[P 13]\left[T f_{2} \mathrm{~N}\right]$ room-temperature ionic liquid and its mixtures with $\mathrm{Li}\left[T f_{2} \mathrm{~N}\right]$ has also been made to investigate the interactions between the ionic liquid and the lithium salt, and the results were compared with previous DSC, Raman, and electrochemical investigations [18].

By means of DFT calculations and Raman spectroscopy on the $[P 14]\left[T f_{2} \mathrm{~N}\right]$ and $[P 14] \mathrm{Br}$ (or [bmpy]$\left[T f_{2} \mathrm{~N}\right]$ and $[$ bmpy] Br) systems, various types of

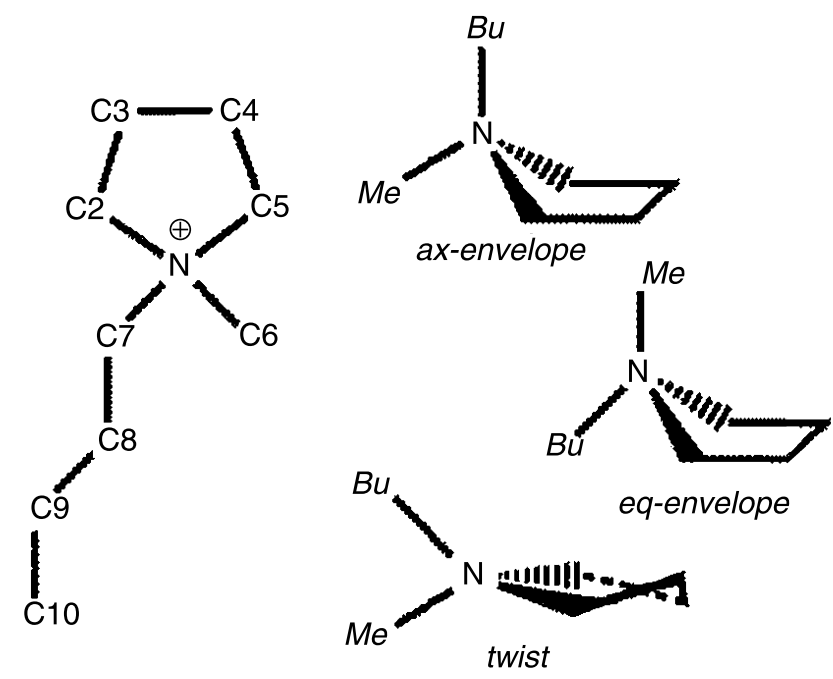

Fig. 24. Structure and conformations of $N$-butyl- $N$-methylpyrrolidinium (or 1-butyl-1-methylpyrrolidinium or $[P 14]^{+}$ or $[\text { bmpy }]^{+}$; several names are used). In $[P 14]^{+} P$ denotes pyrrolidinium and the digits the number of carbon atoms in radicals $R^{1}$ and $R^{2}$. Also, the ion is commonly called [bmpy $]^{+}$ ( $N$ is atom number 1$)$. The ring of the $\left(\mathrm{CH}_{2}\right)_{4} \mathrm{~N} R^{1} R^{2}$ pyrimidinium ion is not planar and has two stable (twist and envelope) forms 
conformations with respect to the pyrrolidinium ring and $N$-butyl group were found [20]. The calculations indicated that, among others, the so-called $e q$ - and ax-envelope conformers with the butyl group at equatorial and axial positions against the plane of four atoms of the envelope pyrrolidinium ring (see Fig. 24) were relatively stable, and the former gave the global minimum [20].

By comparing observed and calculated Raman spectra it was found that the $[P 14]^{+}$ion was present mainly as the ax-envelope conformer in the [P14][Br] crystal, while the eq-and ax-envelope conformers were present in equilibrium in the $[P 14]\left[T f_{2} \mathrm{~N}\right]$ ionic liquid (called [P14][TFSI] [20]). The presence of conformational equilibria was further experimentally supported by Raman spectra measured at different temperatures. It was established that the

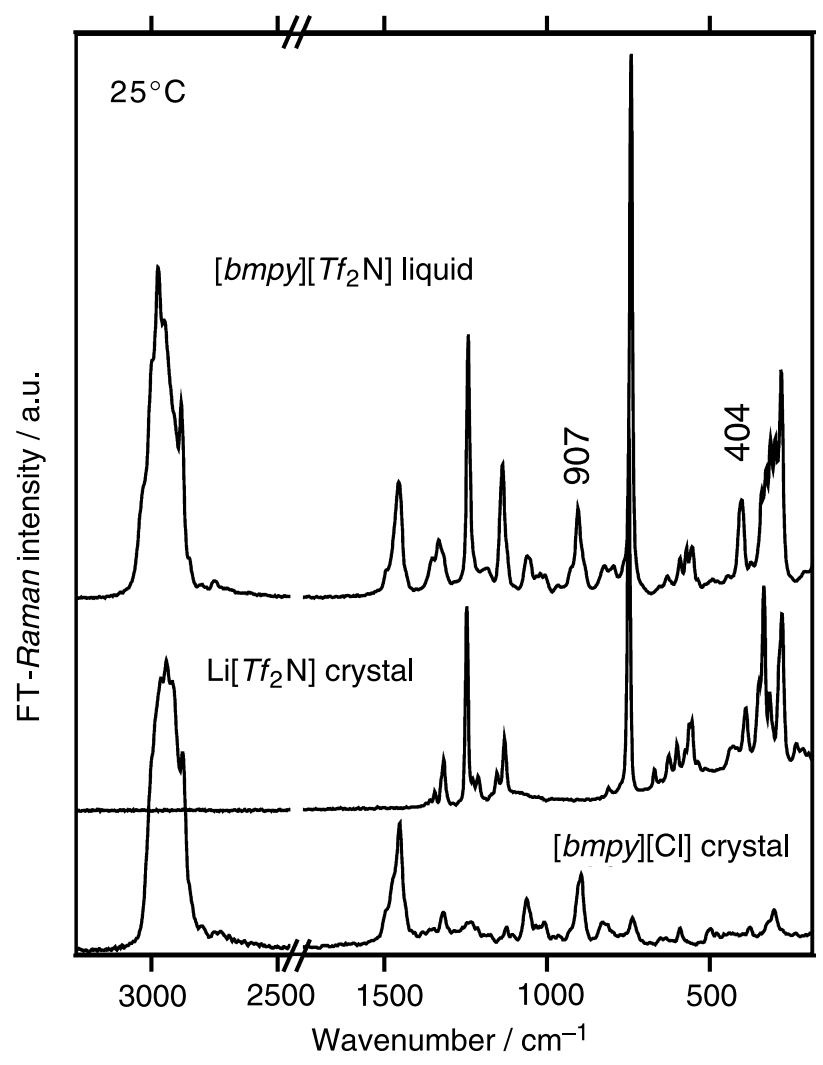

Fig. 25. Experimental FT-Raman spectra for the [bmpy]$\left[T f_{2} \mathrm{~N}\right]$ liquid (also called [P14][TFSI] [20]), showing that the spectum (top) at room temperature essentially consists of bands from both the $\left[T f_{2} \mathrm{~N}\right]^{-}$anion (middle) and the $[\text { bmpy }]^{+}$cation (bottom) (shifted conveniently). The $\mathrm{Li}^{+}$ and $\mathrm{Cl}^{-}$do not contribute bands directly in the liquid but have influence on the structures of the salts and are interacting with the ions and influencing the conformational equilibria in the RTIL [130] conformation of the butyl group was restricted to a so-called trans-TT conformation, in which the butyl group is located trans against a ring carbon atom $(\mathrm{C} 2$ or C5), and all carbon atoms in the butyl chain are located trans to each other [20].

We have briefly investigated some $[b m p y]^{+}$room temperature liquids, namely $[b m p y]\left[T f_{2} \mathrm{~N}\right]$ and [bmpy][TfO] [130]. The experimental Raman spectra of our liquids looked much like sums of the spectrum of the $[\text { bmpy }]^{+}$ion (as measured from the chloride salt) and the spectra of the $\left[T f_{2} \mathrm{~N}\right]^{-}$or $[T f \mathrm{O}]^{-}$ions (as measured from the lithium salts). An example of our results on [bmpy] $\left[T f_{2} \mathrm{~N}\right]$ is shown in Fig. 25. The spectra in Fig. 25 clearly show that the constituent ions in the liquid and in the respective solid salts vibrate rather independent of the surroundings. Therefore the spectrum of the liquid looks much like the sum of those of the solid salts. This conclusion is of course not new, but never the less it is still quite applicable in the evaluation of many RTIL Raman (and IR) spectra. However, the presence of conformational equilibria for both of the RTIL ions makes a closer study worthwhile. We therefore recommend the interested reader to study the work by Fujimori et al. [20], in which subtle spectral band shape details e.g., around $930-880 \mathrm{~cm}^{-1}$ are evaluated to show information on the eq-envelope:trans-TT and ax-envelope:trans-TT interconversion of the $[\mathrm{bmim}]^{+}$ ion in the liquid. Also note that the crystal structure of the $\left[\right.$ bmpy] $\left[T f_{2} \mathrm{~N}\right]$ salt was recently solved; it contained the eq-envelope:trans-TT conformer of the cation [169]. Also conformers of symmetry $C_{1}$ and $C_{2}$ of the $\left[T f_{2} \mathrm{~N}\right]^{-}$ion show their presence burried in the band at $400-440 \mathrm{~cm}^{-1}$ [165].

Prior to the publication of the work by Fujimori et al. [20] on the 1-butyl-1-methyl-pyrrolidinium bis(trifluoromethylsulfonyl)imide, some preliminary calculations were done aiming at a better understanding of the spectra on that system (shown in Fig. 25).

To illustrate how useful such procedures are, we depict two examples of our results in Fig. 26. At first, structures of typical conformations of the 1-butyl-1-methyl-pyrrolidinium ions in assumed gaseous states were minimized. The shown ax-envelope:trans-TG and -TT confomations are just some of the many conformations that came out with bond distances and angles of standard magnitudes [20]. The more likely ones, such as the ax-envelope:trans$T T$ and eq-envelope:trans-TT were included in the 

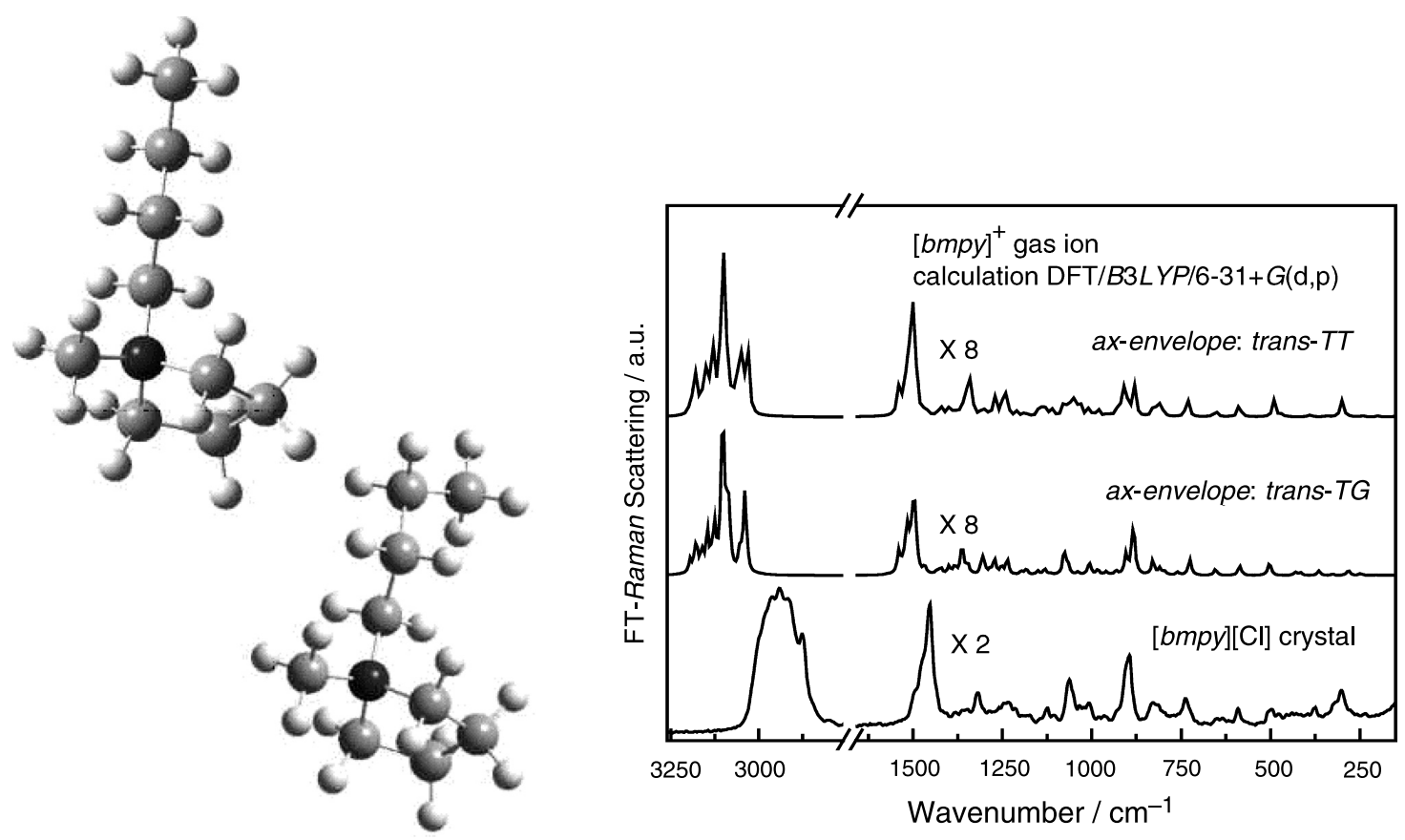

Fig. 26. Minimized structures of the so-called ax-envelope:trans-TT and -TG confomations of the $[\text { bmpy }]^{+}$ion calculated at the DFT/B3LYP/6-31+G(p,d) level. The minimized bond distances and angles had standard magnitudes. The model spectra shown compare well to the experimental FT-Raman spectrum of the [bmpy $]^{+}$ion in the solid chloride salt [130]

study by Fujimori et al. [20]. The calculated spectra of the different conformers looked rather much like each other. Also in Fig. 26 one can compare two theoretically calculated spectra and our experimental Raman result for $[$ bmpy $][\mathrm{Cl}]$ crystalline powder. The calculations (minimum structure and the spectrum) were done by use of the Gaussian03W software [107] at the $B 3 L Y P / D F T / 6-31+\mathrm{G}(\mathrm{d}, \mathrm{p})$ level [130].

As seen in Fig. 26, the gauche form of the C8-C9 bond did not change much relative to the ax-envelope:trans-TT form. Also in Fig. 26, quite satisfactory one-to-one correspondences between calculated and observed bands can be found, but as always and also in the work of Fujimori et al. [20] one should not expect perfect fits (frequencies are calculated too high and intensities are perturbed, because of the simplicity of the modeling).

When the theoretical spectra of the $[b m p y]^{+}$ion (e.g., those in Fig. 26) and similarly calculated spectra of conformations of the $\left[\mathrm{Tf}_{2} \mathrm{~N}\right]^{-}$ion (in Fig. 27, see later) were added, we obtained sums (not shown) that essentially corresponded to the spectrum of the [bmpy] $\left.T f_{2} \mathrm{~N}\right]$ liquid (in Fig. 25, top) [130].

Because of the importance of these melts as battery electrolytes, the surfaces of $N$-methyl- $N$-alkylpyrrolidinium bis(trifluoromethanesulfonyl)imide
$[P 1 \mathrm{x}]\left[T f_{2} \mathrm{~N}\right]$ electrolytes have been recently characterized using various techniques such as XPS, diffuse reflectance FTIR spectroscopy in addition to Raman spectroscopy [17-19].

In a study on Th(IV) dissolved in the RTIL butyltrimethylammonium bis(trifluoromethanesulfonyl)imide $\left(\left[\mathrm{Me}_{3} n \mathrm{BuN}\right]\left[\mathrm{Tf}_{2} \mathrm{~N}\right]\right)$ it has been shown by e.g., Raman spectroscopy that the $\left[T f_{2} \mathrm{~N}\right]^{-}$anion coordinates to the metal center via the sulfonyl oxygen coordination [170].

The molecular vibrations of polycrystalline 1,3dimethylbenzimidazolium chlorate(VII) and 1,3-di1-adamantylbenzimidazolium chlorate(VII) have been investigated by FTIR and FT-Raman spectroscopy [24]. Also for these compounds, DFT methods $(B 3 L Y P)$ were used to determine the geometrical and vibrational characteristics of these salts. In the computations, the cation-chlorate(VII) anion interaction was neglected. The experimental bands were assigned to normal modes on the basis of potential energy distribution analysis. Good agreements between the calculated and observed frequencies were obtained [24].

New 2-hydroxypropyl-functionalized imidazolium cation ionic liquids (containing an appended hydroxyl functionality) have been made [171] by 


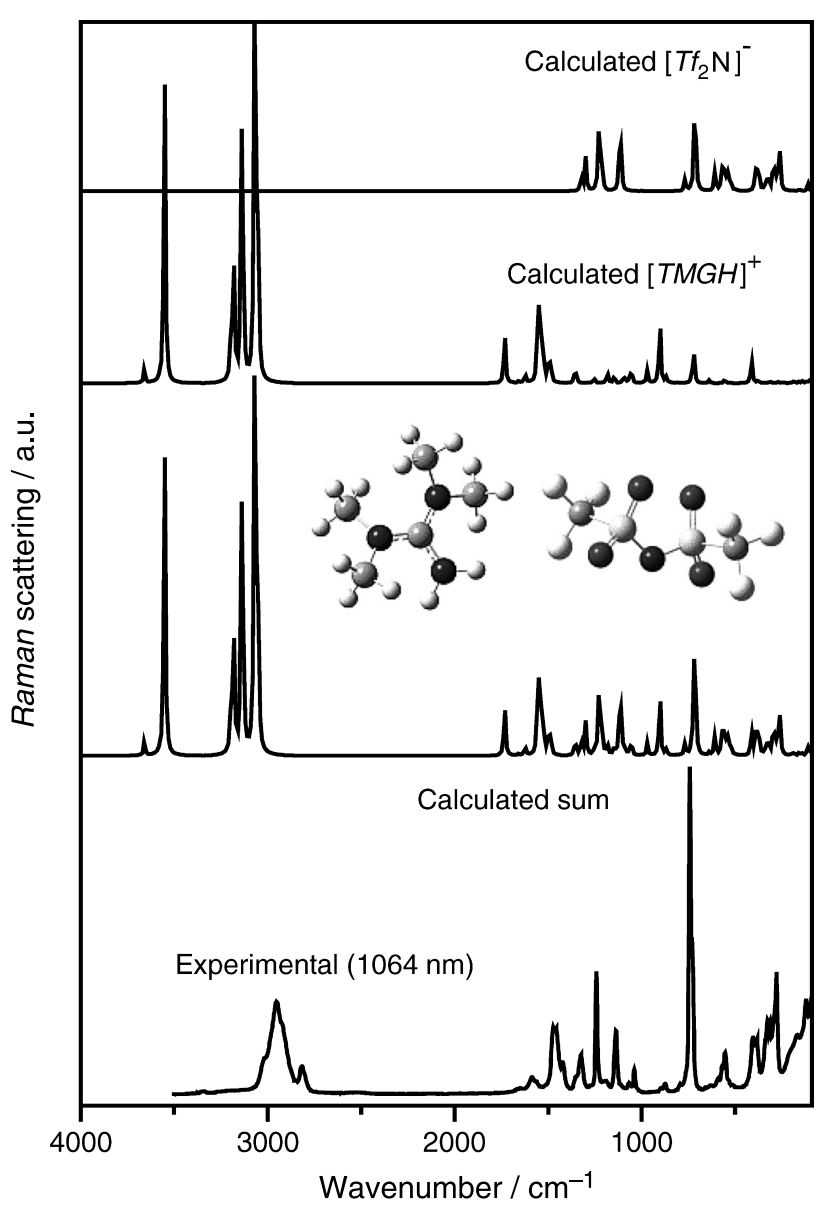

Fig. 27. Illustrative example of the power of $a b$-initio methods combined with Raman spectroscopy, applied on the $[T M G H]\left[T f_{2} \mathrm{~N}\right]$ liquid. The two top spectral curves show calculated Raman spectra of minimized conformers of $\left[T f_{2} \mathrm{~N}\right]^{-}$ and $[T M G H]^{+}$at the DFT/B3LYP/6-31G(d) level. The geometries of the ions are also depicted in the middle together with the sum of the top spectra, constituting a hypothetical $[T M G H]\left[T f_{2} \mathrm{~N}\right]$ liquid of non-interacting ions (shifted conveniently). Bottom: the experimental FT-Raman spectrum. Unfortunately, we could not measure above $3500 \mathrm{~cm}^{-1}$ [130]

use of an "atom efficient one-pot reaction" between 1-methylimidazole and acid with propylene oxide. Unfortunately, the systems were not studied by FTRaman spectroscopy so far. We have shown in a study on 1-hexanol in [1,3-bis-[2-(methoxyethoxy)ethyl]imidazolium] bis-trifluoromethylsulfonyl-imide [83] that Raman spectroscopy has a potential for finding clues to what goes on in ionic liquids that contain hydroxyl groups (alkohols) and where hydrogen bonding between the ionic liquid and the hydroxyl group is of importance.

A rather new class of room temperature ionic liquids is based on the $N, N, N^{\prime}, N^{\prime}$-tetramethylguanid- inium $\left[\left(\left(\mathrm{CH}_{3}\right)_{2} \mathrm{~N}\right)_{2} \mathrm{CNH}_{2}\right]^{+}$or $[\mathrm{TMGH}]^{+}$cation, see Fig. 1. A dedicated force field was developed [21] to fit the experimental bonds and angles and the vibration frequencies, for five kinds of $[T M G H]^{+}$RTILs, where the anion was formate, lactate, perchlorate, trifluoroacetate, and trifluoromethylsulfonate, respectively. Ab-initio calculations were performed and predictions in good agreement with the experimental data obtained. Radial and spatial distribution functions (RDFs and SDFs) were investigated to depict the microscopic structures of the RTILs [22].

We have performed an illustrative experiment on the $[T M G H]\left[T f_{2} \mathrm{~N}\right]$ liquid. We recorded the FTRaman spectrum and calculated equlibrium geometries and spectra of the constituent isolated ions, at the $\mathrm{RHF} / 6-31 \mathrm{G}(\mathrm{d})$ level by using the DFT/B3LYP methods with the help of the Gaussian03W software [107]. Some of the data obtained [130] are shown in Fig. 27. Unfortunately the highest-frequent $\mathrm{N}-\mathrm{H}$ stretchings were out of the instrumental range in our set-up (limited to $3500-100 \mathrm{~cm}^{-1}$ ). However, it is quite convincing to see how many of the experimental details that are being accounted for by the modeling, consisting of summation of the calculated spectra, even when we neglected other conformers.

\section{Conclusions}

Recently Raman spectroscopy has been applied - in combination with other methods - to show that certain characteristic spectral bands can be identified that are characteristic for conformational forms (conformers) of the ionic liquid components, and that the associated conformational equilibria might be partly responsible for the salts to have such low melting points.

In this review we discussed in detail some examples of the conformational equilibria, e.g., those discovered by Ozawa et al. [128] in liquids containing the 1-butyl-3-methylimidazolium cation. Also, we examined in some detail liquids containing the bis(trifluoromethanesulfonyl)imide anion, as described above. We have extended the knowledge on the characteristic Raman bands to include conformers of the 1-hexyl-3-methylimidazolium cation [103]. Vibrational analysis has been made of the components of the systems to improve our understanding of what goes on in the liquids. These results, although not surprising, add weight to our understanding of the existence of mixtures of low 
symmetry conformers that disturb the crystallization process. Arguments were presented for the belief that this is the reason for the low melting points of the RTILs relative to "normal molecular salts" with much higer melting points.

We have seen that the ab-initio self-consistent quantum mechanical functional methods such as e.g., DFT $/ B 3 L Y P$ with the chosen $6-31+\mathrm{G}(\mathrm{d}, \mathrm{p})$ basis sets are well suited to calculate reasonable molecular ion structures and vibrational spectra of these ions. The results obtained by us or others have indicated that the neglect of the prescence of cationanion interactions is a reasonable approximation for a rather successful prediction of the Raman spectra. Based on such calculations detailed and relyable assignments of the spectra can be given and information on conformational equilibria obtained.

\section{Acknowledgements}

We would like to thank N.J. Bjerrum, A. Riisager, R. Fehrmann and I. Shim from Department of Chemistry, DTU, Denmark, C.C. Pye from Department of Chemistry, Saint Mary's University, Halifax, Nova Scotia, Canada, N.L. Lancaster from Department of Chemistry, King's College, London University, UK, K.R. Seddon, QUILL Research Centre, Queen's University Belfast, Northern Ireland, and $S$. Brunsgaard Hansen (formerly from Department of Chemistry, DTU) for help with finishing the manuscript. L. Ryelund and O. Faurskov Nielsen of the Department of Chemistry, H.C. Ørsted Institute, University of Copenhagen are thanked for much measurement assistance. The work was supported by the Technical University of Denmark.

\section{References}

[1] Earle MJ, Esperanca JMSS, Gilea MA, Lopes JNC, Rebolo LPN, Magee JW, Seddon KR, Widegren JA (2006) Nature 439: 831

[2] Wilkes JS, Levisky JA, Wilson RA, Hussey CL (1982) Inorg Chem 21: 1263

[3] Hussey CL (1983) In: Mamantov G, Mamantov CB (eds) Adv Molten Salt Chem. Elsevier, Vol. 5, p 185

[4] Bonhôte P, Dias AP, Armand M, Papageorgiou N, Kalyanasundaram K, Grätzel M (1996) Inorg Chem 35: 1168

[5] Seddon KR (1997) J Chem Tech Biotechnol 68: 351

[6] Gordon CM, Holbrey JD, Kennedy AR, Seddon KR (1998) J Mater Chem 8: 2627

[7] Holbrey JD, Seddon KR (1999) Ionic Liquids. Clean Products Processes 1: 223

[8] Wasserscheid P, Keim W (2000) Angew Chem (Int Edit Engl) 39: 3773

[9] Seddon KR, Stark A, Torres MJ (2000) Pure Appl Chem 72: 2275
[10] Huddleston JG, Visser AE, Reichert WM, Willauer HD, Broker GA, Rogers RD (2001) Green Chem 3: 156

[11] Wasserscheid P, Welton T (eds) (2002-2003) Ionic Liquids in Synthesis. Wiley-VCH

[12] Wilkes JS (2004) J Mol Catal A Chem 214: 11

[13] Wilkes JS (2002) Green Chem 4: 73

[14] Gale RJ, Gilbert B, Osteryoung RA (1978) Inorg Chem 17: 2728

[15] Koura N (2005) Yoyuen oyobi Koon Kagaku 48(1): 11. Journal written in Japanese, cited from Chemical Abstracts

[16] Tian P, Song X, Li Y, Duan J, Liang Z, Zhang H (2006) Huaxue Xuebao 64(23): 2305. Journal written in Chinese, cited from Chemical Abstracts

[17] Castriota M, Caruso T, Agostino RG, Cazzanelli E, Henderson WA, Passerini S (2005) J Phys Chem A 109: 92

[18] Nicotera I, Oliviero C, Henderson WA, Appetecchi GB, Passerini S (2005) J Phys Chem B 109: 22814

[19] Howlett PC, Brack N, Hollenkamp AF, Forsyth M, MacFarlane DR (2006) J Electrochem Soc 153: A595

[20] Fujimori T, Fujii K, Kanzaki R, Chiba K, Yamamoto H, Umebayashi Y, Ishiguro S (2007) J Mol Liquids 131-132: 216

[21] Liu X, Zhang S, Zhou G, Wu G, Yuan X, Yao X (2006) J Phys Chem B 110: 12062

[22] a) Huang J, Riisager A, Wasserscheid P, Fehrmann R (2006) Chem Commun 2006: 4027; b) Huang J, Riisager A, Berg RW, Fehrmann R (2007) Tuning Ionic Liquids for High Gas Solubility Reversible Gas Sorption. J Mol Catal A (Chemical), Doi: 10.1016/ j.molcala.2007.07.036, in press

[23] Malek K, Skubel M, Schroeder G, Shvaika OP, Proniewicz LM (2006) Vibr Spectrosc 42: 317

[24] Malek K, Puc A, Schroeder G, Rybachenko VI, Proniewicz LM (2006) Chem Phys 327: 439

[25] Huddleston JG, Willauer HD, Swatloski RP, Visser AE, Rogers RD (1998) Chem Commun 16: 1765

[26] Rooney DW, Seddon KR (2001) In: Wypych G (ed) Handbook of Solvents. ChemTech Publishing, Toronto, p 1459

[27] Seddon KR (1999) In: Boghosian S, Dracopoulos V, Kontoyannis CG, Voyiatzis GA (eds) Proc. Int. George Papatheodorou Symposium. Patras Institute of Chemical Engineering High Temperature Chemical Processes, Greece, p 131

[28] Seddon KR, Stark A, Torres MJ (2002) In: Abraham MA, Moens L (eds) Clean Solvents Alternative Media for Chemical Reactions Processing. ACS Symp Ser No. 819, Washington, DC, p 34

[29] Aggarwal A, Lancaster NL, Sethi AR, Welton T (2002) Green Chem 4: 517

[30] Crowhurst L, Lancaster NL, Arlandis JMP, Welton T (2004) J Am Chem Soc 126: 11549

[31] Earle MJ, Katdare SP, Seddon KR (2004) Org Lett 6: 707

[32] Welton T (1999) Chem Rev 99: 2071

[33] Gordon CM (2001) Appl Catal A General 222: 101 
[34] Ye CF, Liu WM, Chen YX, Yu LG (2001) Chem Comm 2001: 2244

[35] Earle MJ (2002) In: Rogers RD, Seddon KR (eds) Ionic Liquids: Industrial Applications for Green Chemistry. American Chemical Society, Washington, DC, Symp Ser, vol. 818, p 90

[36] Davis JH Jr (2003) Ionic Liquids in Synthesis. Wiley$\mathrm{VCH}, \mathrm{p} 33$

[37] Davis JH Jr (2004) Chem Lett 33: 1072

[38] Park MJ, Lee JK, Lee BS, Lee YW, Choi IS, Lee S (2006) Chem Mater 18: 1546

[39] Wei D, Kvarnstroem C, Lindfors T, Ivaska A (2007) Electrochem Commun 9: 206

[40] Tait S, Osteryoung RA (1984) Inorg Chem 23: 4352

[41] Dupont J, de Souza RF, Suarez PAZ (2002) Chem Rev (Washington, DC) 102: 3667

[42] Dymek CJ Jr, Stewart JJP (1989) Inorg Chem 28: 1472

[43] Hanke CG, Price SL, Lynden-Bell RM (2001) Molec Phys 99: 801

[44] Meng Z, Dölle A, Carper WR (2002) J Molec Struct (THEOCHEM) 585: 119

[45] Carper WR, Meng Z, Wasserscheid P, Dölle A (2002) In: Trulove PC, DeLong HC, Mantz RA (eds) Int. Symp. Molten Salts. Electrochem. Soc. Proc. Vol. 2002-19 (Molten Salts XIII), p 973

[46] Carper WR, Meng Z, Dölle A (2003) In: Welton T, Wasserscheid P (eds) Ionic Liquids in Synthesis. Wiley, p 152

[47] Shah JK, Brennecke JF, Maginn EJ (2004) Green Chem 4: 112

[48] Dymek CJ, Grossie DA, Fratini AV, Adams WW (1989) J Molec Struct 213: 25

[49] Wilkes JS, Zaworotko MJ (1993) Supramolec Chem 1: 191

[50] Fuller J, Carlin RT, DeLong HC, Haworth D (1994) Chem Commun 1994: 299

[51] Carmichael AJ, Hardacre C, Holbrey JD, Nieuwenhuyzen M, Seddon KR (2001) Molec Phys 99: 795

[52] Bradley AE, Hardacre C, Holbrey JD, Johnston S, McMath SEJ, Nieuwenhuyzen M (2002) Chem Mater 14: 629

[53] Fannin AA, Floreani DA, King LA, Landers LS, Piersma BJ, Stech DJ, Vaughn RL, Wilkes JS, Williams JL (1984) J Phys Chem 88: 2614

[54] Larive CK, Lin M, Piersma BJ, Carper WR (1995) J Phys Chem 99: 12409

[55] Carper WR, Mains GJ, Piersma BJ, Mansfield SL, Larive CK (1996) J Phys Chem 100: 4724

[56] Fuller J, Carlin RT, Osteryoung RA (1997) J Electrochem Soc 144: 3881

[57] Larive CK, Lin M, Kinnear BS, Piersma BJ, Keller CE, Carper WR (1998) J Phys Chem 102B: 1717

[58] McEwen AB, Ngo EL, LeCompte K, Goldman JL (1999) J Electrochem Soc 146: 1687

[59] Dölle A, Carper WR (2003) In: Welton T, Wasserscheid P (eds) Ionic Liquids for Synthesis. Wiley, New York, p 168
[60] Elaiwi A, Hitchcock PB, Seddon KR, Srinivasan N, Tan YM, Welton T, Zora JA (1995) J Chem Soc Dalton Trans 1995: 3467

[61] Abdul-Sada AK, Greenway AM, Hitchcock PB, Mohammed TJ, Seddon KR, Zora JA (1986) J Chem Soc Chem Commun 1986: 1753

[62] Abdul-Sada AK, Al-Juaid S, Greenway AM, Hitchcock PB, Howells MJ, Seddon KR, Welton T (1990) Struct Chem 1: 391

[63] Hitchcock PB, Seddon KR, Welton T (1993) J Chem Soc Dalton Trans 1993: 2639

[64] Avent AG, Chaloner PA, Day MP, Seddon KR, Welton T (1994) J Chem Soc Dalton Trans 1994: 3405

[65] Abdul-Sada AK, Elaiwi AE, Greenway AM, Seddon KR (1997) Eur Mass Spectrom 3: 245

[66] Huang JF, Chen PY, Sun IW, Wang SP (2001) Inorg Chim Acta 320: 7, same paper also published in Spectrosc Lett 34(5): 591

[67] Katsyuba SA, Dyson PJ, Vandyukova EE, Chernova AV, Vidis A (2004) Helv Chim Acta 87: 2556

[68] Cammarata L, Kazarian SG, Salter PA, Welton T (2001) Phys Chem Chem Phys 3: 5192

[69] Welton T, Kazarian S, Crowhurst L, Perez-Arlandis JM, Salter P (2002) Abstr. 224th Am. Chem. Soc. National Meeting, Boston MA, August 18-22, 2002 224: 139

[70] Storhaug VJ, Carper WR (2003) Trends in Phys Chem 9: 173

[71] Endres F, Zein El Abedin S (2006) Phys Chem Chem Phys 8: 2101

[72] Matsumoto K, Hagiwara R, Yoshida R, Ito Y, Mazej Z, Benkic P, Zemva B, Tamada O, Yoshino H, Matsubara S (2004) Dalton Trans 2004: 144

[73] Matsumoto K, Hagiwara R (2005) J Fluorine Chem 126: 1095

[74] Tran CD, Lacerda SHD, Oliveira D (2003) Appl Spectrosc 57: 152

[75] Gilbert B, Chauvin Y, Guibard I (1991) Vibr Spectrosc 1: 299

[76] Gilbert B, Pauly JP, Chauvin Y, Di Marco-Van Tiggelen F (1994) Molten Salts. In: Hussey CL, et al (eds) Proc. 9th Int. Symposium Electrochem. Soc., Pennington NJ, Vol. 94(13), p 218

[77] Chauvin Y, Di Marco-Van Tiggelen F, Olivier H (1993) J Chem Soc Dalton Trans 1993: 1009

[78] He P, Liu H, Li Z, Liu Y, Xu X, Li J (2004) Langmuir 20: 10260

[79] Schafer T, Di Paolo RE, Franco R, Crespo JG (2005) Chem Commun 20: 2594

[80] Nanbu N, Sasaki Y, Kitamura F (2003) Electrochem Commun 5: 383

[81] Santos VO Jr, Alves MB, Carvalho MS, Suarez PAZ, Rubim JC (2006) J Phys Chem B 110: 20379

[82] Romero C, Baldelli S (2006) J Phys Chem B 110: 6213

[83] Riisager A, Fehrmann R, Berg RW, van Hal R, Wasserscheid P (2005) Phys Chem Chem Phys 7: 3052

[84] Raman CV, Krishnan KS (1928) Nature 121: 501

[85] Placzek G (1934) Rayleigh-Streuung und Raman Effekt, in Handbuch der Radiologie, Vol. VI. In: Marx 
E (ed) Akademische Verlagsgesellschaft, Leipzig, Germany, or English translation

[86] Herzberg G (1945) Molecular Spectra Molecular Structure, Vol. II. Infrared Raman Spectra of Polyatomic Molecules. van Nostrand, New York

[87] Wilson EB Jr, Decius JC, Cross PC (1955) Molecular Vibrations. The Theory of Infrared Raman Vibrational Spectra. McGraw-Hill Book Co., New York

[88] Long DA (2002) The Raman Effect: A Unified Treatment of the Theory of Raman Scattering by Molecules. Wiley, ISBN 0471490288

[89] Diem M (1993) Introduction to Modern Vibrational Spectroscopy. Wiley, New York, USA

[90] Laserna JJ (ed) (1996) Modern Techniques in Raman Spectroscopy. Wiley, Chichester UK

[91] Coates J (1998) Appl Spectrosc Rev 33: 267

[92] McCreery RL (2001) Raman Spectroscopy for Chemical Analysis. Wiley, Chichester

[93] Smith E, Dent G (2005) Modern Raman Spectroscopy - A Practical Approach, Wiley

[94] Schrader B (1989) Raman/Infrared Atlas of Organic Compounds, 2nd edn. V.C.H. and Wiley, New York

[95] Lin-Vien D, Colthup NB, Fateley WG, Grasselli JG (1991) Handbook of Infrared and Raman Characteristic Frequencies of Organic Molecules. Academic Press, New York

[96] Nyquist RA, Kagel RO, Putzig CL, Leugers MA (1996) Handbook of Infrared and Raman Spectra of Inorganic Compounds and Organic Salts, 4 vols. Academic Press, New York, London

[97] Nakamoto K (1997) Infrared and Raman Spectra of Inorganic and Coordination Compounds, 5th edn. Part A: Theory and Applications in Inorganic Chemistry, and Part B, Applications in Coordination, Organometallic and Bioinorganic Chemistry. Wiley, New York

[98] Smith BC (1998) Infrared Spectral Interpretation - A Systematic Approach, CRC Press Inc., Boca Raton

[99] Socrates G (2001) Infrared and Raman Characteristic Group Frequencies, Tables and Charts, 3rd edn. Wiley, Chichester, UK

[100] Bishop DM (1973) Group Theory and Chemistry. Clarendon Press, Oxford

[101] Carter RL (1998) Molecular Symmetry and Group Theory. Wiley, New York

[102] Chase DB, Rabolt JF (1994) Fourier Transform Raman Spectroscopy. Academic Press, New York

[103] Berg RW, Deetlefs M, Seddon KR, Shim I, Thompson JM (2005) J Phys Chem B 109: 19018

[104] Atkins P, de Paula J (2006) Atkins' Physical Chemistry, 8th edn. Oxford University Press

[105] Ratner MA, Schatz GC (2001) Introduction to Quantum Mechanics in Chemistry. Prentice-Hall Inc., NJ

[106] Atkins PW, Friedman RS (2004) Molecular Quantum Mechanics, 4th edn. Oxford University Press

[107] Frisch MJ, Trucks GW, Schlegel HB, Scuseria GE, Robb MA, Cheeseman JR, Montgomery JA Jr, Vreven T, Kudin KN, Burant JC, Millam JM, Iyengar SS, Tomasi J, Barone V, Mennucci B, Cossi M, Scalmani G, Rega N, Petersson GA, Nakatsuji H, Hada M, Ehara
M, Toyota K, Fukuda R, Hasegawa J, Ishida M, Nakajima T, Honda Y, Kitao O, Nakai H, Klene M, Li X, Knox JE, Hratchian HP, Cross JB, Adamo C, Jaramillo J, Gomperts R, Stratmann RE, Yazyev O, Austin AJ, Cammi R, Pomelli C, Ochterski JW, Ayala PY, Morokuma K, Voth GA, Salvador P, Dannenberg JJ, Zakrzewski VG, Dapprich S, Daniels AD, Strain MC, Farkas O, Malick DK, Rabuck AD, Raghavachari K, Foresman JB, Ortiz JV, Cui Q, Baboul AG, Clifford S, Cioslowski J, Stefanov BB, Liu G, Liashenko A, Piskorz P, Komaromi I, Martin RL, Fox DJ, Keith T, Al-Laham MA, Peng CY, Nanayakkara A, Challacombe M, Gill PMW, Johnson B, Chen W, Wong MW, Gonzalez C, Pople JA (2004) Gaussian03, Revision C.02, Gaussian, Inc., Wallingford CT

[108] Hamaguchi H, Ozawa R (2005) Adv Chem Phys 131: 85

[109] Holbrey JD, Seddon KR (1999) J Chem Soc Dalton Trans 1999: 2133

[110] Hardacre C, Holbrey JD, McCormac PB, McMath SEJ, Nieuwenhuyzen M, Seddon KR (2001) J Mater Chem 11: 346

[111] Hardacre C, Holbrey JD, McMath SEJ, Bowron DT, Soper AK (2003) J Chem Phys 118: 273

[112] Hardacre C, McMath SEJ, Nieuwenhuyzen M, Bowron DT, Soper AK (2003) J Phys-Condens Matter 15: $\mathrm{S} 159$

[113] Triolo A, Russina O, Arrighi V, Juranyi F, Janssen S, Gordon CM (2003) J Chem Phys 119: 8549

[114] Roche JD, Gordon CM, Imrie CT, Ingram MD, Kennedy AR, Lo Celso F, Triolo A (2003) Chem Mater 15: 3089

[115] Firestone MA, Dzielawa JA, Zapol P, Curtiss LA, Seifert S, Dietz ML (2002) Langmuir 18: 7258

[116] Saha S, Hayashi S, Kobayashi A, Hamaguchi H (2003) Chem Lett 32: 740

[117] Holbrey JD, Reichert WM, Nieuwenhuyzen M, Johnston S, Seddon KR, Rogers RD (2003) Chem Commun 2003: 1636

[118] Katayanagi H, Hayashi S, Hamaguchi H, Nishikawa K (2004) Chem Phys Lett 392: 460

[119] Bowers J, Vergara-Gutierrez MC, Webster JRP (2004) Langmuir 20: 309

[120] Bowers J, Butts CP, Martin PJ, Vergara-Gutierrez MC, Heenan RK (2004) Langmuir 20: 2191

[121] Takahashi S, Curtiss LA, Gosztola D, Koura N, Saboungi ML (1995) Inorg Chem 34: 2990

[122] Hayashi S, Ozawa R, Hamaguchi H (2003) Chem Lett 32: 498

[123] Nishikawa K, Wang S, Katayanagi H, Hayashi S, Hamaguchi H, Koga Y, Tozaki K (2007) J Phys Chem B 111: 4894

[124] Cambridge Crystallographic Data Centre, $\left[\mathrm{C}_{4} \mathrm{mim}\right] \mathrm{Cl}$ "Crystal (1)" $\left[\mathrm{C}_{4} \mathrm{mim}\right] \mathrm{Br}$ data are registered as CCDC deposition numbers 213959 and 213960, respectively, see http://www.ccdc.cam.ac.uk

[125] Aakeröy CB, Evans TA, Seddon KR, Pálinkó I (1999) New J Chem 23: 145

[126] van den Berg JA, Seddon KR (2003) Crystal Growth Design 3: 643 
[127] Matsumoto K, Hagiwara R, Mazej Z, Benkič P, Žemva B (2006) Solid State Sci 8: 1250

[128] Ozawa R, Hayashi S, Saha S, Kobayashi A, Hamaguchi H (2003) Chem Lett 32: 948

[129] Okajima H, Hamaguchi H (2006) Abstr. 231st ACS National Meeting, Atlanta, GA, US, March 26-30, 2006, IEC-015. Am Chem Soc, Washington, DC

[130] Berg RW (2007) unpublished results

[131] Turner EA, Pye CC, Singer RD (2003) J Phys Chem A 107: 2277

[132] Talaty ER, Raja S, Storhaug VJ, Dölle A, Carper WR (2004) J Phys Chem B 108: 13177

[133] Antony JH, Mertens D, Dölle A, Wasserscheid P, Carper WR (2003) Chem Phys Chem 4: 588

[134] Antony JH, Mertens D, Breitenstein T, Dölle A, Wasserscheid P, Carper WR (2004) Pure Appl Chem 76: 255

[135] Heimer NE, Del Sesto RE, Carper WR (2004) Magn Reson Chem 42: 71

[136] Heimer NE, Del Sesto RE, Meng Z, Wilkes JS, Carper WR (2006) J Mol Liquids 124: 84

[137] Umebayashi Y, Fujimori T, Sukizaki T, Asada M, Fujii K, Kanzaki R, Ishiguro S (2005) J Phys Chem A 109: 8976

[138] Downard A, Earle MJ, Hardacre C, McMath SEJ, Nieuwenhuyzen M, Teat SJ (2004) Chem Mater 16: 43

[139] Giraud G, Gordon CM, Dunkin IR, Wynne K (2003) J Chem Phys 119: 464

[140] Triolo A, Mandanici A, Russina O, Rodriguez-Mora V, Cutroni M, Hardacre C, Nieuwenhuyzen M, Bleif HJ, Keller L, Ramos MA (2006) J Phys Chem B 110: 21357

[141] Shigeto S, Hamaguchi H (2006) Chem Phys Lett 427 : 329

[142] a) Morrow TI, Maginn EJ (2002) J Phys Chem B 106: 12807; b) Erratum: Morrow TI, Maginn EJ (2003) J Phys Chem B 107: 9160

[143] Morrow TI, Maginn EJ (2003) ACS Symp Ser 2003 (Ionic Liquids as Green Solvents) 856: 1624

[144] Shah JK, Maginn EJ (2004) Fluid Phase Equilibria 195-203: 222

[145] Hayashi S, Hamaguchi H (2004) Chem Lett 33: 1590

[146] Hayashi S, Saha S, Hamaguchi H (2006) IEEE Trans Magnetics 42: 12

[147] Hamaguchi H, Saha S, Ozawa R, Hayashi S (2005) ACS Symp Ser 901 (Ionic Liquids IIIA: Fundamentals, Progress, Challenges, Opportunities) 68
[148] Canongia Lopes JN, Costa Gomes MF, Pádua AAH (2006) J Phys Chem B 110: 16816

[149] Canongia Lopes JN, Deschamps J, Pádua AAH (2004) J Phys Chem B 108: 2038 and correction 11250

[150] Canongia Lopes JN, Pádua AAH (2004) J Phys Chem B 108: 16893

[151] Canongia Lopes JNA, Pádua AAH (2006) J Phys Chem B 110: 7485

[152] Canongia Lopes JNA, Pádua AAH (2006) J Phys Chem B 110: 3330

[153] De Andrade J, Böes ES, Stassen H (2002) J Phys Chem B 106: 3546

[154] De Andrade J, Böes ES, Stassen H (2002) J Phys Chem B 106: 13344

[155] Margulis CJ, Stern HA, Berne BJ (2002) J Phys Chem B 106: 12017

[156] Del Pópolo MG, Voth GA (2004) J Phys Chem B 108: 1744

[157] Yan T, Burnham CJ, Del Pópolo MG, Voth GA (2004) J Phys Chem B 108: 11877

[158] Liu Z, Huang S, Wang W (2004) J Phys Chem B 108: 12978

[159] Urahata SM, Ribeiro MCC (2004) J Chem Phys 120: 1855

[160] Miki H, Hayashi S, Kikura H, Hamaguchi H (2006) J Raman Spectrosc 37: 1242

[161] Saha S, Hamaguchi H (2006) J Phys Chem B 110: 2777

[162] Heimer NE, Wilkes JS, Wahlbeck PG, Carper WR (2006) J Phys Chem A 110: 868

[163] Rey I, Johansson P, Lindgren J, Lassegues JC, Grondin J, Servant L (1998) J Phys Chem A 102: 3249

[164] Rey I, Lassegues JC, Grondin J, Servant L (1998) Electrochim Acta 43: 1505

[165] Fujii K, Fujimori T, Takamuku T, Kanzaki R, Umebayashi Y, Ishiguro S (2006) J Phys Chem B 110: 8179

[166] Matsumoto K, Hagiwara R, Tamada O (2006) Solid State Sci 8: 1103

[167] Lancaster NL, Salter PA, Welton T, Young GB (2002) J Org Chem 67: 8855

[168] Dal E, Lancaster NL (2005) Org Biomol Chem 3: 682

[169] Choudhury AR, Winterton N, Steiner A, Cooper AI, Johnson KA (2005) J Am Chem Soc 127: 16792

[170] Bhatt AI, Duffy NW, Collison D, May I, Lewin RG (2006) Inorg Chem 45: 1677

[171] Holbrey JD, Turner MB, Reichert WM, Rogers DR (2003) Green Chem 5: 731 